REVISÃO ESTRATIGRÁFICA DAS UNIDADES SUPERIORES DA FAIXA PARAGUAI NORTE: LITOESTRATIGRAFIA, QUIMIOESTRATIGRAFIA (C e Sr) E GEOCRONOLOGIA (U-Pb). MATO GROSSO, BRASIL

DISSERTAÇÃO DE MESTRADO

$\mathrm{N}^{\circ} 349$

Samille Cristine dos Reis de Souza

BRASÍLIA - DF 


\section{REVISÃO ESTRATIGRÁFICA DAS UNIDADES SUPERIORES DA FAIXA PARAGUAI NORTE: LITOESTRATIGRAFIA, QUIMIOESTRATIGRAFIA (C e Sr) E GEOCRONOLOGIA (U-Pb). MATO GROSSO, BRASIL}

DISSERTAÇÃO DE MESTRADO

$\mathrm{N}^{\circ} 349$

Samille Cristine dos Reis de Souza

Dissertação de Mestrado apresentada em 28 de julho de 2015, visando obtenção do grau de Mestre em Geologia Regional pelo Programa de Pós-Graduação em Geologia do Instituto de Geociências da Universidade de Brasília.

Orientador:

Prof. Dr. Carlos José Souza de Alvarenga

Banca examinadora:

Prof. Dr. Carlos José Souza de Alvarenga (IG-UnB) Profa. Dr ${ }^{\mathrm{a}}$. Lucieth Cruz Vieira (IG-UnB) $\mathrm{Dr}^{\mathrm{a}}$. Milene Freitas Figueiredo (Petrobrás) 
À Papai e Mamãe... da Terra e do Astral. 


\title{
AGRADECIMENTOS
}

\author{
“Assim como quem esteve no \\ Sol não precisa dizê-lo \\ não quero expressar meus \\ agradecimentos com palavras \\ na verdade, espero tê-los \\ demonstrado na convivência \\ que tive com todos.”
}

Gratidão...

Deus e Santa Maria.

Meus pais, Marlos e Odinea Souza, pelo apoio e amor incondicional.

Guilherme Vilela, meu marido, pelo companheirismo e incentivo diário.

Universidade de Brasília - UnB.

Instituto de Geociências - IG.

PETROBRÁS.

\section{CAPES.}

Prof. Dr. Carlos José de Souza Alvarenga, querido orientador, pela oportunidade, paciência e dom de ensinar.

Prof. Dr. Carlos Jorge de Abreu, pela valiosa contribuição.

Prof $^{\text {as }}$. Dr ${ }^{\text {as }}$. Edi Mendes Guimaraes e Lucieth Cruz Vieira pela essencial ajuda durante a preparação das amostras.

Prof. Dr. Nilson Francisquini Botelho pelo apoio no uso da microssonda.

Túlio Gabriel e Mendes pela parceria durante a etapa de campo.

Alice Maria Falquetto e Maristela Menezes Araújo por tudo.

Luis Bonfim, Mariana Guimarães e Barbara Duarte pela aventura amazônida no cerrado.

Professores e colegas que tive a honra e oportunidade de conviver e receber auxílio nestes pouco mais de dois anos. 
"Portadores dos registros da Terra, Tereis a bondade de explicar

A história que nos deu à luz, A verdade que só vós comportais? Como as vossas primas dos mares, As conchas que nos permitem ouvir Os sagrados murmúrios são a chave Da história que nos é cara. Povos de Pedra, queremos ouvir-vos. Ensinai-nos os antigos meios Para que possamos construir um futuro Baseado na oração e no louvor." 


\section{RESUMO}

A Faixa Paraguai contém registros dos eventos glaciais globais Neoproterozóicos, incluindo sedimentação que avançou até o limite Neoproterozóico-Cambriano Inferior. Os depósitos superiores da Faixa Paraguai dispõem numerosos dados geológicos que apresentam diversas interpretações e controvérsias quanto sua evolução. Na tentativa de melhor posicionar estes depósitos no contexto evolutivo, realizou-se revisão estratigráfica considerando a literatura disponível, levantamento litoestratigráfico, quimioestratigrafia isotópica (C e $\mathrm{Sr}$ ) e geocronologia (U-Pb). Na região estudada, segmento E-W da Faixa Paraguai, arredores de Planalto da Serra-MT, afloram pelitos carbonáticos/calcários estromatolíticos da Formação Pacu, unidade recém-incluída ao topo do Grupo Araras; seguido dos diamictitos-ritmitos depositados sobre limite bem marcado da base da Formação Serra Azul, a qual é limitada acima por contato brusco definido pelos arenitos-pelitos da Formação Raizama, seguido bruscamente de arcóseos-pelitos da Formação Diamantino, Grupo Alto Paraguai. A sucessão estromatolítica da Formação Pacu apresenta valores $\delta^{13} \mathrm{C}$ de $+6.5 \%$ (base) a +8.9\%o (topo) e razões ${ }^{87} \mathrm{Sr} /{ }^{86} \mathrm{Sr}$ entre $0.7087-0.7088$. Os valores $\delta^{13} \mathrm{C}$ são bem

distintos daqueles já definidos para o restante do Grupo Araras. As razões ${ }^{87} \mathrm{Sr} /{ }^{86} \mathrm{Sr}$ da Formação Pacu, quando plotadas na curva global marinha, referem-se a valores compatíveis com o final do Ediacarano, apesar dessa formação estar estratigraficamente abaixo da Formação Serra Azul, considerada correlata à Glaciação Gaskiers (582 Ma). Idades U-Pb obtidas em grãos de zircão detrítico mostram mudanças de áreas fontes entre as rochas da Formação Diamantino e as demais unidades do Grupo Alto Paraguai.

Palavras-chave: Neoproterozóico. Glaciações Neoproterozóicas. Ediacarano. Isótopos de C. Isótopos de Sr. Idades de zircões detríticos. 


\begin{abstract}
The Paraguay Belt contains records of global Neoproterozoic glacial events, including sedimentation that lasted the Neoproterozoic-Cambrian Lower limit. The upper deposits of Paraguay Belt have many geological data that present different interpretations and controversies about their evolution. In an attempt to better position these deposits in the evolutionary context, a stratigraphic review was realized considering available literature, lithostratigraphy, isotopic Chemostratigraphy (C and $\mathrm{Sr}$ ) and geochronology (U-Pb). In the region studied, EW segment of the Paraguay Belt, surrounding Planalto da Serra-MT outcrop carbonatic mudstone/stromatolitic limestone of Pacu Formation, a new unit added on the top of Araras Group; followed by diamictes-rhythmites deposited on well marked limits at the base of Serra Azul Formation, which is bounded above by sharp contact defined by sandstones-pelites of the Raizama Formation, followed sharply from arkoses-pelites Diamantino Formation, Alto Paraguay Group. The stromatolitic succession of Pacu Formation show $\delta^{13} \mathrm{C}$ values from $+6.5 \%$ (base) to $+8.9 \%$ (top) and ratios ${ }^{87} \mathrm{Sr} /{ }^{86} \mathrm{Sr}$ between 0.7087 and 0.7088. The $\delta^{13} \mathrm{C}$ values are very different from those already defined for the rest of the Araras Group. The Pacu Formation ${ }^{87} \mathrm{Sr} /{ }^{86} \mathrm{Sr}$ rates, when plotted on marine global curve, refer to values compatible with the end of the Ediacaran, despite this formation be stratigraphically below the Serra Azul Formation, considered related Gaskiers Glaciation of (582 Ma). U-Pb ages of detrital zircon grain show changes in source areas between the rocks of Diamantino Formation and the remaining units of the Upper Paraguay Group.
\end{abstract}

Key-words: Paraguay Belt. Neoproterozoic. Neoproterozoic Glaciations. Ediacaran. C isotopes. Sr isotopes. Age of detritic zircon. 


\section{LISTA DE FIGURAS}

Figura 1.1: Mapa de localização e vias de acesso a área de estudo (Adaptado a partir do Mapa Político do Estado do Mato Grosso; Ministério do Planejamento, Orçamento e Gestão; IBGE; Edição 2009).

Figura 2.1: Mapa geológico da Faixa Paraguai, situada à margem sudeste do Cráton Amazônico e leste do Bloco do Rio Apa, porção central da América do Sul (modificado de Schobbenhaus et al., 1981; Litherland et al., 1986; Boggiani, 1998).

Figura 3.1: A) Localização regional da Faixa Paraguai, inserida no contexto da Placa SulAmericana, com destaque para localização da área de estudo (em vermelho - adaptado a partir de Figueiredo et al., 2008). B) Mapa geológico que mostra a distribuição das unidades estratigráficas Neoproterozóicas na porção centro-norte da Faixa Paraguai Norte e localização das seções estudadas (Adaptado a partir das Folhas SD 21-Z-B-V-Brasilândia e SD 21-Z-BIV-Caiana, Escala 1:100.000; Souza et al.; CPRM,

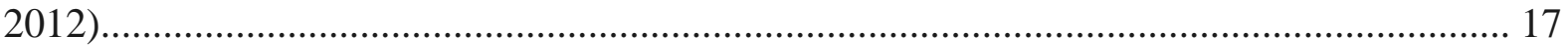

Figura 3.2: Imagem de satélite do Sinclinal Serra Azul (Faixa Paraguai Norte) com a localização das seções estudadas nas regiões de Planalto da Serra e "Sete Placas", estado do Mato Grosso (Zona UTM21; Image Landsat, Google 2014). 18

Figura 3.3: Representação das seções estratigráficas estudadas na Faixa Paraguai Norte (Seção 1, 2 e 3; ver Figura 3.1). Seções estratigráficas representativas da Formação Pacu (Base da Seção 3) e Grupo Alto Paraguai (Seção 1, 2 e 3) mapeadas na região de Planalto da Serra - MT. 20

Figura 3.4: Imagem de satélite da Região de Planalto da Serra, estado do Mato Grosso; com localização dos pontos descritos na Seção 1 e esboço do limite espacial das formações que compõem o Grupo Alto Paraguai (Formações Serra Azul, Raizama e Diamantino) e topo do Grupo Araras (Formação Pacu - Zona UTM21; Cnes/Spot Image, Google 2014)....... 21

Figura 3.5: Formação Pacu (Grupo Araras). A) Afloramento pertencente à Facies Argilosa (base), composto por Laminito (Facies $\mathrm{Lm}$ ). Nível argiloso, avermelhado, intemperizado; nível escuro, carbonático B) Afloramento pertencente à Facies Carbonática (topo), representado por Calcário estromatolítico colunar (Facies Lc).

Figura 3.6: Formação Pacu, Facies Argilosa. A) Detalhe da Facies Lm. Laminito, granulação muito fina (lama carbonática) formada pela recorrência de laminações delgadas. As laminações tendem a ser planoparalelas, com superfície lisa. Lâminas escuras mais pelíticas, lâminas claras mais carbonáticas. B) Detalhe da Facies Fl. Argilito carbonático, granulação 
fina, laminado, silicificado (Fotomicrografia sob nicóis cruzados, óptica $2,5 X)$

Figura 3.7: Formação Pacu, Facies Carbonática. A - B) Seções panorâmicas de lâminas delgadas do Calcário estromatolítico colunar (Facies Ls). É observável os níveis de crescimento dos microrganismos que geraram a laminação estromatolítica. Porção esquerda da Figura A e direita da Figura B é observável lâminações côncavas para baixo, alternando micrita (lâmina escura) e esparita (lâmina clara). Intraclastos, pelóides carbonáticos e oóides encontram-se dispersos nos espaços entre as colunas de estromatólitos. Os veios/vênulas são preenchidos por material calcítico/quartzoso. (Fotomicrografia sob nicóis cruzados, óptica $2,5 X)$. 25

Figura 3.8: Formação Pacu, Facies Carbonática. Detalhe da Facies Ls. A) Em destaque, oólito com estrutura fibro radiada e grão de quartzo (Fotomicrografia sob nicóis cruzados, óptica 10X). B) Intraclastos, pelóides carbonáticos e oóides dispersos nos espaços entre as colunas de estromatólitos cimentadas por calcita (Fotomicrografia sob nicóis cruzados, óptica 10X). 26

Figura 3.9: Formação Serra Azul, Unidade A: Diamictito. A) Diamictito maciço (Facies Dm) com fragmentos de rocha de composição variada e tamanho de até $\sim 1 \mathrm{~cm}$. B) Diamictito maciço (Facies Dm) com grande clasto de quartzito com tamanho de $\sim 7 \mathrm{~cm}$. C) Área arrasada, domínio da 'Unidade A', com ocorrência de grandes blocos de granito que resistiram ao processo erosivo atuante nos diamictitos. D) Aspecto mesoscópico deste granito, composto essencialmente por cristais de quartzo e

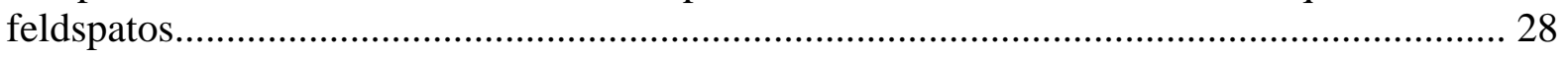

Figura 3.10: Unidade A: Diamictito. Diamictito maciço (Facies Dm). A e B) Paraconglomerado intraformacional com matriz silto-argilosa (Fotomicrografia sob nicóis paralelos e cruzados, respectivamente; óptica 10X). Qtz - quartzo; Ms - muscovita; Frx fragmento de rocha.

Figura 3.11: Formação Serra Azul, porção intermediária da Unidade B. A) Seção panorâmica (Seção 1, ponto PS 40; ver Figura 3.3) formada por intercalações rítmicas de pelito finamente laminado e arenito maciço (Facies Fl-Sm), com destaque para as camadas de arenito/conglomerado ferruginoso (Facies $S p-G m$ ). É possível perceber a repetição dos ciclos (base à esquerda). B) Seção panorâmica (Seção 2, ponto PS 69; ver figura 3.3) lateralmente correlacionável a seção panorâmica da Figura 3.11-A. Os ciclos rítmicos são similares à seção do ponto PS 40 (base à direita), com as mesmas ocorrências de camadas de arenito/conglomerado ferruginoso (Facies Sp-Gm). 31

Figura 3.12: Formação Serra Azul, porção intermediária da Unidade B. A) Intercalação rítmica entre pelito finamente laminado e arenito maciço (Facies $\mathrm{Fl}-\mathrm{Sm}$ ). Atentar ao detalhe (setas) do arenito com superfície ondulada/retrabalhada por onda intercalado ao pelito. B) Detalhe, arenito ferruginoso (cimentado por óxido de Fe) com estratificação cruzada tabular de baixo ângulo (Facies Sp). Figuras A e B são representativas da Seção 1, ponto PS 40 (ver Figura 3.3 e 3.11-A). C) Detalhe, nível conglomerático (Facies $\mathrm{Gm}$ ) ferruginoso (cimentado por óxido de $\mathrm{Fe}$ ) que ocorre associado à porção basal da Facies Sp. C) Detalhe, arenito 
ferruginoso (cimentado por óxido de Fe) com estratificação cruzada tabular de baixo ângulo (Facies Sp). Figuras B e C são representativas da Seção 2, ponto PS 69 (ver Figura 3.3 e 3.11B).

Figura 3.13: Unidade B: Sucessão Siltito - Pelito/Arenito. Arenito com estratificação tabular (Facies Sp). A) Fotomicrografia do arenito ferrificado (Fotomicrografia sob nicóis cruzados, óptica 5X). B e C) Compõe-se principalmente por grãos de quartzo e ocorrência de quartzo policristalino e biotita cloritizada, cimentadas por óxido de ferro (Fotomicrografia sob nicóis cruzados, óptica 10X). D) Imagem de varredura eletrônica; seta - indica Ba com borda de alteração por óxido de Fe hematítico. Ba - Barita; Mn - Monazita; Im - Ilmenita; Bt Biotita; Zr - Zircão.

Figura 3.14: A) Seção panorâmica que registra contato brusco descrito entre o topo da Formação Serra Azul e base da Formação Raizama (Ciclo A), na região de Planalto da SerraMT (Ponto PS 43, ver Figura 3.3 e 3.4). B) Contato brusco que limita o topo da Formação Serra Azul e o aparecimento do primeiro grande banco de arenito grosso, muito silicificado (Ciclo A), que sustenta a base da Formação Raizama. C) Detalhe deste contato. 36

Figura 3.15: Formação Raizama; Ciclo A. A) Arenito maciço (Facies Sm), granulometria fina. B) Siltito finamente laminado (Facies Fl), com finas lâminas ferrificadas. C) Banco de arenito com estratificação cruzada tabular e/ou laminação plano-paralela truncadas por estruturas de ondas (Facies Sp), com ocorrência de finas lâminas de argila/silte. D) Conglomerado maciço (Facies Gm), com clastos de

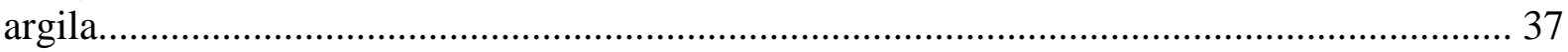

Figura 3.16: Formação Raizama; Ciclo B. A) Seção panorâmica que demonstra os ciclos internos compostos por sucessões rítmicas (Facies $\mathrm{Fl}-\mathrm{Sm}$ ) limitadas por grandes bancos de arenito com estratificação plano-paralela (Facies $S p$ ) destacados pelas linhas tracejadas em vermelho (base à direita). B) Detalhe das sucessões rítmicas centimétricas $(3-7 \mathrm{~cm})$ de siltito laminado (Facies Fl) intercalado com finas lâminas de arenito maciço (Facies Sm). C) Detalhe do contato entre estas sucessões rítmicas e banco arenoso composto por arenito com estratificação/laminação plano-paralela (Facies $\quad S p$ ), grosso/muito grosso. 40

Figura 3.17: Formação Raizama; Ciclo C. Sessão panorâmica que demonstra banco de arenito maciço que marca o topo do Ciclo C (cerca de $18 \mathrm{~m}$ de espessura - Facies Sm), quartzo-felspático, médio-grosso, bem silicificado, fraturado (PS 59; ver Figura 3.3 e 3.4)...... 41

Figura 3.18: Formação Raizama; Ciclo D. Seção panorâmica que demonstra os ciclos rítmicos internos do 'Ciclo D', bastante intemperizado, formados por intercalações de siltito laminado (Facies Fl) com arenito maciço (Facies Sm - PS 77; ver Figura 3.3 e 3.4).

Figura 3.19: Formação Raizama. Arenito maciço (Facies Sm). A) Fotomicrografia do arenito maciço sob nicóis cruzados (óptica 5X). Setas indicam ocorrência de porosidade. B) Compõe- 
se principalmente por quartzo e feldspatos detríticos cimentados por sílica (Fotomicrografia sob nicóis cruzados, óptica 10X). D) Ocorrência de zircão detrítico e mimerquita. (Fotomicrografia sob nicóis cruzados, óptica 10X). D) Ocorrência de mica (Fotomicrografia sob nicóis cruzados, óptica 10X). Qz - Quartzo; Qzp - Quartzo policrisalino; Fld - Feldspato indiferenciado; K-F - Feldspato potássico; Plg - Plagioclásio; Ms - Muscovita; Zr Zircão.

Figura 3.20: Formação Diamantino. Área arrasada de relevo pouco acentuado que marca a Formação Diamantino na região de Planalto da Serra-MT.

Figura 3.21: Imagem de satélite da região de "Sete Placas"; onde foram estudadas as Seções 4 (perfil A-B) e 5 . O esboço marca o limite entre a Cobertura Cretácea, Formação Raizama e a Formação Diamantino. Abaixo, seção transversal esquemática da Seção 4 (perfil A-B), com espessura estimada das Formações Raizama e Diamantino (Zona UTM21; Imagen Digital Globe - Cnes/Spot Image, Google 2014).

Figura 3.22: Imagem de satélite da região de "Sete Placas". Detalhe da Seção 5 (ver Figura 3.1, 3.2 e 3.21) com a localização dos pontos descritos. O esboço marca o limite entre a Cobertura Cretácea, Formação Raizama e a Formação Diamantino. Na Formação Raizama os bancos de arenito que limitam os grandes ciclos sedimentares são bem nítidos e encontram-se destacados pelas linhas tracejadas (Zona UTM21; Imagen Digital Globe - Cnes/Spot Image, Google 2014).

Figura 3.23:Formação Raizama, Seção 4. A) Camadas de arenito com estratificação cruzada acanalada com estrutura de onda ao topo (Facies St). B) Camadas de arenito com estratificação cruzada tabular de baixo ângulo (Facies Sp). C) Base formada por camada de arenito com estrutura de onda (Facies Sr), intercalado a um ciclo rítmico de pelito maciço (Facies Fm) com arenito maciço (Facies Sm), de granulometria fina, encerrado ao topo por arenito com estratificação cruzada hummocky (Facies Sh). 48

Figura 3.24: Formação Raizama, Seção 5. A) Banco de arenito com estratificação cruzada incipiente (Facies Sp), conglomerático na base dos sets. B) Detalhe da Facies Sp, com ocorrência de seixos e grânulos. C) Intercalações rítmicas $(\sim 0,5 \mathrm{~m})$ de pelito laminado (Facies Fl) com arenito maciço (Facies Sm). D) Detalhe destas intercalações rítmicas (Facies $\mathrm{Fl} / \mathrm{Sm})$

Figura 3.25: Formação Diamantino, Seção 4. A) Ciclo formado por siltito finamente laminado (Facies Fl) e arenito com estratificação cruzada (Facies Sp), com placas de mica marcando o plano de estratificação. B) Afloramento em forma de lajedo, constituído de arenito com ocasionais lentes de arglito, onde há marcas de ondas simétricas (Facies Sr). C) Paredão com camadas sub-horizontais de arenito maciço (Facies Sm) intercalado a lâminas centimétricas de argilito maciço esverdeado (Facies Fm). D) Sucessão com níveis esverdeados, ricos em mica, de espessura centimétrica e contínuos lateralmente, intercalados às camadas de argilito-arenito (Facies $\quad$ Fm Sm). 
Figura 4.1: Curvas quimioestratigráficas de $\delta^{13} \mathrm{C}$ e $\delta^{18} \mathrm{O}$ e razões isotópicas de ${ }^{87} \mathrm{Sr} /{ }^{86} \mathrm{Sr}$ para a Facies Carbonática da Formação Pacu, Grupo Araras, região de Planalto da Serra (ver Figura 3.2 - Seção 3). 55

Figura 5.1: Gráficos de probabilidade relativa para análise U-Pb em zircão detrítico nas amostras do Grupo Alto Paraguai: PS 22, PS 07, PS 08A, PS 40C (Formação Serra Azul); PS 11 e PS 30 (Formação Raizama); PS 10 (Formação Diamantino). Sombreamento em azul representa todos os grãos analisados. Linha vermelha apresenta a probabilidade de ocorrência dos principais agrupamentos de idade. Nos histogramas, foram consideradas as idades concordantes entre 90 e $110 \%$. 58

Figura 5.2: Probabilidade das idades relativas U-Pb obtidas em zircões detríticos das amostras coletadas nas formações Serra Azul, Raizama e Diamantino, Grupo Alto Paraguai. 59

Figura 6.1: Curva marinha de razões isotópicas de Sr para o Neoproterozóico e Cambriano (Adaptado de Halverson et al., 2007, 2010). Os calcários da Formação Pacu, estão estratigráficamente abaixo da Formação Serra Azul, e a plotagem das razões ${ }^{87} \mathrm{Sr} /{ }^{86} \mathrm{Sr}$ dessa formação levou em consideração que os diamictitos da Formação Serra Azul sejam correlatos à Glaciação Gaskiers. 62

Figura 6.2: A) Mapa com a localização da Faixa Paraguai dentro do contexto da Placa SulAmericana e área de estudo (área em vermelho - adaptado a partir de Figueiredo et al., 2008). B) Mapa simplificado do SW do Cráton Amazônico, Faixas Paraguai e Brasília indicando as potenciais áreas fontes para os depósitos superiores da Faixa Paraguai Norte (Grupo Alto Paraguai). Os sedimentos das Formações Serra Azul e Raizama são provenientes principalmente de NNW e para a Formação Diamantino são provenientes principalmente de ESE, como indicado pelas faixas cinzas. Cráton Amazônico (Tassinari \& Macambira, 1999, 2004). Cráton São Francisco - cobertura sedimentar (Babinski \& Kaufman, 2003). Faixa Brasília - margem passiva (Coelho et al., 2008); Sequência Rift, Greenstons Belts, Faixa de dobras e empurrões (Pimentel et al., 1991; 1998; 2000); Complexo Anápolis-Itaçu (Giustina, 2010). Maciço de Goiás - Grupo Serra da Mesa (Pimentel et al., 1991; Pimentel \& Fuck, 1992); Complexo máfico-ultramáfico (Nilson et al., 1997); Granito-Greenstones (Pimentel \& Fuck, 1994; Nilson et al., 1997). Arco magmático Juvenile - Vulcano-sedimentar (Viana et al., 1995); Ortognaisses (Pimentel et al., 1997). Faixa Araguaia - Supracrustais (Moura et al., 2008); Embasamento siálico (Pimentel et al., 2000). Faixa Paraguai - Grupo Cuiabá, Formação Puga, Grupo Araras, Grupo Alto Paraguai (Cordani et al., 1978, 1985; Bonhomme et al., 1982; Nogueira, 2003; Nogueira et al., 2003; Babinski et al., 2006, 2007; Figueiredo, 2006; Dantas et al., 2009; Bandeira et al., 2012; McGee et al., 2015a,b; este trabalho). 
LISTA DE TABELAS

Tabela 4.1: Isótopos de C, O, Sr e geoquímica elementar dos calcários da Formação

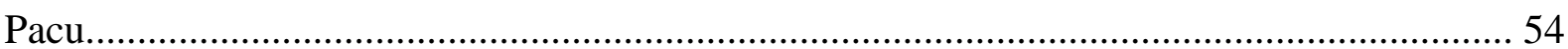




\section{SUMÁRIO}

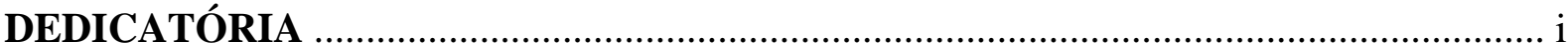

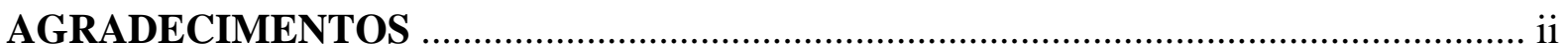

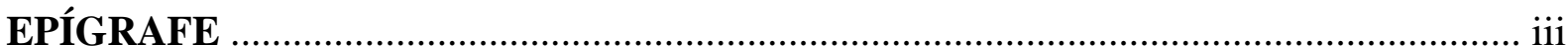

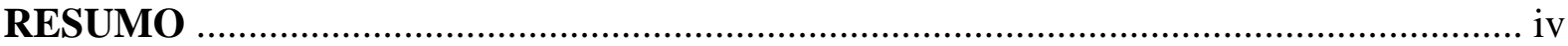

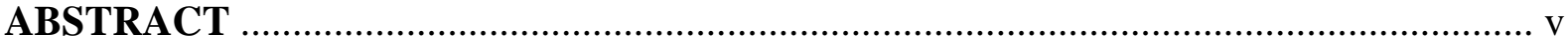

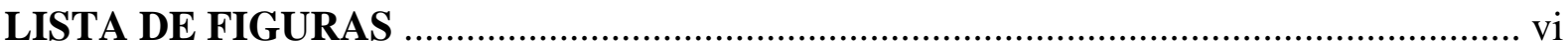

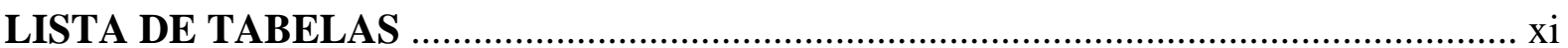

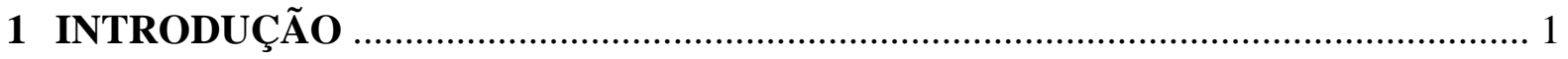

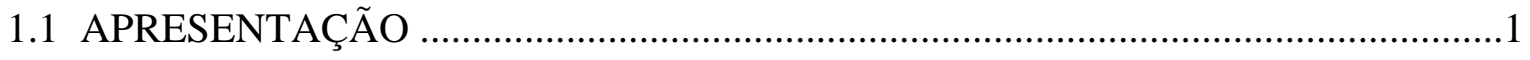

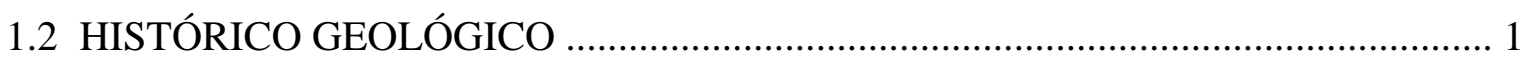

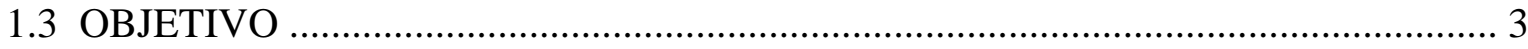

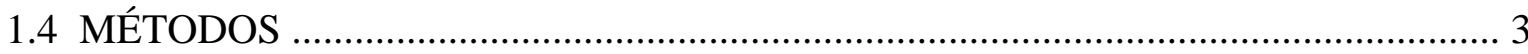

1.4.1 Análise sedimentológica e estratigráfica …................................................ 3

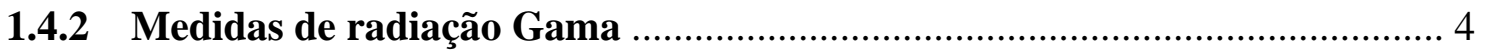

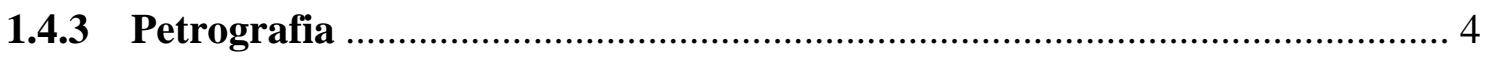

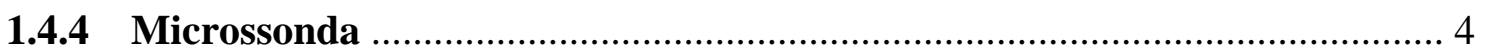

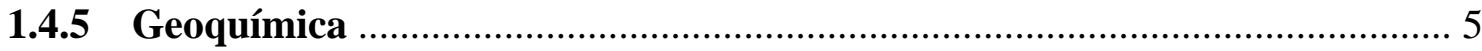

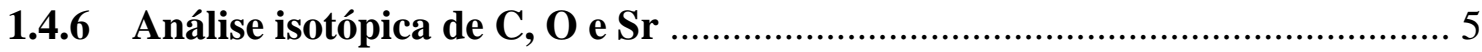

1.4.6.1 Isótopos Estáveis: C e O ....................................................................... 5

1.4.6.2 Isótopos Radiogênicos: $\mathrm{Sr}$................................................................... 5

1.4.7 U-Pb em zircões detríticos via LA-MC-ICP-MS ...................................... 6

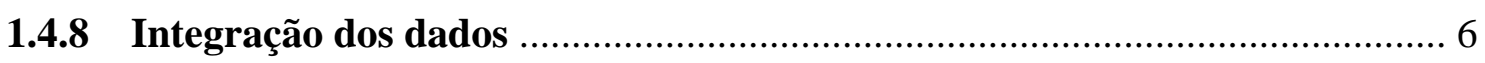

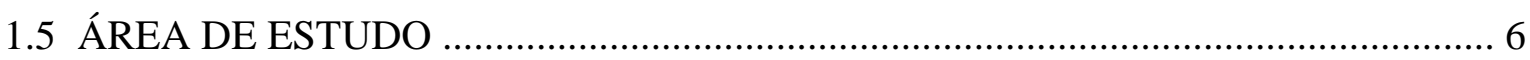

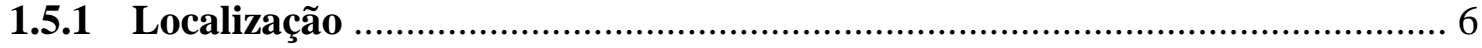

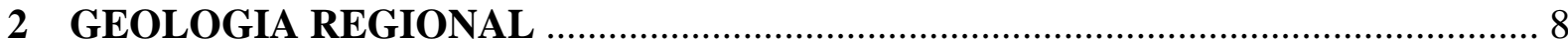

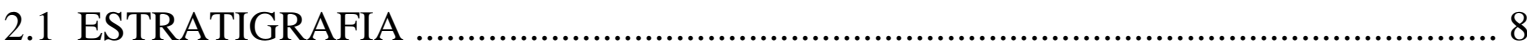

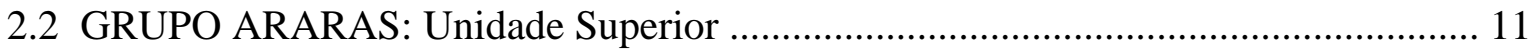

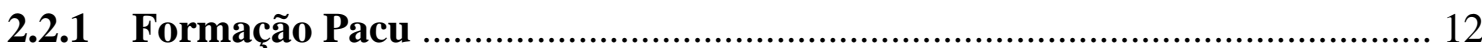




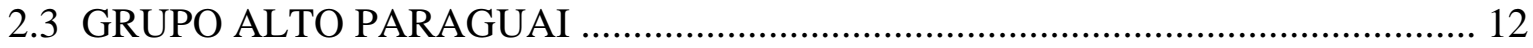

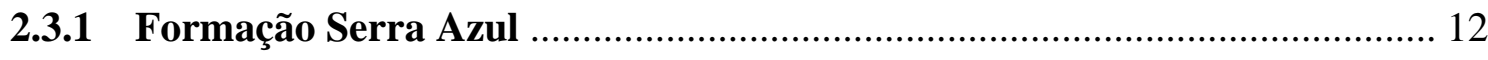

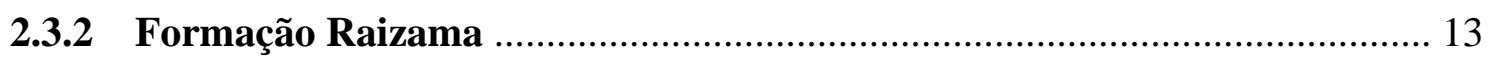

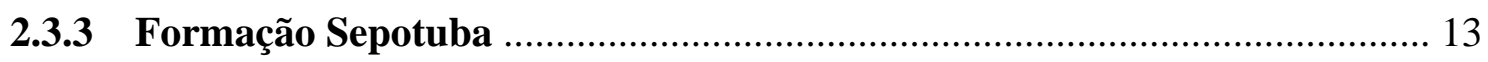

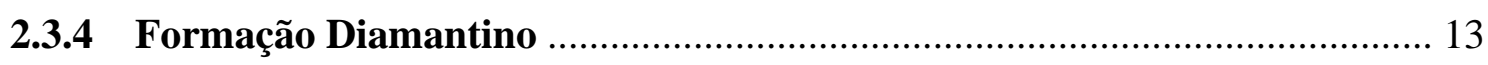

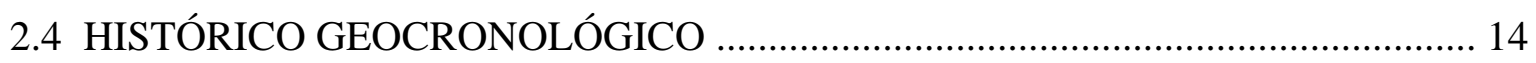

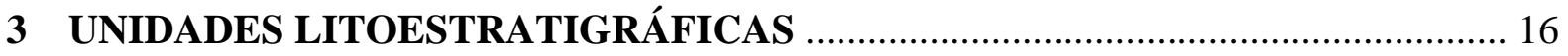

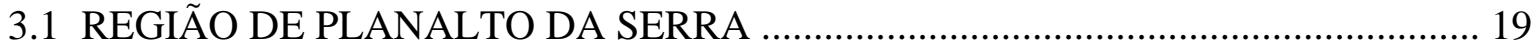

3.1.1 Grupo Araras: Unidade Superior ......................................................... 22

3.1.1.1 Formação Pacu ............................................................................... 22

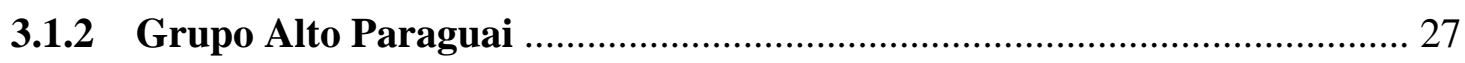

3.1.2.1 Formação Serra Azul .......................................................................... 27

3.1.2.1.1 Unidade A: Diamictito ...................................................... 27

3.1.2.1.2 Unidade B: Sucessão Siltito - Pelito/Arenito ........................... 30

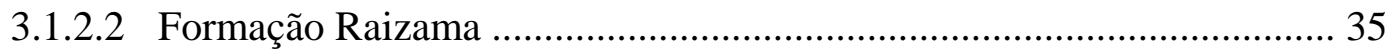

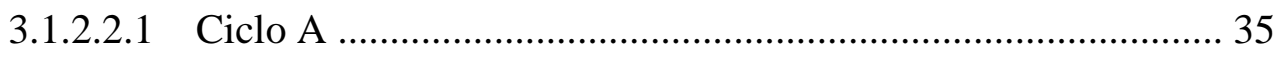

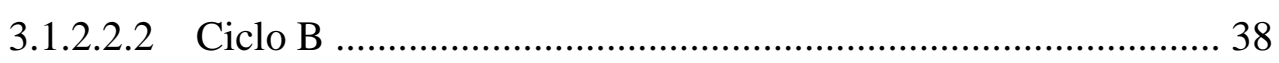

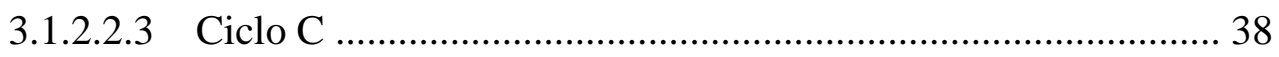

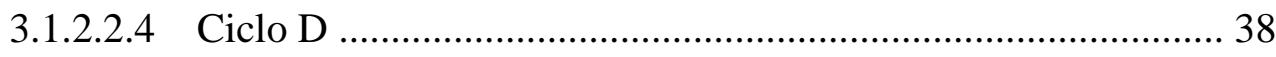

3.1.2.3 Formação Diamantino ....................................................................... 44

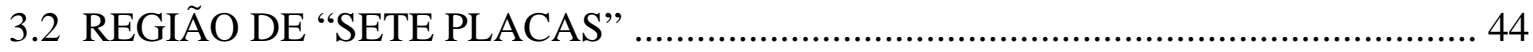

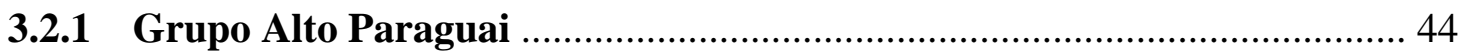

3.2.1.1 Formação Raizama ....................................................................... 44

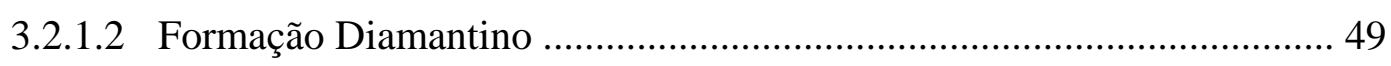

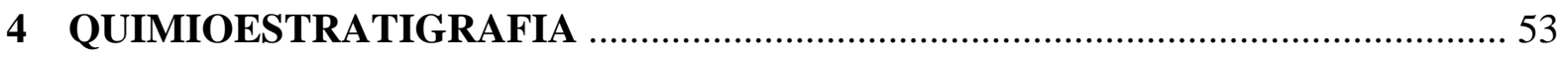

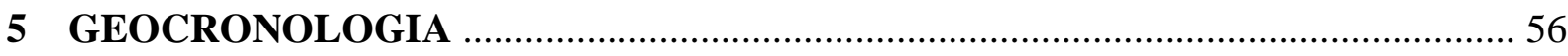

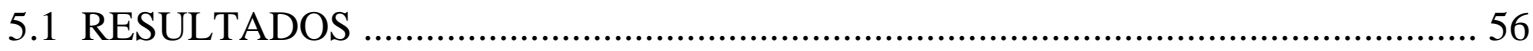

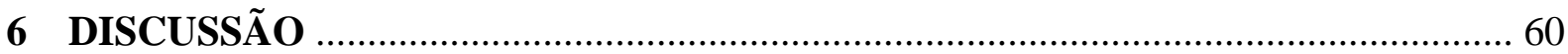

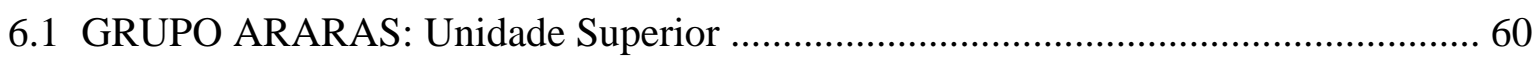

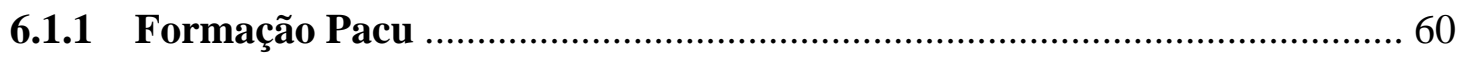

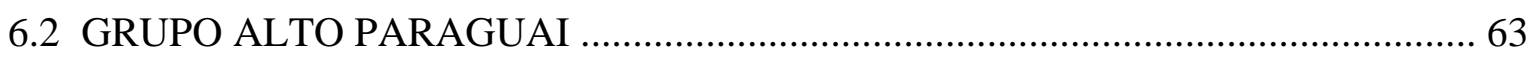

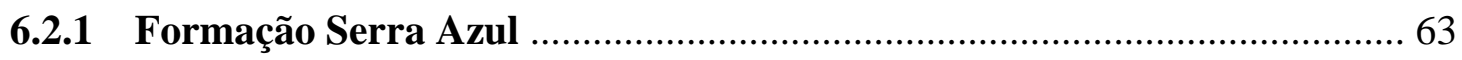

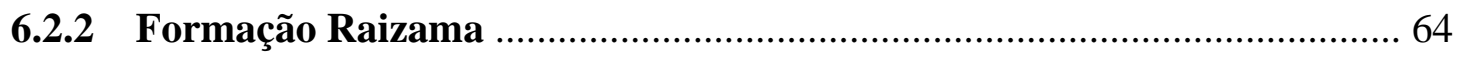

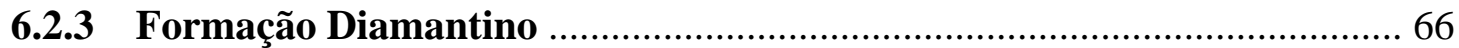


6.3 MODELOTECTÔNICO E CONTEXTO EVOLUTIVODA FAIXA PARAGUAI

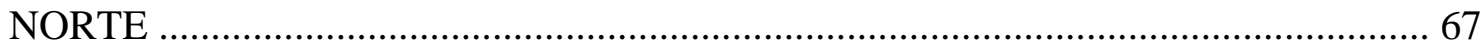

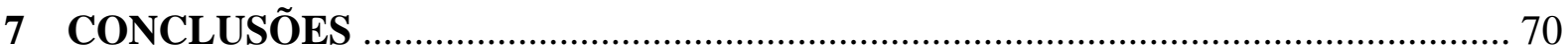

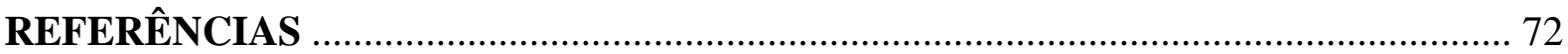

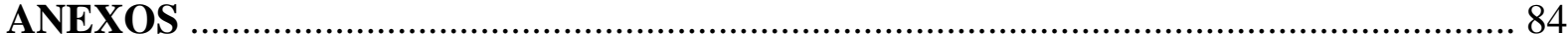




\section{INTRODUÇÃO}

\subsection{APRESENTAÇÃO}

A Faixa de Dobramentos Paraguai (Faixa Paraguai), localizada na região central da América do Sul, exibe conjunto de rochas sedimentares dobradas/metamorfizadas inseridas no contexto tectônico da borda sudeste do Cráton Amazônico e porção oriental do Bloco do Rio Apa (Almeida, 1964a-b). Estas rochas representam uma sucessão de margem passiva invertida para bacia foreland, que contém registros dos eventos glaciais globais Neoproterozóicos, incluindo sedimentação que avançou até o limite NeoproterozóicoCambriano Inferior (Nogueira et al., 2003, 2007; Figueiredo et al., 2004, 2008; Alvarenga et al., 2007, 2008; Dantas et al., 2009; McGee et al., 2015a,b). Dados geológicos publicados a respeito dessas rochas apresentam a complexidade dos processos que ocorreram neste período, originando diversas interpretações e controvérsias quanto sua evolução. Dessa forma, a revisão estratigráfica associada ao levantamento litoestratigráfico, quimioestratigrafia com base em isótopos de $\mathrm{C}$ e $\mathrm{Sr}$ e, datação $\mathrm{U}-\mathrm{Pb}$ em zircões detríticos via laser ablation multicollector inductively coupled plasma mass spectrometry (LA-MC-ICP-MS), demonstram ser ferramentas importantes para correlações em escala regional e global, contribuindo assim para uma melhor contextualização das discussões e apresentação do panorama geológico/estratigráfico das rochas da Faixa Paraguai Norte.

\subsection{HISTÓRICO GEOLÓGICO}

A Faixa Paraguai foi individualizada pioneiramente por Evans (1894). Almeida (1964a-b, 1965a-b) lançou as primeiras sínteses referentes à estratigrafia e a evolução geotectônica de suas rochas. Trabalhos de mapeamento geológico sistemático realizado pelo DNPM e CPRM (Figueiredo \& Olivatti, 1974; Ribeiro Filho \& Figueiredo, 1974; Ribeiro Filho et al., 1975; Nogueira \& Oliveira, 1978; Luz et al., 1978, 1980; Corrêa et al., 1979), derivaram em uma importante base de dados que originaram sinopses estratigráficas e mapas geológicos regionais na escala 1:1.000.000 (Oliva et al., 1979; Schobbenhaus Filho \& Oliva, 1979; Schobbenhaus Filho \& Soares, 1979; Araújo et al., 1982; Barros et al., 1982; Del’Arco et al., 1982), tendo em vista que a maior parte destes trabalhos descreve apenas a geologia de 
porções isoladas da Faixa Paraguai. Almeida (1984) propôs uma síntese estratigráfica e tectônica que envolveria toda sua extensão. Dentre estas publicações havia questões quanto as diferentes propostas estratigráficas que, segundo Alvarenga (1984), se deram principalmente em relação aos limites entre as zonas estruturais da Faixa Paraguai. Desta forma, novas interpretações estratigráficas e estruturais foram propostas: Zona Interna, Zona Externa e Coberturas Sedimentares de Plataforma, as quais conteriam as rochas do Grupo Cuiabá e das formações Puga, Bauxi, Araras, Raizama e Diamantino (Alvarenga, 1988; Alvarenga \& Trompete, 1992).

Outros trabalhos dispõem dados quimioestratigráficos das sucessões carbonáticas dos grupos Corumbá e Araras (Boggiani et al., 2003; Gaucher et al., 2003; Nogueira et al., 2003, 2007; Pinho et al., 2003; Alvarenga et al., 2004, 2008; Font et al., 2006; Riccomini et al., 2007). A partir destes trabalhos, análises estratigráficas, sedimentológicas e isotópicas realizadas no Grupo Araras na região de Mirassol d'Oeste, confirmaram a identificação de uma capa carbonática na margem sudeste do Cráton Amazônico. Esta capa carbonática foi interpretada como tendo sido depositada em plataforma profunda e as características de deformação soft em sua base é uma forte evidência de que a deposição dos dolomitos ocorreu imediatamente após a Glaciação Marinoana, a qual deu origem aos diamictitos da Formação Puga (Nogueira et al., 2003; Alvarenga et al., 2004, 2008).

Ainda no contexto dos eventos glaciais, também foram encontrados na Faixa Paraguai Norte diamictitos sobrepostos aos calcários de topo do Grupo Araras e recobertos por arenitos da base da Formação Raizama (Figueiredo et al., 2004). Este nível de diamictito encontra-se associado com siltitos-arenitos que ocorrem em afloramentos descontínuos, e são considerados produtos pós Glaciação Marinoana, sugerindo uma glaciação mais jovem possivelmente correlata a Glaciação Gaskiers (582 Ma - Figueiredo et al. 2004; Figueiredo, 2006; Alvarenga et al., 2007). Estes depósitos foram elevados ao status de Formação Serra Azul e hoje encontram-se inseridos na base do Grupo Alto Paraguai (Figueiredo et al., 2008).

Recentemente, durante a execução do projeto "Planalto da Serra", a CPRM mapeou uma nova unidade denominada Formação Pacu, composta por dois membros, o inferior pelítico, conhecido como Facies Argilosa, e um superior, carbonático/estromatolítico, conhecido como Facies Carbonática, posicionada ao topo do Grupo Araras (Souza et al., 2012). 


\subsection{OBJETIVO}

Esta dissertação tem por objetivo ampliar o conhecimento geológico da transição Neoproterozóico-Cambriano Inferior da Faixa Paraguai Norte através do estudo litoestratigráfico, quimioestratigráfico e geocronológico desse intervalo, de forma a quantificar as sucessões e definir com mais detalhe o posicionamento destas ao longo do tempo geológico, tendo em vista a problemática da Glaciação Gaskiers (582 Ma).

Os objetivos específicos englobam:

a) Levantamento medido de seções estratigráficas em campo, visando o detalhamento das facies sedimentares entre a Formação Pacu (Grupo Araras) e a Formação Diamantino (Grupo Alto Paraguai), utilizando os métodos clássicos de análise faciológica e estratigráfica que serviram de base para a caracterização paleoambiental;

b) Definir uma curva quimioestratigráfica para os carbonatos da Formação Pacu, com o objetivo de comparar as curvas isotópicas existentes para o grupo Araras;

c) Integração dos dados geocronológicos existentes (Rb-Sr, Sm-Nd, U-Pb, etc.) e discutir as idades U-Pb em zircões detríticos dentro do contexto da evolução tectonosedimentar, com o objetivo de estabelecer o estágio de conhecimento sobre o assunto;

d) Posicionar os depósitos estudados dentro do contexto de evolução da passagem Neoproterozóico-Cambriano Inferior.

\subsection{MÉTODOS}

\subsubsection{Análise sedimentológica e estratigráfica}

Durante o desenvolvimento do trabalho foram utilizados os conceitos de análise de facies e estratigrafia de sequências (Walker, 1976; 1984; Eyles et al., 1985; Tucker \& Wright, 1990; Walker \& James, 1992; Tucker, 2003; Catuneanu, 2006; Nichols, 2009; Plint, 2010).

A metodologia de campo empregada considera os seguintes aspectos:

a) Individualização e definição de facies, registrando suas características sedimentológicas, tais como: estruturas sedimentares, textura, mineralogia, padrão de paleocorrentes, traços fósseis, etc. A coleta sistemática de amostras obedeceu à individualização faciológica;

b) Mapeamento vertical e lateral de facies e associações de facies deposicionais utilizando perfis estratigráficos, seções esquemáticas e panorâmicas; 
c) Mapeamento e/ou correlação de superfícies chaves (i.e. superfícies de descontinuidades), que permitiram delimitar as unidades deposicionais posicionandoas dentro do contexto evolutivo e;

d) A análise destas características permitiu a interpretação dos processos sedimentares, e as relações espaciais de facies e associação de facies serviram de base para a caracterização paleoambiental, paleoclimática e tectônica.

\subsubsection{Medidas de radiação Gama}

A quantificação da radiação Gama foi feita in situ nas rochas intermediárias da Unidade B da Formação Serra Azul (Grupo Alto Paraguai), utilizando um espectrômetro diferencial portátil de Raios Gama que quantifica os elementos radioativos como o K, U e Th. Com o equipamento a cerca de $1 \mathrm{~m}$ do chão foram feitas as contagens totais por segundo (cps), com tempo de medida de 120 segundos, registrando-se a data e hora de medição.

\subsubsection{Petrografia}

Apenas as amostras coletadas durante os levantamentos de campo nos arredores de Planalto da Serra foram selecionadas para análises texturais e composicionais por meio de microscopia óptica (seções polidas) no Instituto de Geociências da Universidade de Brasília, efetuando-se os seguintes estudos: a) identificação de estruturas, distribuição granulométrica, grau de arredondamento e esfericidade; b) classificação de pelitos e arenitos segundo Folk (1974); c) determinação do cimento nos arenitos; d) distinção dos tipos de carbonatos segundo Tucker \& Wright (1990) e, e) interpretação de diamictitos segundo Eyles et al. (1985).

\subsubsection{Microssonda}

A análise química pontual de minerais em microssonda, baseada no espectro de raios-X emitidos pela amostra sob impacto de feixe de elétrons, foi realizada na amostra 40-C da Formação Serra Azul (Grupo Alto Paraguai), no Laboratório de Microssonda Eletrônica do Instituto de Geociências da Universidade de Brasília. O equipamento usado é uma sonda eletrônica JEOL, modelo Superpobe JXA-8230, e as condições de operação foram $15 \mathrm{kV}$ de voltagem de aceleração e $10 \mu \mathrm{A}$ de corrente, com tempo de contagem entre 10 e 50 segundos e o diâmetro do feixe entre 2 e $5 \mu \mathrm{m}$. Os padrões dos elementos empregados foram: albita (Na), forsterita (Mg), microclínio ( $\mathrm{Al}$ e K), topázio (F), andradita (Ca e $\mathrm{Si}$ ), $\mathrm{Fe}_{2} \mathrm{O}_{3}(\mathrm{Fe})$, 
vanadinita (V e $\mathrm{Cl}$ ), $\mathrm{TiMnO}_{3}$ ( $\mathrm{Ti}$ e $\mathrm{Mn}$ ) e espinélio (Cr). O cálculo das fórmulas estruturais dos minerais foi realizado com planilhas do programa EXCEL.

\subsubsection{Geoquímica}

Determinações químicas feitas por fluorescência de Raio X, tiveram a sua preparação em pastilha fundidas, com determinações de perda ao fogo. As leituras foram feitas em espectrômetro de Fluorescência de Raio X RIGAKU no Laboratório de Geocronologia do Instituto de Geociências da Universidade de Brasília.

\subsubsection{Análise isotópica de C, O e Sr}

A amostragem para o estudo das assinaturas isotópicas de carbono (C), oxigênio (O) e estrôncio (Sr) foram feitas nas mesmas amostras de calcários estromatolíticos da Formação Pacu (Grupo Araras), coletadas com espaçamento de $3 \mathrm{~m}$. Foram selecionadas apenas amostras homogêneas e sem venulações. Para evitar contaminação, as amostras foram pulverizadas em moinho de bolas no Laboratório de Raio-X do Instituto de Geociências da Universidade de Brasília.

\subsubsection{Isótopos Estáveis: C e O}

Isótopos de $\mathrm{C}$ e $\mathrm{O}$ foram obtidos em espectrômetro de massa Delta $V$ Advantage conectado a Gas Bench II no Laboratório de Geocronologia do Instituto de Geociências da Universidade de Brasília. O erro analítico para as medidas dos isótopos de carbono é de 0,05\% e para os isótopos de oxigênio é de $\pm 0,10 \%$. Todos os valores de isótopos de C e O são expressos na notação por mil (\%) relativa ao padrão PDB (Pee Dee Belemnites).

\subsubsection{Isótopos Radiogênicos: $\mathrm{Sr}$}

Para a análise de ${ }^{87} \mathrm{Sr} /{ }^{86} \mathrm{Sr}, 50 \mathrm{mg}$ de amostras em pó foram pesadas em beakers de teflon e diluídos em ácido acético $(0,5 \mathrm{~N})$ para dissolver apenas a fração carbonática e evitar a lixiviação de Sr e Rb radiogênicos dos constituintes não carbonatados das amostras. As razões ${ }^{87} \mathrm{Sr} /{ }^{86} \mathrm{Sr}$ foram medidas usando um espectômetro MC-ICP-MS Neptune Thermo no Laboratório de Geocronologia do Instituto de Geociências da Universidade de Brasília. As incertezas nas análises individuais foram de \pm 1 (2SE). 


\subsubsection{U-Pb em zircões detríticos via LA-MC-ICP-MS}

Amostras extraídas das formações Serra Azul, Raizama e Diamantino (Grupo Alto Paraguai) foram inicialmente trituradas na moagem, desfragmentadas em SELFRAG, separando-se as frações mais finas por peneiramento seguido de individualização magnética no Separador Eletromagnético Frantz. A separação e concentração dos minerais pesados foram feitas com auxílio de líquido denso, sendo os grãos de zircão detríticos selecionados sob lupa binocular. Os grãos de zircão detríticos selecionados foram dispostos em mounts de epóxi, metalizados, imageados por Microscópio Eletrônico de Varredura (MEV) e suas idades determinadas pelo método U-Pb via laser ablation multi-collector inductively coupled plasma mass spectrometry (LA-MC-ICP-MS) no Laboratório de Geocronologia do Instituto de Geologia da Universidade de Brasília. Seguindo os procedimentos analíticos descritos por Bühn et al. (2009), as idades foram calculadas em função de padrões internacionais para zircão, G-1 (Jackson et al., 2004) e 91500 (Wiedenbeck et al., 1995), usados como amostras padrões para balanço de massa e correção de desvios. As incertezas nos cálculos e teores derivados da medição em LA-MC-ICP-MS são da ordem de \pm 0,5\% (1б). Isótopos radiogênicos de $\mathrm{Pb}$ foram corrigidos para valores originais de isótopos radiogênicos segundo o modelo para a idade aproximada da amostra de Stacey \& Kramers (1975). As razões ${ }^{207} \mathrm{~Pb} /{ }^{235} \mathrm{U}$ e ${ }^{206} \mathrm{~Pb} /{ }^{238} \mathrm{U}$ das amostras analisadas foram corrigidas e lançadas em gráficos de probabilidade relativa usando o programa ISOPLOT 3.0 (Ludwing, 2003), adotando-se grau de concordância no intervalo de 90-110\%.

\subsubsection{Integração dos dados}

A interpretação dos dados e aplicação destes no contexto de evolução tectonosedimentar da Faixa Paraguai Norte será apresentada ao decorrer desta dissertação.

\section{5 ÁREA DE ESTUDO}

\subsubsection{Localização}

A área de estudo está localizada na porção central da Placa Sul-Americana, Centro-Sul do Estado do Mato Grosso, nos arredores da cidade de Planalto da Serra, distante cerca de 259 Km da capital Cuiabá (Figura 1.1). O acesso à região de Planalto da Serra se dá a partir de Cuiabá por via pavimentada pela MT 351, seguindo pelas vias não pavimentadas MT 020 e MT 244 até a referida cidade. Nesta região o acesso aos pontos estudados foi realizado em estradas vicinais de leito natural. 

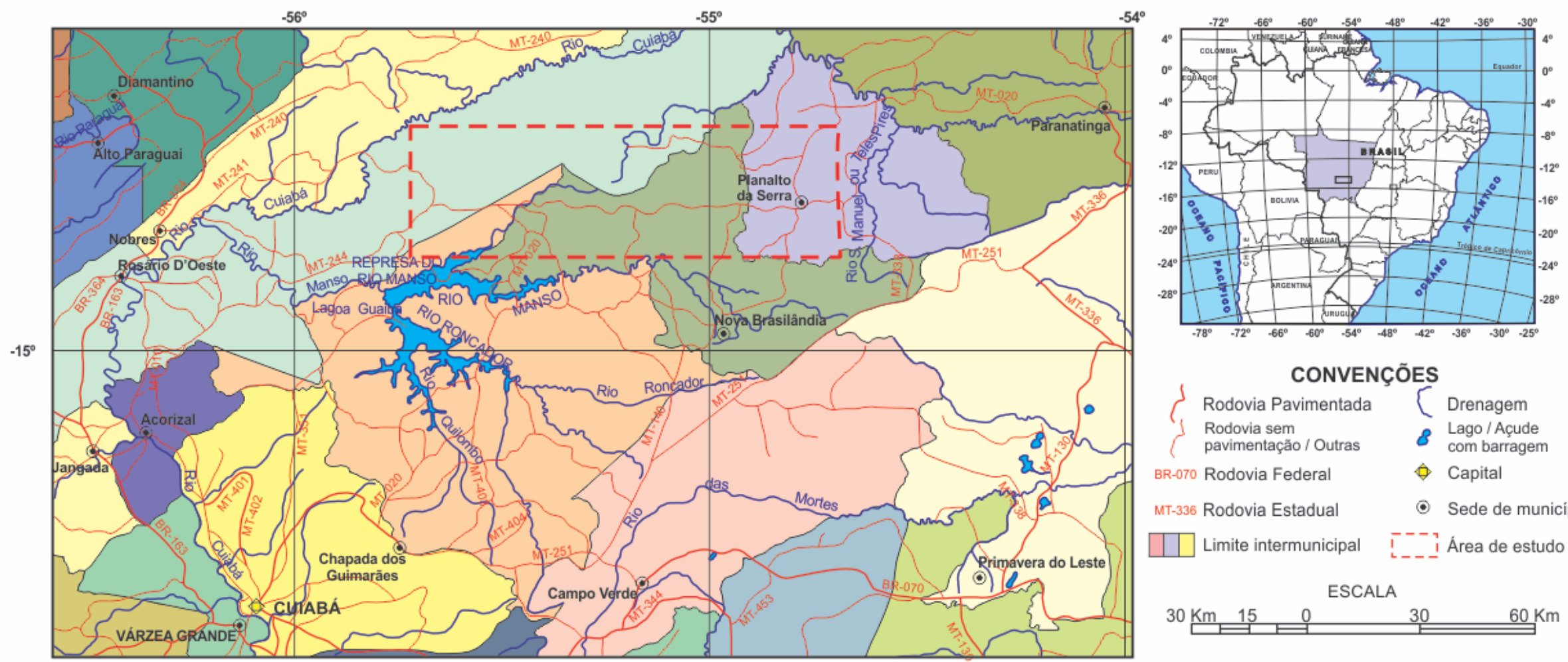

\section{CONVENÇÕES}

$\int$ Rodovia Pavimentada [ Drenagem

Rodovia sem \& Lago/Açude

pavimentaçăo/Outras $\quad \mathcal{B}$ com barragem

BR-070 Rodovia Federal $\Leftrightarrow$ Capital

MT-336 Rodovia Estadual $\odot$ Sede de município

$\square \square$ Limite intermunicipal $\quad i_{---}$Área de estudo

$30 \mathrm{Km} 15 \quad 00^{\text {ESCALA }}$

Figura 1.1: Mapa de localização e vias de acesso a área de estudo (Adaptado a partir do Mapa Político do Estado do Mato Grosso; Ministério do Planejamento, Orçamento e Gestão; IBGE; Edição 2009). 


\section{GEOLOGIA REGIONAL}

\subsection{ESTRATIGRAFIA}

A Faixa Paraguai é uma unidade tectônica Neoproterozóica situada à margem sudeste do Cráton Amazônico e leste do Bloco do Rio Apa (Figura 2.1 - Almeida 1964). Seus limites são recobertos pelas bacias sedimentares Fanerozóicas do Paraná, Parecis e Pantanal. Apresenta geometria em forma de arco com concavidade voltada para SE, orientada na direção NE-SW na sua porção Norte e N-S na porção Sul, com extensão e largura média de 1500 e 300 km, respectivamente. Ao sul, a Faixa Paraguai ramifica-se na direção NW-SE, estendendo-se de Corumbá até a Bolívia na forma de um sinclinal, denominado Faixa Tucavaca, interpretado como aulacógeno (Alvarenga et al., 2000). Além disso, sedimentos Neógenos pertencentes à Bacia do Pantanal dividem espacialmente a Faixa Paraguai em Norte e Sul, circundando afloramentos da região de Corumbá e da Serra da Bodoquena (Litherland et al., 1986).

A espessa sequência sedimentar da Faixa Paraguai inclui depósitos glaciomarinhos, turbidíticos, carbonáticos e siliciclásticos (Figura 2.2), resultado de uma sedimentação em margem passiva, seguidas de uma fase compressiva que culminou na inversão da bacia e estabelecimento de bacia foreland registrada nos estágios finais de sedimentação (Almeida, 1974, Alvarenga \& Trompette, 1992, 1993; Alvarenga et al., 2000; Dantas et al., 2009; Bandeira et al., 2012; McGee et al., 2015a,b). 


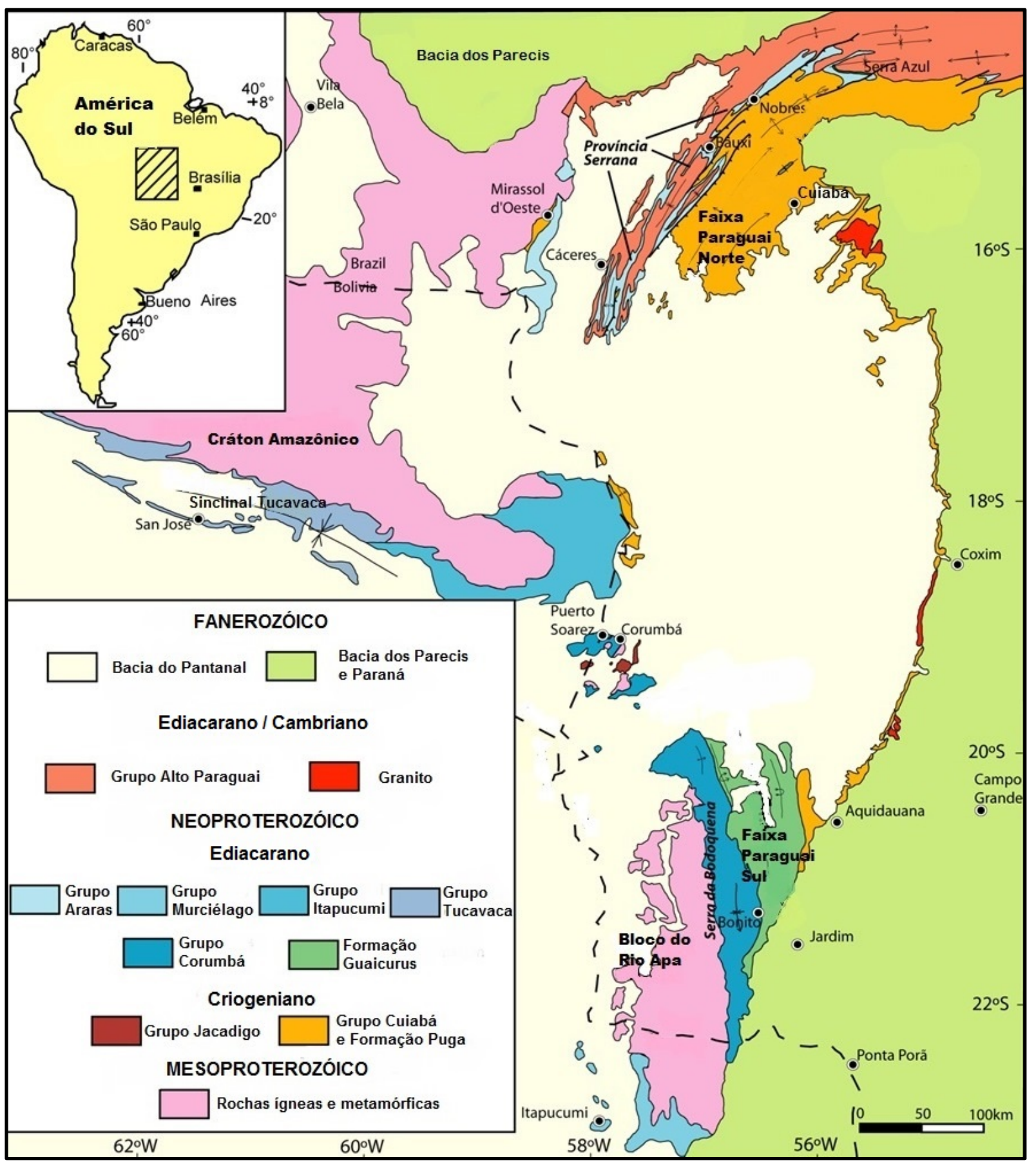

Figura 2.1: Mapa geológico da Faixa Paraguai, situada à margem sudeste do Cráton Amazônico e leste do Bloco do Rio Apa, porção central da América do Sul (modificado de Schobbenhaus et al., 1981; Litherland et al., 1986; Boggiani, 1998).

A Faixa Paraguai Norte é formada por quatro grandes sucessões estratigráficas (Alvarenga, 1988, 1990; Lacerda Filho et al., 2004; Dantas et al., 2009), designadas da base para o topo por: Grupo Cuiabá, unidade mais antiga, composta por uma sequência de metassedimentos dobrados, subdividida em nove subunidades litoestratigráficas (Luz et al., 1980), podendo ser interpretada como uma sequência turbidítica formada por sedimentos 
pelíticos, detríticos e psefíticos, depositados provavelmente durante o período glacial Criogeniano (670-630 Ma - Alvarenga, 1990), associados a depósitos glacio-marinhos (Alvarenga, 1985; Alvarenga \& Trompette, 1988); Formação Puga, que apresenta diamictitos glaciogênicos ocasionalmente interestratificados com conglomerados, arenitos, siltitos e folhelhos, depositados durante a glaciação global Marinoana no período Criogeniano Superior (635 Ma), pertencente a um modelo glaciomarinho no qual os sedimentos foram parcialmente retrabalhados por fluxos gravitacionais (Figura 2.2 - Alvarenga, 1988, 1990; Alvarenga \& Trompette 1992); Grupo Araras, que compreende, da base para o topo, a Formação Mirassol d’Oeste/Capa carbonática, composta por dolomitos associados a microbialitos, Formação Guia, com calcários, argilitos e folhelhos, Formação Serra do Quilombo, composta por doloarenitos e brechas, Formação Nobres, que constitui-se de dolomitos, silexitos, arenitos e lamitos calcários (Alvarenga \& Saes, 1992; Nogueira et al., 2003; Riccomini \& Nogueira, 2004; Alvarenga et al., 2000, 2004, 2008) e Formação Pacu, unidade recentemente incluída ao topo do Grupo Araras, formada por calcários calcíticos laminados ou com estruturas estromatolíticas, intercalados a arenitos, calcarenitos e pelitos (Souza et al, 2012), admitindose para este grupo deposição em ambiente marinho raso, de águas calmas, tipo plataformal, com idade estimada em 600 Ma (Figura 2.2 - Barros et al., 1982; Alvarenga, 1990; Rodrigues et al., 1994) e; Grupo Alto Paraguai, que compreende conglomerados e arenitos feldspáticos da Formação Raizama, folhelhos e pelitos da Formação Sepotuba e os argilitos, siltitos e arcóseos da Formação Diamantino (Almeida; 1964a; Alvarenga \& Saes, 1992; Bandeira, 2006, 2011; Bandeira et al., 2007), que evoluem da base para o topo, de ambiente plataformal marinho para continental (Figura 2.2 - Figueiredo et al., 1974). Entretanto, estudos recentes revelaram uma nova unidade estratigráfica situada à base deste grupo e designada Formação Serra Azul (Figura 2.2 - Figueiredo et al., 2004, 2008; Alvarenga et al., 2007). A Formação Serra Azul posiciona-se entre os calcários do topo do Grupo Araras e os arenitos da base da Formação Raizama (Grupo Alto Paraguai) e, é composta por diamictitos maciços e siltitos laminados intercalados com arenitos muito finos e tem idade Ediacarana Superior relacionada à Glaciação Gaskiers (582 Ma - Figueiredo et al., 2004, 2008; Alvarenga et al., 2007). 


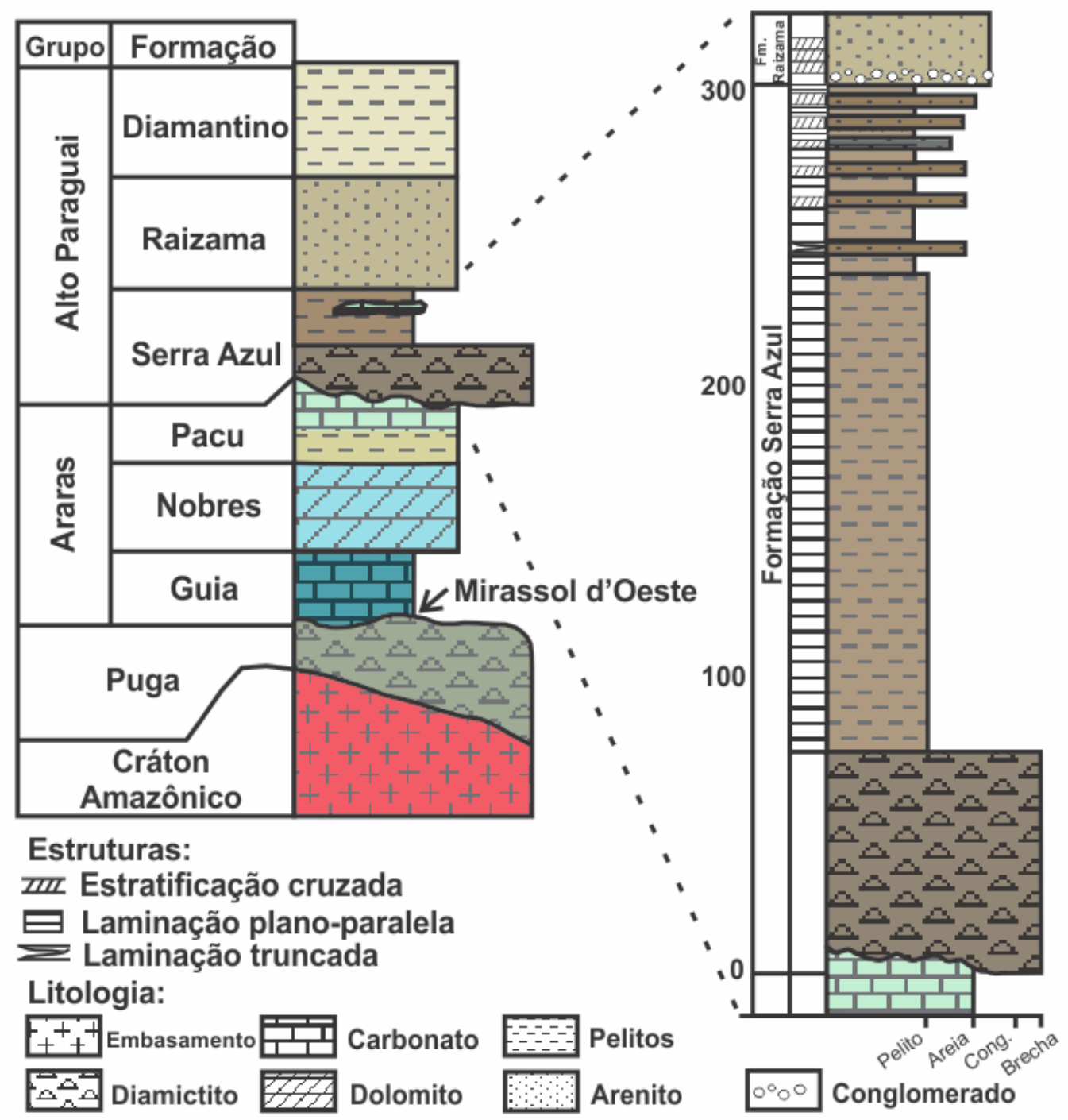

Figura 2.2: Estratigrafia da região plataformal da Faixa Paraguai Norte e perfil estratigráfico detalhado da Formação Serra Azul na porção norte da faixa (Adaptado a partir de Figueiredo et al., 2011).

\subsection{GRUPO ARARAS: Unidade Superior}

Os primeiros trabalhos sobre rochas carbonáticas no Mato Grosso são de Castelnau (1857) e Evans (1894) que as chamaram de Araras Limestone. O termo Grupo Araras foi empregado por Almeida (1964a) que o subdividiu em unidade Guia e Nobres. Hennies (1966) propôs sua subdivisão nas formações Guia e Nobres. Alguns autores usaram esta proposta, porém com designações diferentes (Luz et al., 1978). Outros rebaixaram o Gupo Araras para Formação Araras (Figueiredo \& Olivatti, 1974). Nogueira (2003) e Nogueira \& Riccomini (2006) reclassificaram as unidades como Grupo Araras, subdividindo-o nas formações Mirassol d’Oeste, Guia, Serra do Quilombo e Nobres. Em 2012, Souza et al. mapearam uma sequência de rochas argilosas vermelhas, cobertas por calcários calcíticos laminados ou com 
estruturas estromatolíticas, com intercalações de arenitos, calcarenitos e pelitos. Esta sequência, por conta das características dos ambientes deposicionais, foi definida como unidade pertencente ao topo do Grupo Araras e denominada Formação Pacu.

\subsubsection{Formação Pacu}

A Formação Pacu ocorre entre os doloarenitos da Formação Nobres (Grupo Araras) e os diamictitos da Formação Serra Azul (Grupo Alto Paraguai). Seu contato basal não está exposto, já o contato superior com os diamictitos é brusco. Esta formação tem espessura estimada em mais de 200 m e é subdividida em Facies Argilosa (base) e Facies Carbonática (topo), ocorrendo em faixas alongadas de direção N70E, acompanhando os dobramentos regionais. A Facies Argilosa, depositada imediatamente acima dos dolomitos da Formação Nobres, é interpretada como pertencente a ambiente marinho profundo e representaria uma transgressão marinha, enquanto que a Facies Carbonática é interpretada como representante de uma plataforma carbonática rasa transicionando para ambiente continental (Souza et al., 2012).

\subsection{GRUPO ALTO PARAGUAI}

As unidades do Grupo Alto Paraguai ocorrem ao longo da borda sudeste do Cráton Amazônico com espessura avaliada acima dos 3000 m por Almeida (1964a), onde a Formação Raizama teria 1600 m de espessura e os depósitos pelíticos da Formação Sepotuba alcançariam cerca de 900 m, já os pelitos e arenitos da Formação Diamantino teriam em torno de $600 \mathrm{~m}$. Porém, trabalhos recentes sugerem uma espessura aproximada de $2400 \mathrm{~m}$, composta por três formações: Serra Azul, Raizama e Diamantino (Alvarenga \& Saes, 1992; Figueiredo et al., 2004, 2008; Alvarenga et al., 2007; Bandeira, 2006, 2011; Bandeira et al., 2007).

\subsubsection{Formação Serra Azul}

A Formação Serra Azul posiciona-se entre os calcários laminados/estromatolíticos da Formação Pacu (Grupo Araras) e os arenitos da base da Formação Raizama. Seu contato basal na seção tipo, embora não esteja exposto, é considerado erosivo devido à presença de fragmentos de carbonatos e chert pertencentes às unidades inferiores e o contato superior tem sido descrito como gradacional (Figueiredo et al., 2004, 2008; Alvarenga et al., 2007). Esta formação é composta por diamictitos maciços (>70 m), siltitos laminados avermelhados e 
argilitos acinzentados (>200), com ocorrência de lentes de carbonatos e, arenitos muito finos com laminação plano-paralela, e/ou truncada por onda (hummocky) em camadas com espessamento para o topo (Figueiredo et al., 2004, 2008; Alvarenga et al., 2007). Os diamictitos apresentam-se maciços a pobremente estratificados, com matriz silto-argilosa avermelhada, contendo clastos de composição heterogênea (carbonatos, cherts, quartzoarenitos, quartzitos, rochas graníticas, máficas e metamórficas), de tamanho que varia de grânulo a matacão, dispersos na matriz. Isto além, de clastos facetados e estriados. Levandose em consideração o ambiente marinho raso a transicional das unidades sotopostas (Nogueira et al., 2003) interpretou-se que os diamictitos tenham se depositado num ambiente glaciomarinho raso a transicional (Figueiredo et al., 2004, 2008; Alvarenga et al., 2007).

\subsubsection{Formação Raizama}

A Formação Raizama é composta de arenito ortoquartzítico conglomerático, intercalado com camadas de arenito arcoseano fino a grosso, com estratificações cruzadas e marcas de onda, siltito e folhelho (Ribeiro Filho et al., 1975), depositados em águas epineríticas, pouco profundas, e ambiente dominado por marés, durante subsidência lenta e continua (Almeida, 1964a). Tanto o contato basal com a Formação Serra Azul (Figueiredo et al., 2008), quanto o contato superior com a Formação Diamantino são considerados gradacionais (Alvarenga, 1984; Alvarenga et al., 2000).

\subsubsection{Formação Sepotuba}

A Formação Sepotuba, definida por Almeida (1964a), é composta por uma sequência de sedimentos pelíticos com cerca de 900 m de espessura. Esta formação recobre a Formação Raizama e é sotoposta a Formação Diamantino. É constituída por pelitos, folhelhos e arenitos de granulação fina a médio, interpretados como depósitos de plataforma marinha e face litorânea inferior (Bandeira, 2006; 2011; Bandeira et al., 2007). Todavia, devido sua a semelhança litológica e perfeita continuidade com a Formação Diamantino, esta unidade foi considerada neste trabalho como Facies Sepotuba e inserida à base da Formação Diamantino.

\subsubsection{Formação Diamantino}

A Formação Diamantino é composta pela intercalação de arcóseo fino, siltito e folhelho, finamente estratificados, calcíferos e intercalados por bancos de arcóseo, mostrando estratificações cruzadas de pequeno porte e marcas de ondas (Alvarenga, 1984), depositados 
durante o soerguimento de porções mais a sudeste, gerando a inversão da bacia precursora para uma bacia sucessora com influência marinha e continental tipo foreland (Dantas et al., 2009; Bandeira et al., 2012; McGee et al., 2015a,b). O contato inferior é gradacional e o superior ocorre por discordância erosiva angular com as rochas Fanerozóicas do Grupo Parecis (Alvarenga, 1988).

\subsection{HISTÓRICO GEOCRONOLÓGICO}

A idade mínima para toda sucessão sedimentar da Faixa Paraguai foi definida com base na idade obtida para o Granito São Vicente, intrusivo no Grupo Cuiabá, cuja idade K-Ar é $504 \pm 12$ Ma (Hasui \& Almeida, 1970) e Rb-Sr é $483 \pm 8$ Ma (Almeida \& Mantovani, 1975). A Formação Puga, considerada produto da glaciação Marinoana (630 Ma), é recoberta pelos grupos Araras na Faixa Paraguai Norte e Corumbá na Faixa Paraguai Sul, os quais possuem capas carbonáticas em suas bases que exibem valores de $\delta^{13} \mathrm{C}$ próximos de $-5 \%$ $\mathrm{PDB}$, típicos de eventos glaciais do final do Neoproterozóico, e razões de ${ }^{87} \mathrm{Sr} /{ }^{86} \mathrm{Sr}$ entre 0,7075 e 0,7081, que caracterizam capas carbonáticas depositadas após a Glaciação Marinoana (Boggiani, 1998; Nogueira et al., 2003; Alvarenga et al., 2004). Estes carbonatos são mapeados em sucessões Neoproterozóicas ao redor do globo, e interpretados como eventos de deposição anômala logo após uma glaciação global, sob hipótese da Snowball Earth (Kennedy et al., 2001; Hoffman \& Schrag, 2002; Haverlson et al., 2005). Este marco estratigráfico sugere que ambas sucessões podem ser correlacionadas com outras sucessões de idade Ediacarana (635-580 Ma - i.e. Nogueira et al., 2003, 2007; Alvarenga et al., 2000, 2004, 2008).

Dados radiométricos Rb-Sr de sedimentos argilosos da Formação Sepotuba, Grupo Alto Paraguai forneceram idades de $569 \pm 20 \mathrm{Ma}$, previamente interpretadas como idades deposicionais (Cordani et al., 1978). Posteriormente esta idade foi admitida como marcadora do evento deformacional Brasiliano que teria afetado a Faixa Paraguai (Bonhomme et al., 1982). Na tentativa de se chegar a idade do Grupo Alto Paraguai, amostras de sedimentos da parte superior da Formação Diamantino, forneceram idade Rb-Sr de $660 \pm 60$ Ma (Cordani et al. 1985), porém esta determinação é considerada duvidosa. Idades U-Pb, obtidas em zircões detríticos da Formação Diamantino, sugerem idade máxima de deposição em $541 \pm 7$ Ma, indicando que a sedimentação do Grupo Alto Paraguai se estendeu por pelo menos até o Cambriano Inferior (Bandeira et al., 2012; McGee et al., 2015a,b). 
A Formação Serra Azul, em termos litoestratigráficos e isotópicos (Figueiredo, 2006, 2010), é comparável à Formação Gaskiers (Newfoundland, Canadá - Carto \& Eyles, 2011) que possui valores de $\delta^{13} \mathrm{C}$ entre -6\% e -1,5\% (Myrow \& Kaufman, 1999). Ademais, datação Pb-Pb em lentes carbonáticas da Formação Serra Azul estabeleceu idade mínima de deposição de 570 Ma e máxima de 622 Ma (Figueiredo, 2010). A idade mínima é coerente com um sistema U-Pb não afetado pela tectônica compressiva da Faixa Paraguai. A idade máxima confirma deposição da Formação Serra Azul pós Glaciação Marinoana, corroborando com a hipótese de os diamictitos glaciais serem correlatos à Glaciação Gaskiers de 582 Ma (Bowring et al., 2003; Figueiredo, 2010). 


\section{UNIDADES LITOESTRATIGRÁFICAS}

As unidades litoestratigráficas descritas neste trabalho correspondem às unidades superiores do segmento E-W da Faixa Paraguai (Figura 3.1 - Almeida, 1984) e, englobam a unidade de topo do Grupo Araras (Formação Pacu - Souza et al., 2012) e o Grupo Alto Paraguai (formações Serra Azul, Raizama e Diamantino - Figueiredo et al., 1974; Alvarenga \& Saes, 1992; Figueiredo et al., 2004, 2008; Alvarenga et al., 2007; Bandeira, 2006, 2011; Bandeira et al., 2007). Estas unidades geológicas foram estudadas em perfis de campo e cortes de estrada nos arredores do município de Planalto da Serra e na localidade conhecida como “Sete Placas”, a Norte de Cuiabá, Mato Grosso (Figura 3.1 e 3.2). Nos arredores de Planalto da Serra foram estudadas três seções com boa continuidade estratigráfica, onde os estratos arranjam-se em camadas com ampla distribuição vertical/lateral e mergulhos principalmente sub-verticais (Seção 1, 2 e 3 - Figura 3.1, 3.2 e 3.3). Na localidade de "Sete Placas” foram estudadas duas seções, as quais apresentam afloramentos com precária continuidade estratigráfica e mergulhos principalmente sub-horizontais (Figura 3.1, 3.2, 3.21). Dessa forma, as unidades geológicas serão apresentadas a seguir de acordo com a região estudada. 


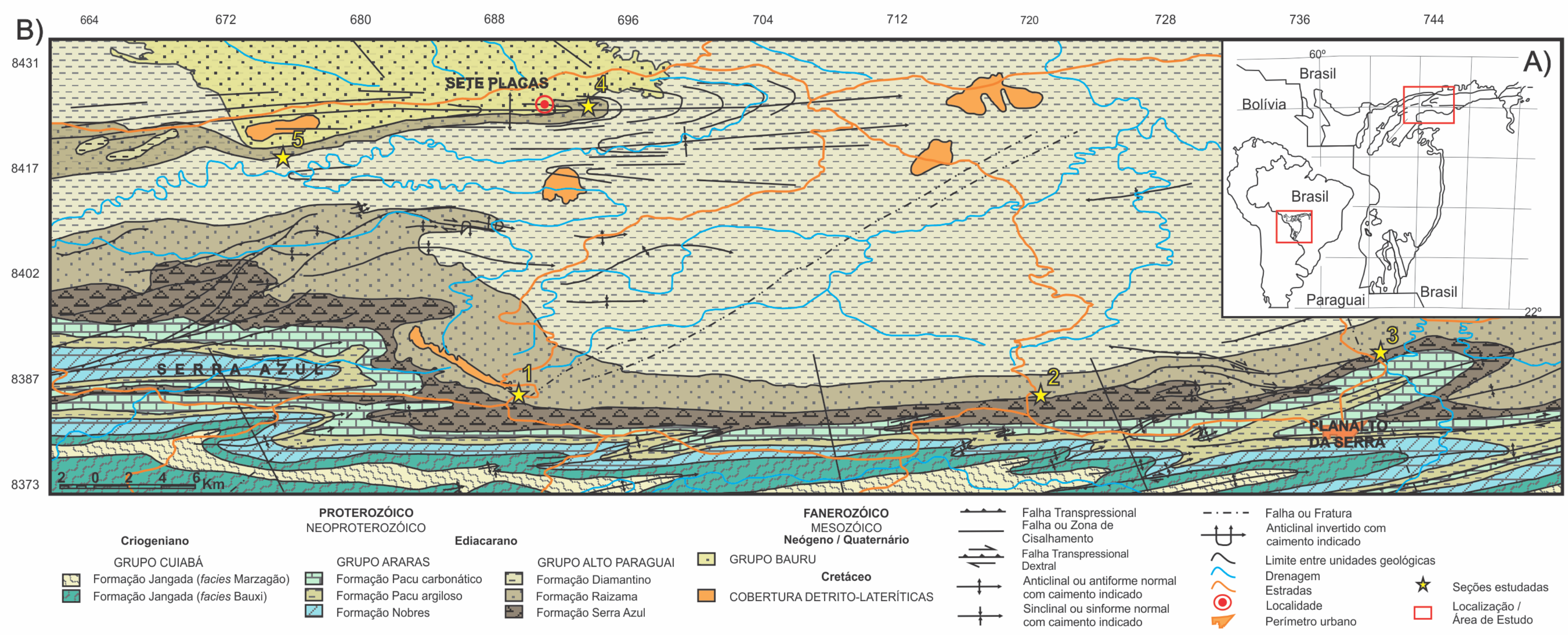

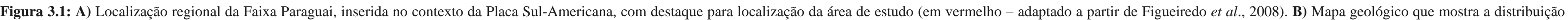

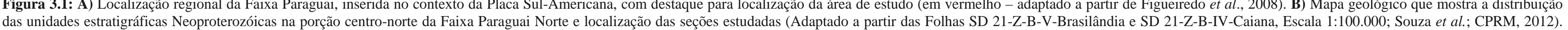




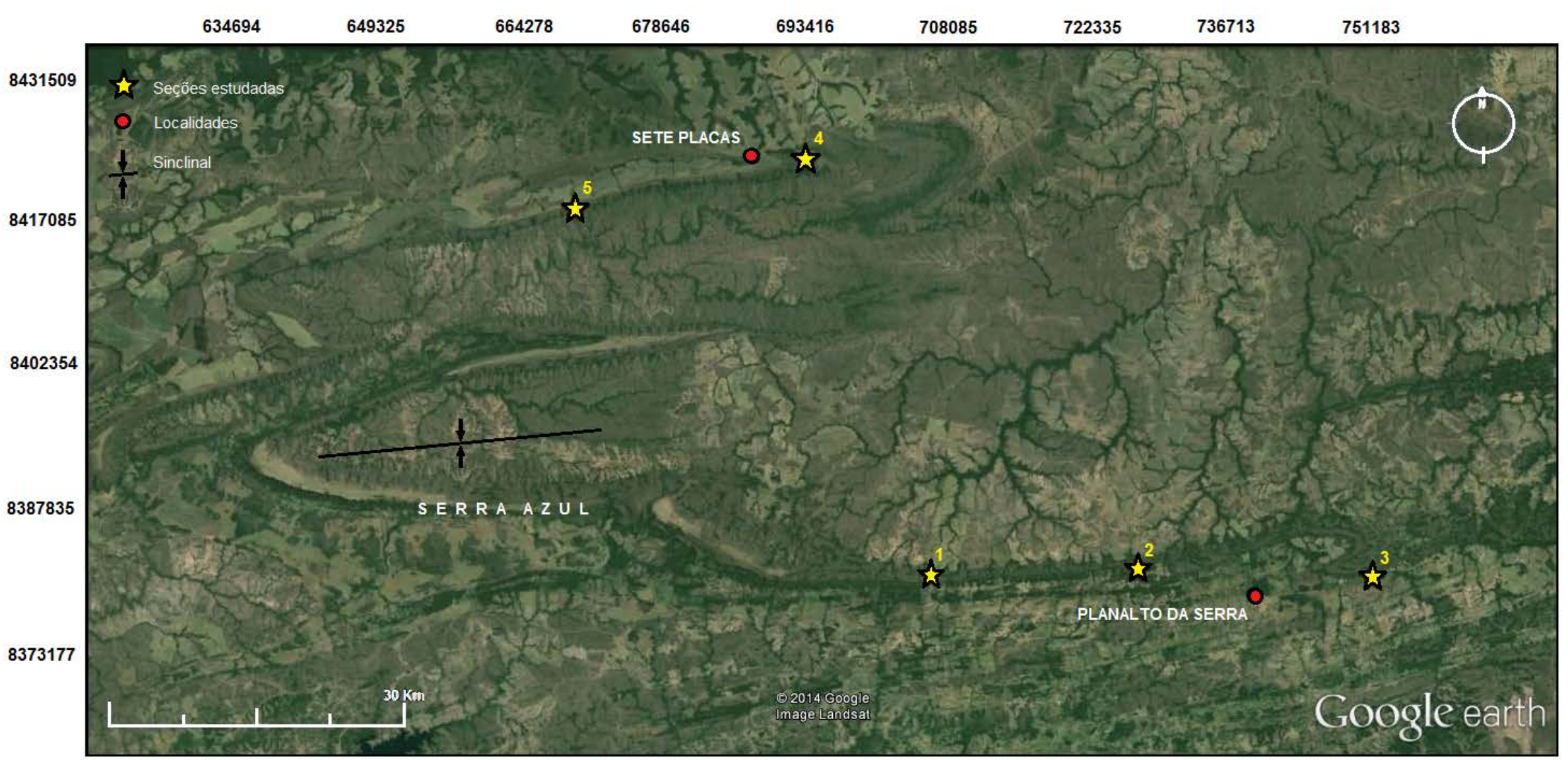

Figura 3.2: Imagem de satélite do Sinclinal Serra Azul (Faixa Paraguai Norte) com a localização das seções estudadas nas regiões de Planalto da Serra e "Sete Placas", estado do Mato Grosso (Zona UTM21; Image Landsat, Google 2014). 


\subsection{REGIÃO DE PLANALTO DA SERRA}

Nos arredores de Planalto da Serra foram encontrados estratos pertencentes à unidade superior do Grupo Araras (Formação Pacu) e Grupo Alto Paraguai (Figura 3.1 - formações Serra Azul, Raizama e Diamantino). Três seções principais foram estudadas, Seções 1, 2 e 3 (Figura 3.1, 3.2, 3.3 e 3.4), as quais apresentam bons afloramentos com boa continuidade lateral/vertical. Adiante segue descrição detalhada dos estratos mapeados nesta região. 

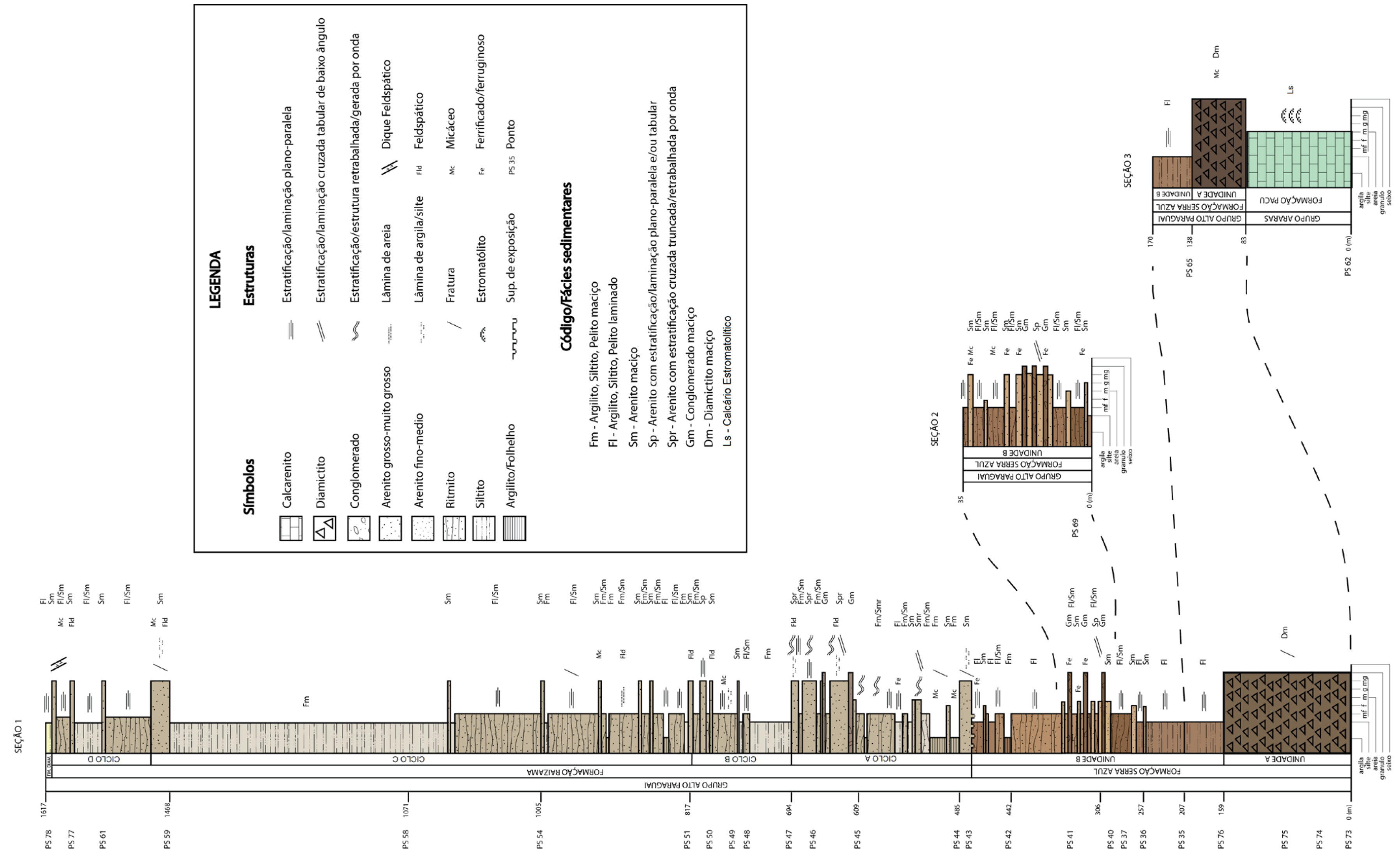


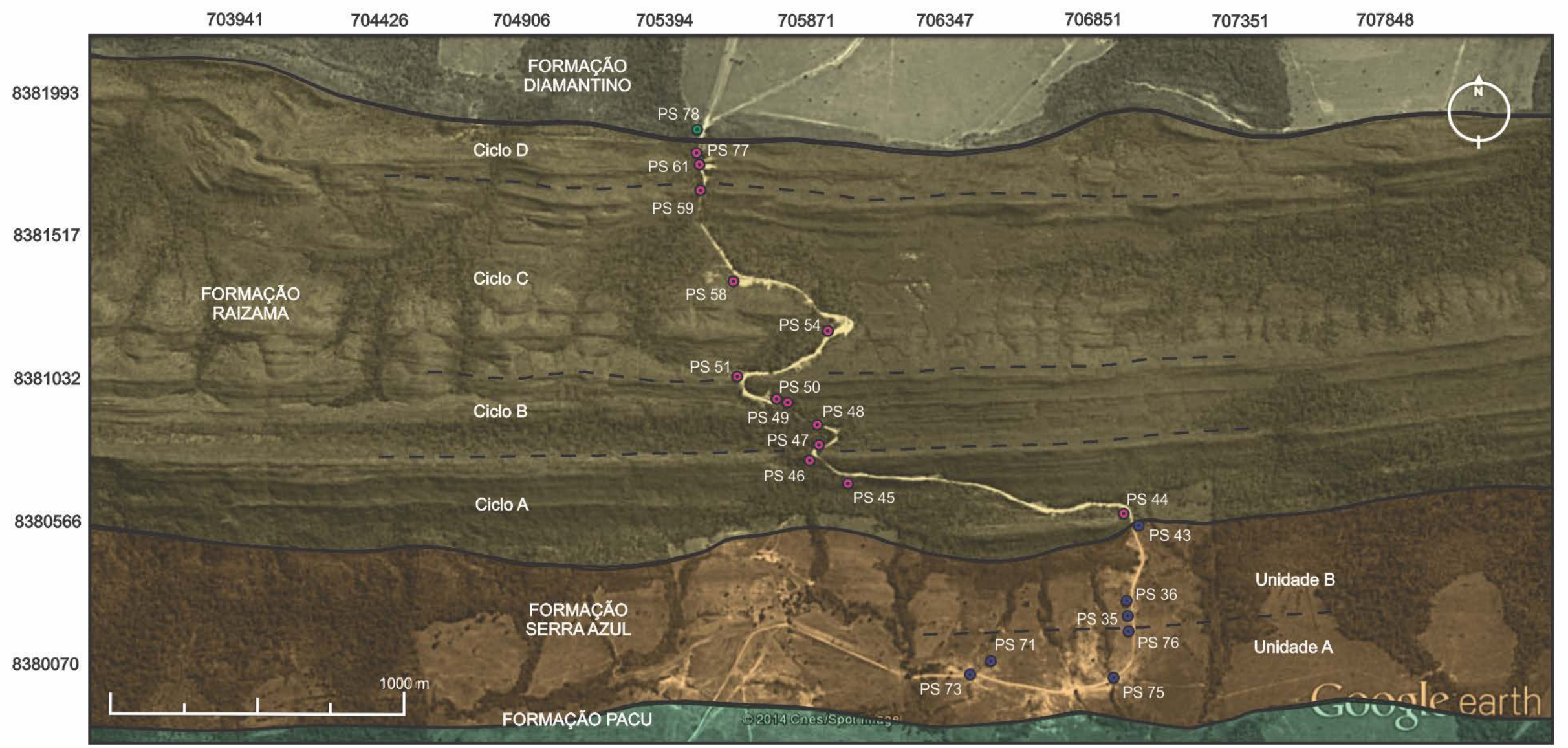

Figura 3.4: Imagem de satélite da Região de Planalto da Serra, estado do Mato Grosso; com localização dos pontos descritos na Seção 1 e esboço do limite espacial das formações que compõem o Grupo Alto Paraguai (Formações Serra Azul, Raizama e Diamantino) e topo do Grupo Araras (Formação Pacu - Zona UTM21; Cnes/Spot Image, Google 2014). 


\subsubsection{Grupo Araras: Unidade Superior}

\subsubsection{Formação Pacu}

Nos arredores de Planalto da Serra foram encontrados afloramentos pertencentes à Formação Pacu (Figura 3.1, 3.2 e 3.3), que é dividida internamente em Facies Argilosa (base) e Facies Carbonática (topo - Souza et al., 2012).

Litologias como laminito (Facies $\mathrm{Lm}$ ) e argilito carbonático/silicificado laminado (Facies Fl) encontradas nesta região foram atribuídas à Facies Argilosa (Figura 3.5-A). Boas exposições da Facies Carbonática foram encontradas na "Fazenda Gezo" (Seção 3 Coordenadas UTM 0750899/8380324), alcançando cerca de 80 m de espessura (Figura 3.3 e 3.5-B). Estes afloramentos são compostos por calcários com estruturas estromatolíticas colunares (Facies Ls), maciços a subordinadamente estratificados, cinza-esbranquiçado, fábrica não-orientada, com esparitos de tamanho areia fina/média, inequigranulares, dispostos em camadas subverticalizadas $\left(\mathrm{S}_{0}\right.$ 358/70 Az) com ocorrência de veios preenchidos por material de composição calcítica e/ou quartzosa (Figura 3.3 e 3.5-B).

Petrográficamente, a facies laminito (Facies Lm) possui granulação muito fina (lama carbonática) formada pela recorrência de laminações delgadas. As laminações tendem a ser plano-paralelas, com superfície lisa (Figura 3.6-A). A facies argilito carbonático/silicificado laminado (Facies Fl) possui granulação fina, finamente laminado, fortemente silicificado (Figura 3.6-B). Na facies calcário estromatolítico colunar (Facies Ls), observa-se níveis claros e escuros de crescimento dos microorganismos que geraram a laminação estromatolítica. Estes níveis são marcados por laminações côncavas para baixo, alternando esparita (lâmina clara) e micrita (lâmina escura). Os veios/vênulas são compostos por material calcítico/quartzoso (Figura 3.7-A, B). Intraclastos, pelóides carbonáticos e oóides encontramse dispersos nos espaços entre as colunas de estromatólitos cimentadas por calcita (Figura 3.8A, B).

Os afloramentos desta formação são descontínuos, parcialmente preservados, com aspecto cavernoso em alguns pontos (Facies Carbonática), formando um relevo pouco acentuado com predominância de vegetação de mata mais densa. O contato basal desta formação encontra-se encoberto, e o contato superior com a formação sobrejacente (Formação Serra Azul) é discordante e bem marcado em campo (Figura 3.4). Este contato é marcado por uma pequena drenagem de direção NE-SW (coordenadas 0750949/8380409), entre os afloramentos de calcários estromatolíticos numa margem e diamictitos na margem oposta. 

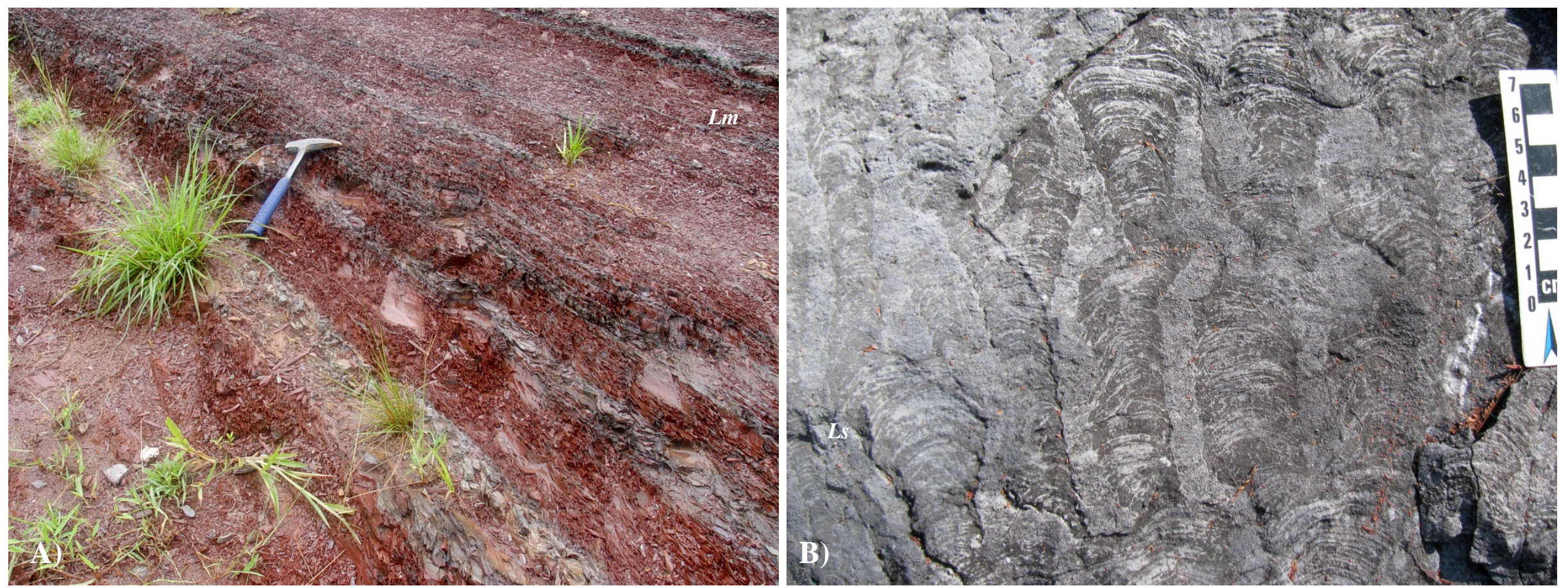

Figura 3.5: Formação Pacu (Grupo Araras). A) Afloramento pertencente à Facies Argilosa (base), composto por Laminito (Facies Lm). Nível argiloso, avermelhado, intemperizado; nível escuro, carbonático B) Afloramento pertencente à Facies Carbonática (topo), representado por Calcário estromatolítico colunar (Facies Lc). 

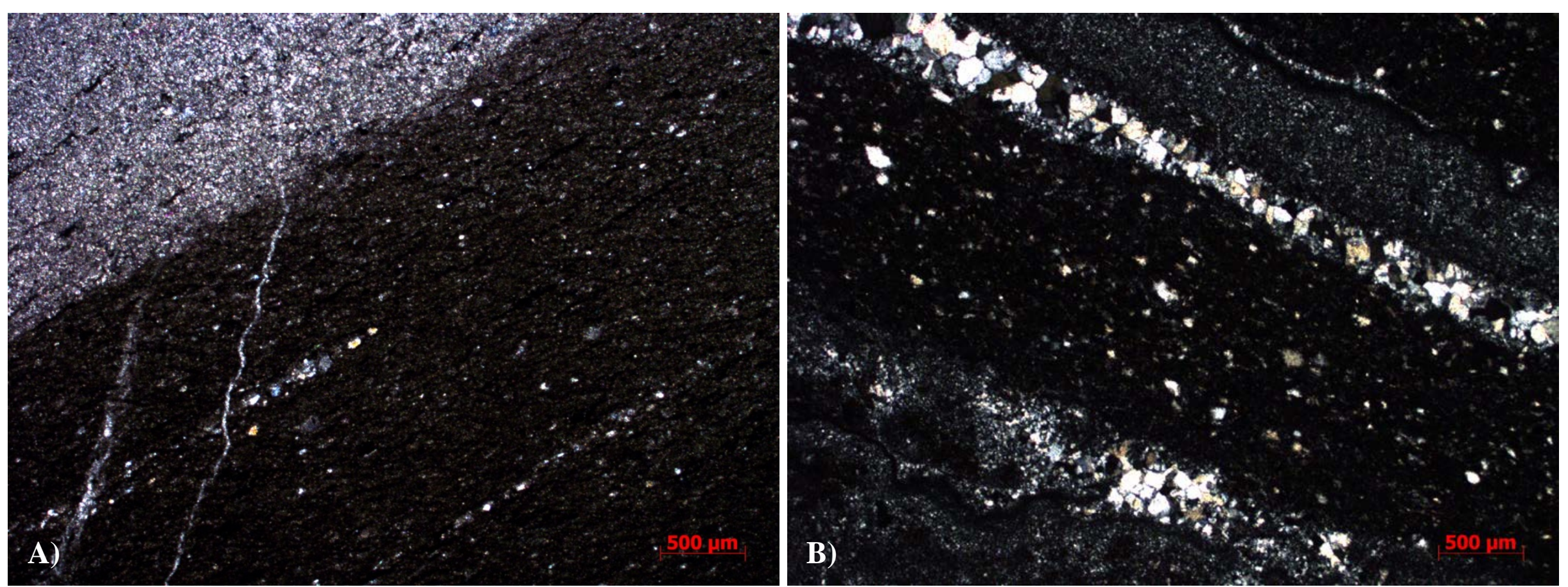

Figura 3.6: Formação Pacu, Facies Argilosa. A) Detalhe da Facies Lm. Laminito, granulação muito fina (lama carbonática) formada pela recorrência de laminações delgadas. As laminações tendem a ser planoparalelas, com superfície lisa. Lâminas escuras mais pelíticas, lâminas claras mais carbonáticas. B) Detalhe da Facies Fl. Argilito carbonático, granulação fina, laminado, silicificado (Fotomicrografia sob nicóis cruzados, óptica 2,5X). 

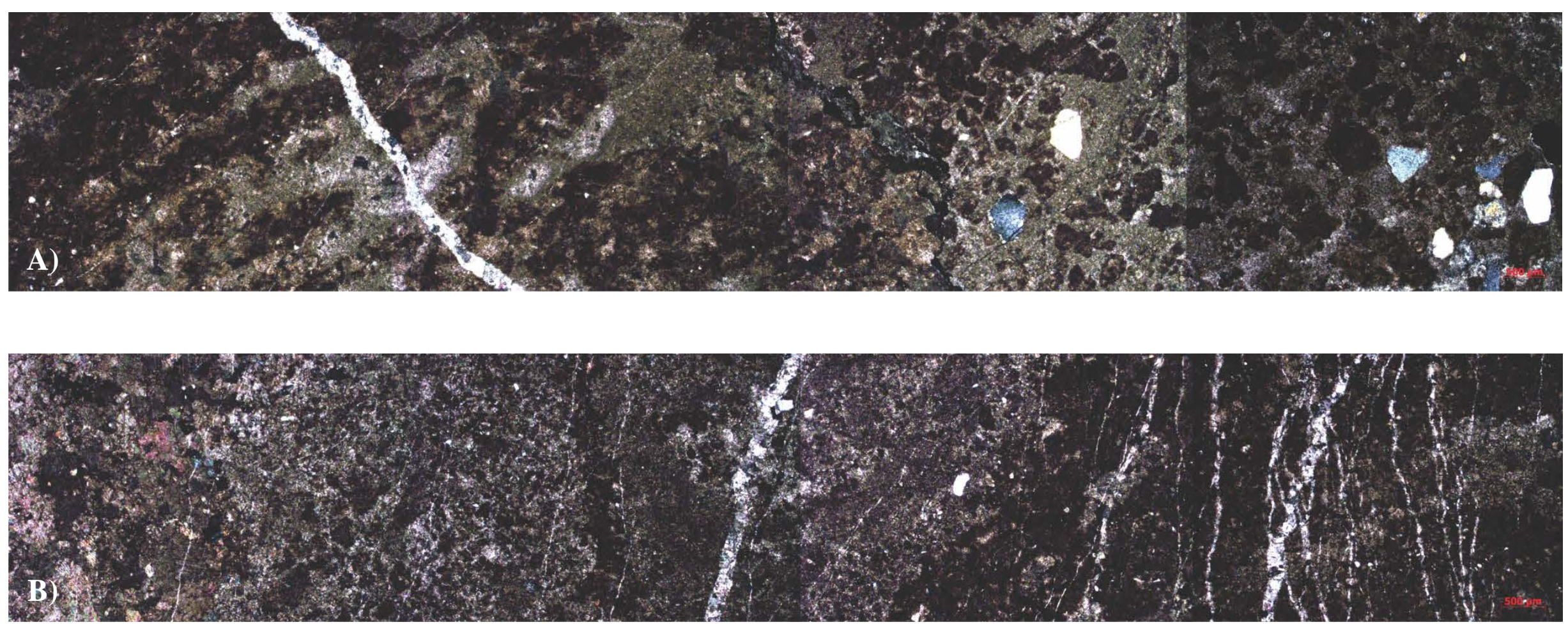

Figura 3.7: Formação Pacu, Facies Carbonática. A - B) Seções panorâmicas de lâminas delgadas do Calcário estromatolítico colunar (Facies Ls). É observável os níveis de crescimento dos microrganismos que geraram a laminação estromatolítica. Porção esquerda da Figura A e direita da Figura B é observável lâminações côncavas para baixo, alternando micrita (lâmina escura) e esparita (lâmina clara). Intraclastos, pelóides carbonáticos e oóides encontram-se dispersos nos espaços entre as colunas de estromatólitos. Os veios/vênulas são preenchidos por material calcítico/quartzoso. (Fotomicrografia sob nicóis cruzados, óptica 2,5X). 

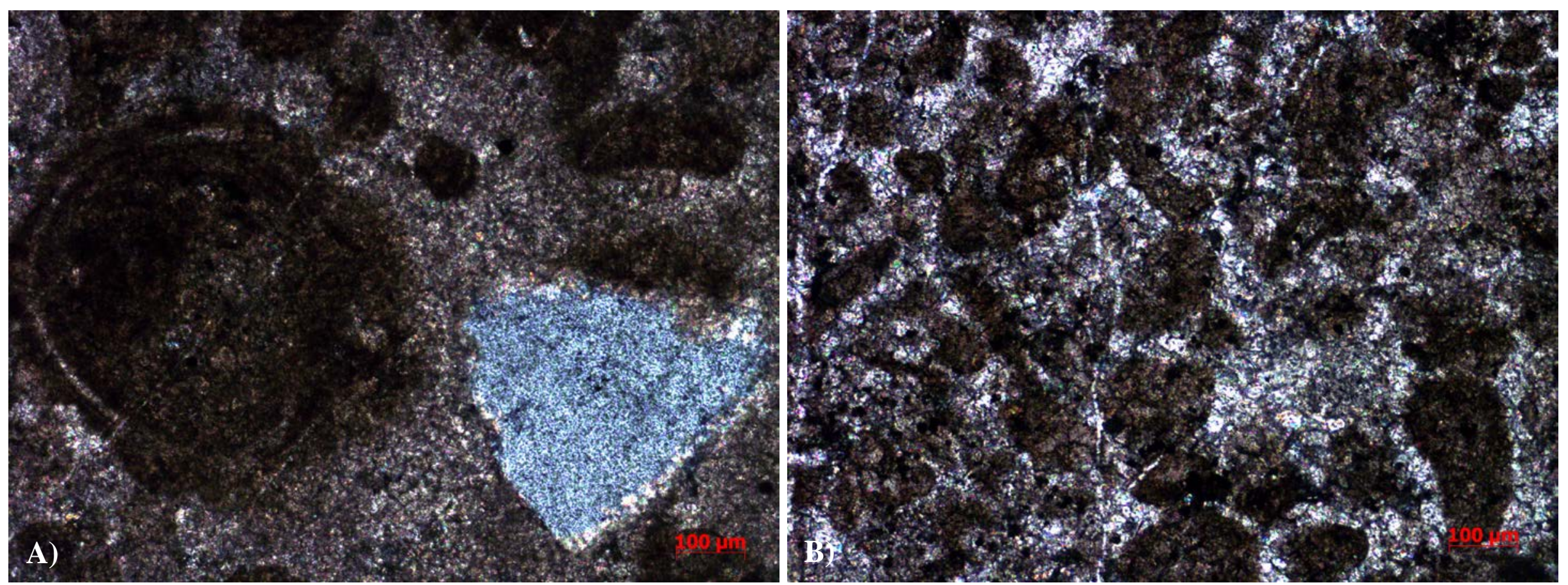

Figura 3.8: Formação Pacu, Facies Carbonática. Detalhe da Facies Ls. A) Em destaque, oólito com estrutura fibro radiada e grão de quartzo (Fotomicrografia sob nicóis cruzados, óptica 10X). B) Intraclastos, pelóides carbonáticos e oóides dispersos nos espaços entre as colunas de estromatólitos cimentadas por calcita (Fotomicrografia sob nicóis cruzados, óptica 10X). 


\subsubsection{Grupo Alto Paraguai}

\subsubsection{Formação Serra Azul}

Na região de Planalto da Serra a Formação Serra Azul é composta por diamictitos recobertos por siltitos-pelitos/arenitos que alcançam cerca de $470 \mathrm{~m}$ de espessura (Figura 3.1, 3.2, 3.3e 3.4). Ocorre em pontos restritos, geralmente recoberta por depósitos recentes de talude e frequentemente bastante intemperizada. Os afloramentos são descontínuos, pobremente preservados, apresentando relevo pouco acentuado/arrasado (Figura 3.4). O contato basal com os calcários da Formação Pacu (Grupo Araras) é discordante e bem marcado em campo (Figura 3.1 e 3.4) e o contato superior com os pelitos/arenitos da Formação Raizama é do tipo brusco (Figura 3.14). Assim, para efeito descritivo será adotado aqui a mesma subdivisão proposta por Alvarenga et al. (2007) para esta formação.

\subsection{Unidade A: Diamictito}

A 'Unidade A' corresponde à porção basal da Formação Serra Azul e encontra-se disposta em camadas sub-verticais ( $\mathrm{S}_{0}$ 350/90 Az) de espessura variável, entre $55 \mathrm{~m}$ e $159 \mathrm{~m}$ (Figura 3.3 e 3.4). É formada por diamictitos maciços (Facies Dm), cinza-esverdeado, composto por grandes seixos/clastos de tamanho (milimétrico a centimétrico) e composição variada (i.e. arenito, carbonato, granito) mergulhados/suportados por fina matriz siltoargilosa, muito mal selecionado, fábrica não orientada, fraturado, com clivagem associada (Figura 3.8-A, B). Há ocorrência de grandes blocos de quartzito/granito nas áreas mais arrasadas do domínio desta formação (Figura 3.9-C, D), os quais resistiram ao processo erosivo atuante nos diamictitos.

Petrográficamente, a facies diamictito maciço (Facies Dm) é composta por grãos/clastos de carbonato indiferenciado, quartzo detrítico e fragmentos de rochas (i.e. rocha vulcânica) mergulhados em matriz silto-argilosa (Figura 3.10). Características microscópicas texturais: intervalo de tamanho de grão varia de silte $(0.0540 \mathrm{~mm})$ a seixo $(8.5 \mathrm{~mm})$. Arcabouço composto por grãos/clastos tamanho cascalho (27\%), areia (39\%) e lama (34\%). Muito mal selecionado (2.4). Esfericidade média; subarredondado devido a faturamento/deformação. Fábrica com orientação caótica. Grãos/clastos suportados pela matriz. Empacotamento frouxo (5). Contatos entre grãos/clastos são abundantemente do tipo grão/não-grão ( 95\%), raramente pontuais (4\%). Classificação modal: Paraconglomerado intraformacional. 

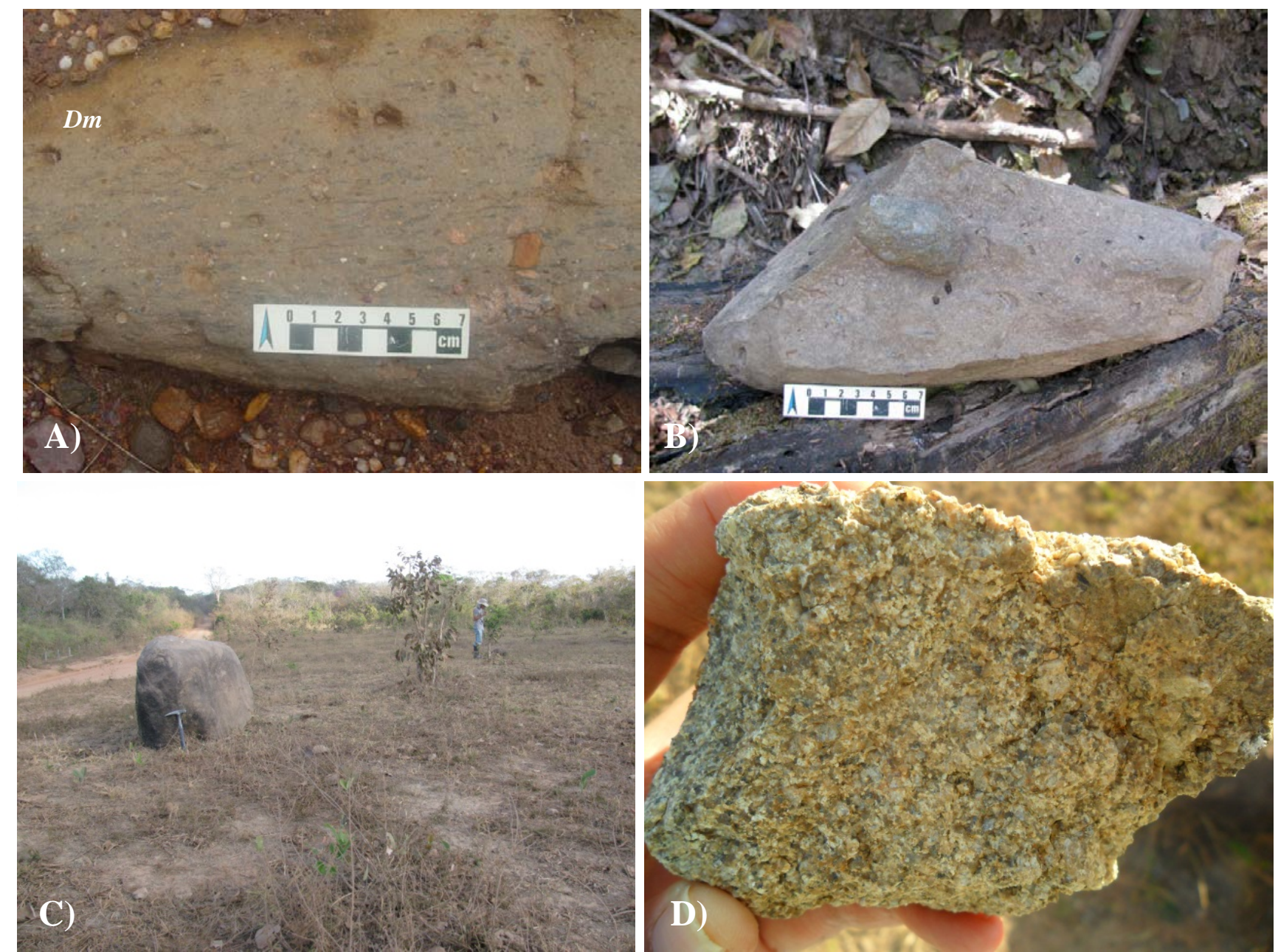

Figura 3.9: Formação Serra Azul, Unidade A: Diamictito. A) Diamictito maciço (Facies Dm) com fragmentos de rocha de composição variada e tamanho de até 1 cm. B) Diamictito maciço (Facies Dm) com grande clasto de quartzito com tamanho de $\sim 7 \mathrm{~cm}$. C) Área arrasada, domínio da 'Unidade A', com ocorrência de grandes blocos de granito que resistiram ao processo erosivo atuante nos diamictitos. D) Aspecto mesoscópico deste granito, composto essencialmente por cristais de quartzo e feldspatos. 


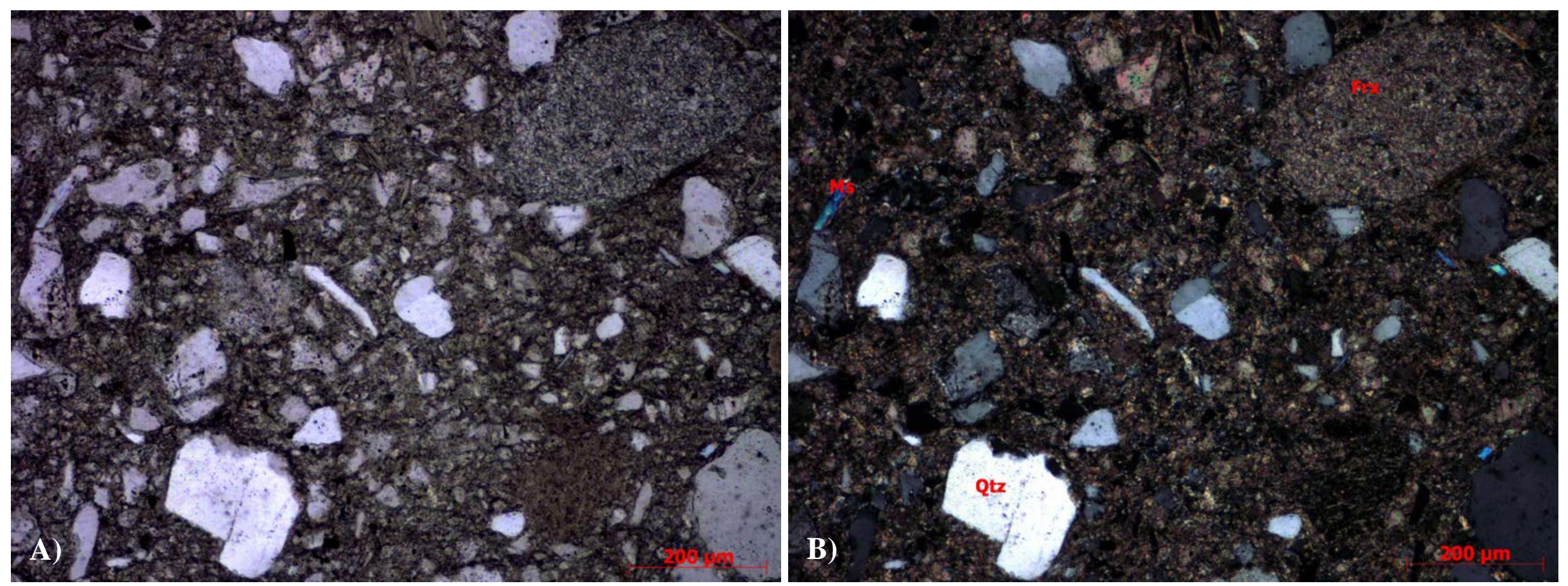

Figura 3.10: Unidade A: Diamictito. Diamictito maciço (Facies Dm). A e B) Paraconglomerado intraformacional com matriz silto-argilosa (Fotomicrografia sob nicóis paralelos e cruzados, respectivamente; óptica 10X). Qtz - quartzo; Ms - muscovita; Frx - fragmento de rocha. 


\subsection{Unidade B: Sucessão Siltito - Pelito/Arenito}

A 'Unidade B' corresponde à porção intermediária e superior da Formação Serra Azul (Figura 3.3 e 3.4) e, é formada por siltitos que gradam para intercalações rítmicas de pelito/arenito ao topo, organizadas em camadas sub-verticais $\left(\mathrm{S}_{0} 350 / 80 \mathrm{Az}\right)$, alcançando cerca de 300 m de espessura (Seção 1 e 2 - Figura 3.3).

Os siltitos recobrem bruscamente os diamictitos (Unidade A) e abrangem os primeiros 120 m desta Unidade (Figura 3.3). São siltitos finamente laminados (Facies Fl), argilosos, coloração de alteração amarelo-avermelhado, com esparsas lentes (0,5 m) de arenito maciço (Facies Sm), fino, avermelhado.

Estes siltitos (Facies Fl) gradam para uma sucessão rítmica, que compõe os últimos 194 m desta Unidade (Figura 3.3). Os ritmitos são compostos por intercalações (0,5 m) de pelito finamente laminado (Facies Fl), micáceo e, arenito maciço (Facies Sm), fino, avermelhado, por vezes com superfície ondulada/retrabalhada por onda (Figura 3.11e 3.12-A, B). Em direção ao topo, há o aumento das intercalações destes ciclos rítmicos e ocorrência de camada de folhelho argiloso (Facies Fm) na base dos ciclos. Encerrando a unidade ao topo há o reaparecimento de siltitos laminados (Facies Fl - Figura 3.3).

Na porção intermediária desta unidade, intercalados aos ritmitos, ocorrem camadas com até $2 \mathrm{~m}$ de espessura, compostas por arenito com estratificação cruzada tabular de baixo ângulo (Facies Sp), médio/grosso, marrom-avermelhado, ocasionalmente sustentados por níveis conglomeráticos (Facies Gm) de até $1 \mathrm{~m}$ de espessura (Figura 3.11e 3.12-B, C, D). Estas camadas possuem ampla distribuição lateral (Figura 3.3) e apresentam aspecto ferruginoso, devido a forte cimentação por óxido de ferro hematítico (Figura 3.11e 3.12-B, C, D).

Determinações obtidas em espectrômetro diferencial portátil de Raios Gama mostram que valores médios de 120 cps passam para intervalos entre 450 e 840 cps nas amostras de arenitos ferrificados. A geoquímica da amostra de arenito ferrificado PS 40-C (ver Figura 3.3), mostra concentrações de 0,55\% de $\mathrm{K}_{2} \mathrm{O}$; 5,7 ppm de U e 76,3 ppm de Th, enquanto que os elementos considerados mais relevantes foram Ba e Zr, com concentrações de 5949 ppm e 3833 ppm, respectivamente. 

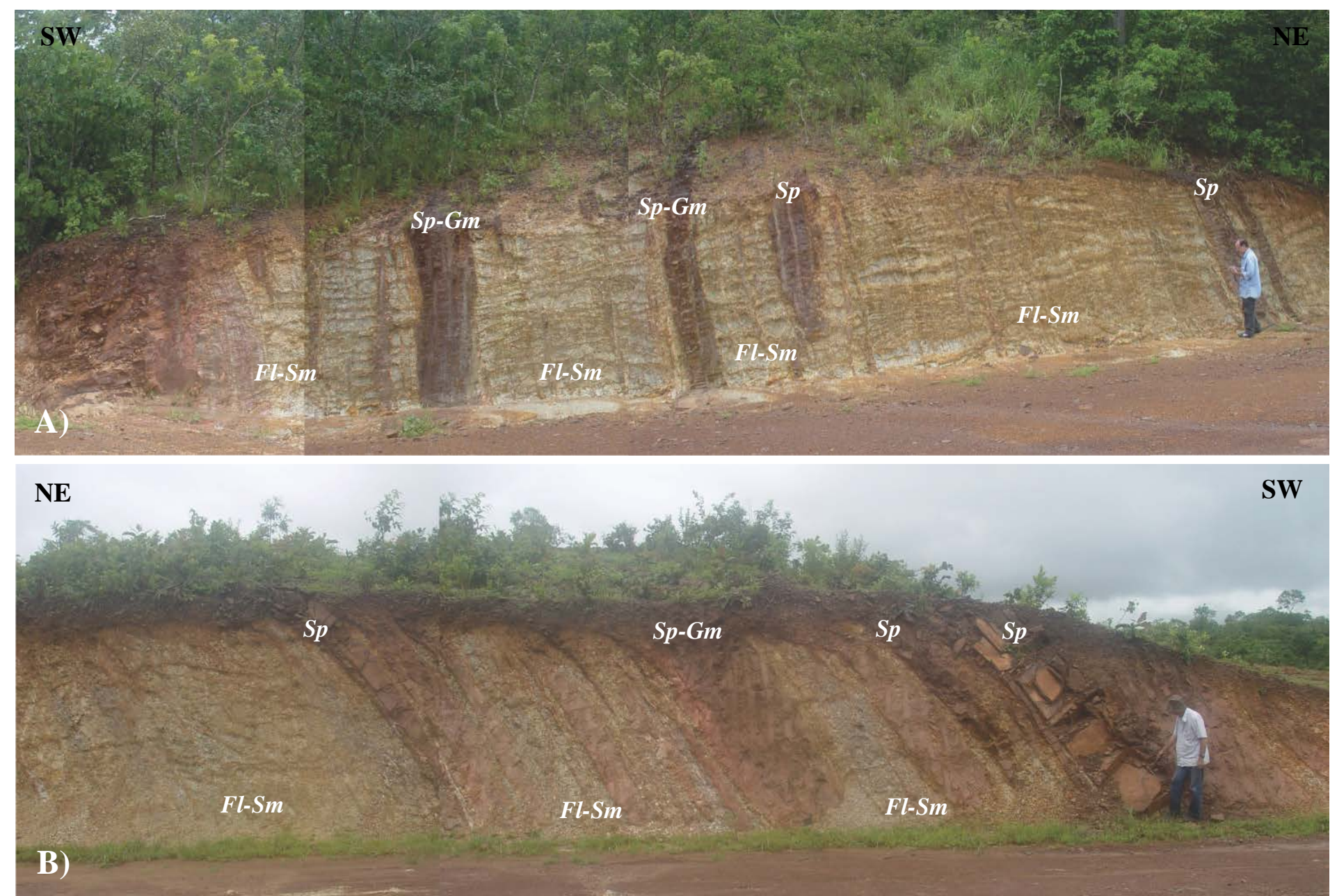

Figura 3.11: Formação Serra Azul, porção intermediária da Unidade B. A) Seção panorâmica (Seção 1, ponto PS 40; ver Figura 3.3) formada por intercalações rítmicas de pelito finamente laminado e arenito maciço (Facies Fl-Sm), com destaque para as camadas de arenito/conglomerado ferruginoso (Facies Sp-Gm). É possível perceber a repetição dos ciclos (base à esquerda). B) Seção panorâmica (Seção 2, ponto PS 69; ver figura 3.3) lateralmente correlacionável a seção panorâmica da Figura 3.11-A. Os ciclos rítmicos são similares à seção do ponto PS 40 (base à direita), com as mesmas ocorrências de camadas de arenito/conglomerado ferruginoso (Facies Sp-Gm). 

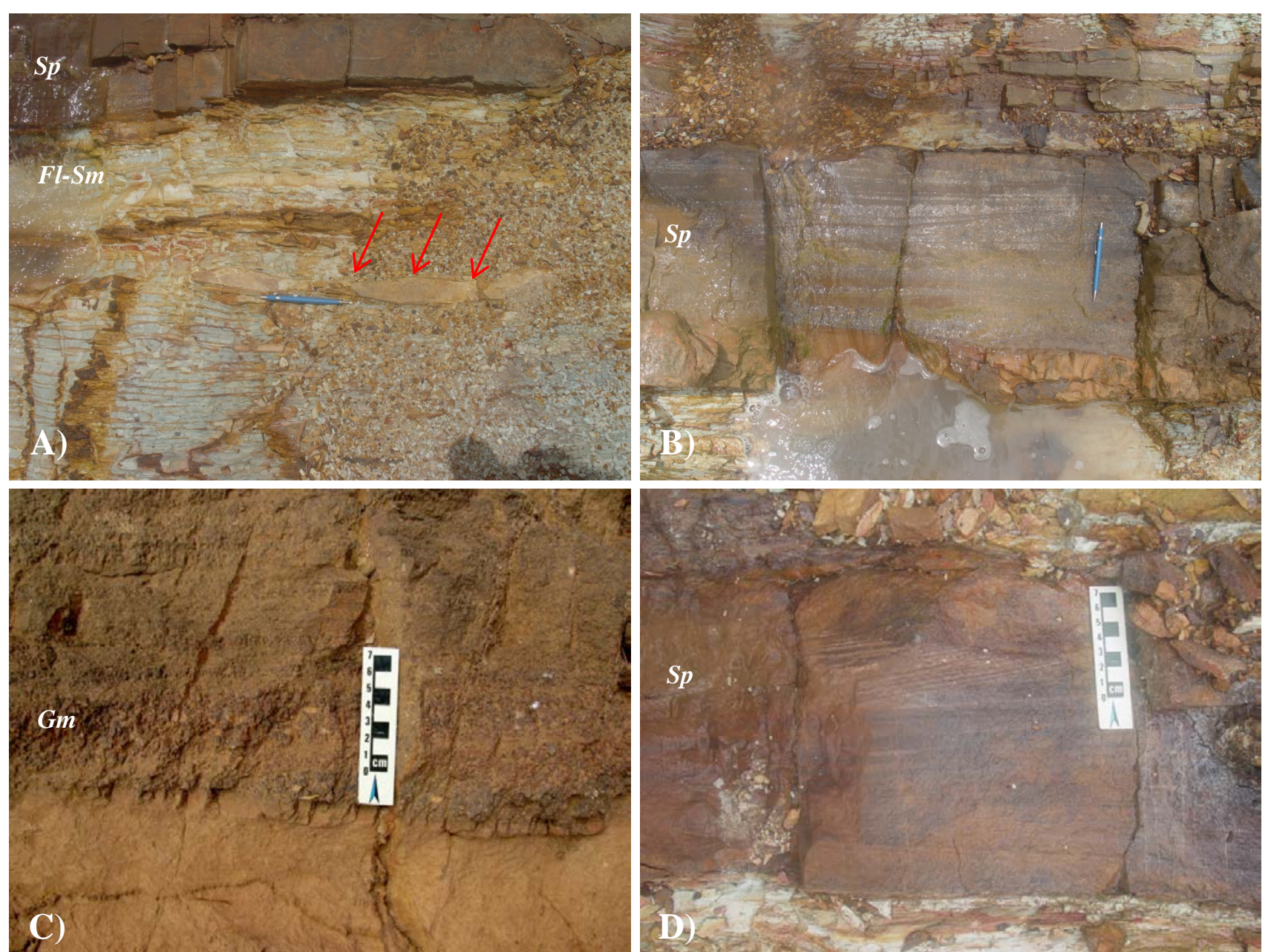

Figura 3.12: Formação Serra Azul, porção intermediária da Unidade B. A) Intercalação rítmica entre pelito finamente laminado e arenito maciço (Facies Fl-Sm). Atentar ao detalhe (setas) do arenito com superfície ondulada/retrabalhada por onda intercalado ao pelito. B) Detalhe, arenito ferruginoso (cimentado por óxido de Fe) com estratificação cruzada tabular de baixo ângulo (Facies Sp). Figuras A e B são representativas da Seção 1, ponto PS 40 (ver Figura 3.3 e 3.11-A). C) Detalhe, nível conglomerático (Facies Gm) ferruginoso (cimentado por óxido de Fe) que ocorre associado à porção basal da Facies Sp. C) Detalhe, arenito ferruginoso (cimentado por óxido de Fe) com estratificação cruzada tabular de baixo ângulo (Facies Sp). Figuras B e C são representativas da Seção 2, ponto PS 69 (ver Figura 3.3 e 3.11-B). 
Nesta unidade foram analisados em microscópio petrográfico apenas os arenitos ferrificados (Facies Sp). Arenito composto por grãos de quartzo detrítico indiferenciado e ocorrência de quartzo policristalino, biotita cloritizada, zircão e grãos opacos, suportados pelos próprios grãos e por cimento de óxido de ferro (Figura 3.12-A, B, C). Características microscópicas texturais: intervalo de tamanho grão varia de silte $(0.05 \mathrm{~mm})$ a areia média $(0.27 \mathrm{~mm})$. Tamanho de grão modal: areia fina $(0.1599 \mathrm{~mm})$. Arcabouço composto por cristais tamanho areia (100\%). Moderadamente selecionado (0.6). Esfericidade média; subangular devido a dissolução por pressão, faturamento/deformação. Fábrica com orientação caótica. Arcabouço suportado pelos próprios grãos e por cimento de óxido de ferro. Intergranular, seleção ruim, distribuição heterogênea, não-orientados. Empacotamento apertado (84). Contatos entre grãos são 33\% suturados, 27\% longos, 21\% côncavo-convexos, 16 \% grão/não-grão e $3 \%$ pontuais.

Para melhor definição qualitativa e quantitativa dos elementos químicos presente nestes arenitos foi realizada análise em microssonda eletrônica de varredura, que revelou a ocorrência de componentes não visualizados em microscópio petrográfico, tais como: barita, ilmenita e monazita, além de biotita cloritizada e zircão identificados anteriormente. Destas, destaca-se borda de alteração por Fe nas Baritas (seta), o enriquecimento em Fe em direção às bordas dos grãos de biotita e o processo de hematização (Figura 3.13-D). 

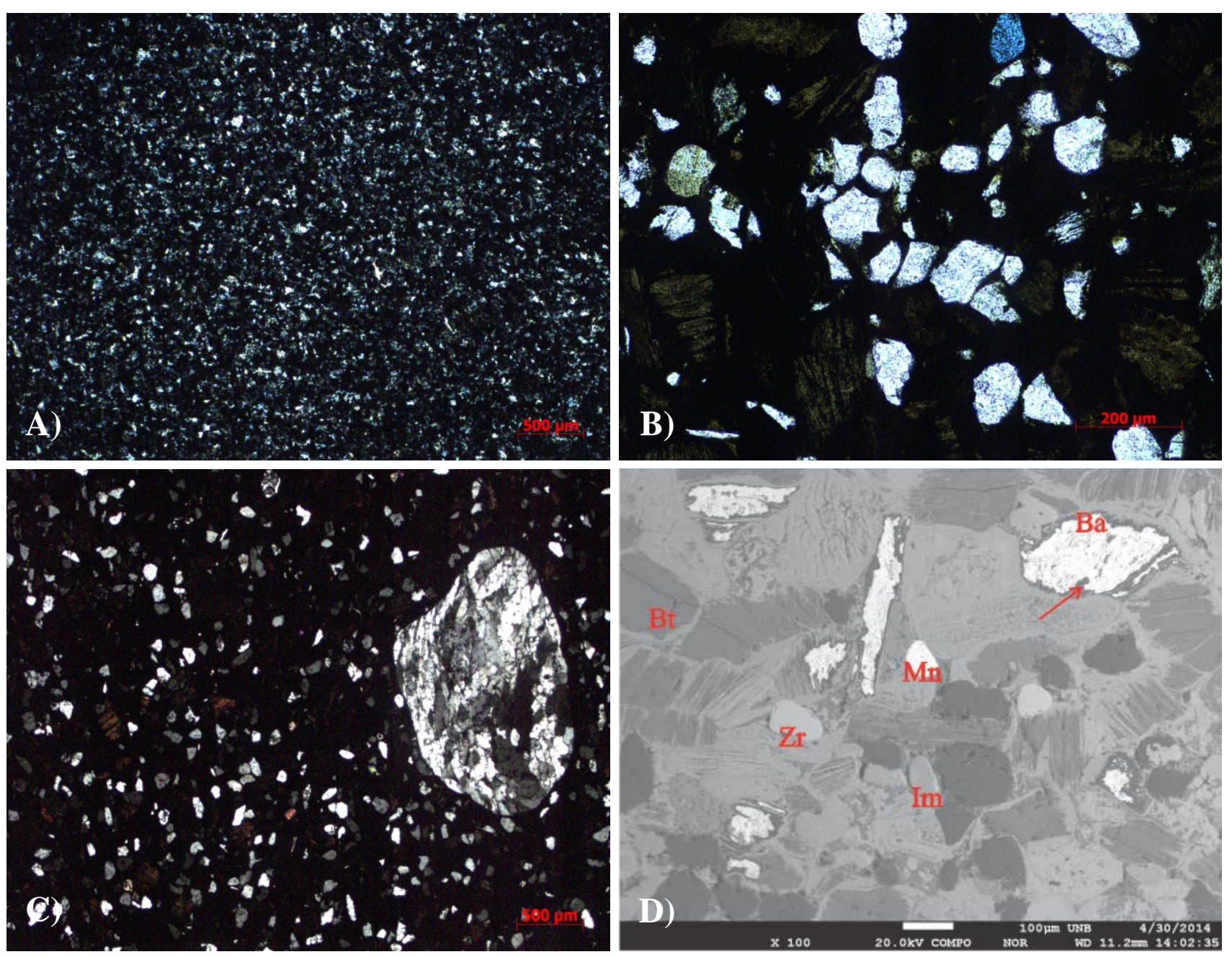

Figura 3.13: Unidade B: Sucessão Siltito - Pelito/Arenito. Arenito com estratificação tabular (Facies Sp). A) Fotomicrografia do arenito ferrificado (Fotomicrografia sob nicóis cruzados, óptica 5X). B e C) Compõe-se principalmente por grãos de quartzo e ocorrência de quartzo policristalino e biotita cloritizada, cimentadas por óxido de ferro (Fotomicrografia sob nicóis cruzados, óptica 10X). D) Imagem de varredura eletrônica; seta - indica Ba com borda de alteração por óxido de Fe hematítico. Ba - Barita; Mn - Monazita; Im - Ilmenita; Bt - Biotita; Zr - Zircão. 


\subsubsection{Formação Raizama}

A Formação Raizama, região de Planalto da Serra, possui boa continuidade estratigráfica (Figura 3.1), afloramentos bem preservados, alcançando cerca de $1140 \mathrm{~m}$ espessura (Seção 1 - Figura 3.3 e 3.4). O contato basal com a Formação Serra Azul, região de Marzagão (seção tipo), foi anteriormente definido como gradacional (Figueiredo et al., 2008), entretanto, na seção aqui descrita foi identificado contato brusco entre os ritmitos, 'Unidade B’ da Formação Serra Azul, com o aparecimento do primeiro grande banco de arenito grosso, muito silicificado, com cerca de $14 \mathrm{~m}$ de espessura, definido aqui como base dos ciclos sedimentares que caracterizam a Formação Raizama (Figura 3.3, 3.4e 3.14). A ocorrência destes grandes bancos de arenito grosso, muito silicificado, com espessuras variando de centimétricas a decamétricas, sustentam as maiores elevações da região. Dessa forma, com base na proporção/ocorrência destes arenitos nos ciclos sedimentares foi possível individualizar a Formação Raizama em quatro ciclos (Ciclos A-D - Figura 3.3e 3.4), compostos por intercalações rítmicas sub-verticais $\left(S_{0} 9 / 70 \mathrm{Az}\right)$ de pelitos e arenitos finos/médios a conglomeráticos, pouco a bastante silicificados, arranjados em grandes ciclos de raseamento ascendente com tendência granocrescente. Notam-se ainda, estruturas do tipo plano-paralelas, cruzadas planares/tabulares e estruturas retrabalhadas por onda. A descrição detalhada de cada ciclo segue a diante.

\subsection{Ciclo A}

O 'Ciclo A', membro basal da Formação Raizama, encontra-se organizado em alguns pequenos ciclos internos, alcançando cerca de $220 \mathrm{~m}$ de espessura (Figura 3.3 e 3.4). Na base dos ciclos, ocorre argilito maciço (Facies Fm), micáceo, cinza-esverdeado, fraturado, com presença esporádica de finas camadas $(0,03 \mathrm{~m})$ de arenito maciço (Facies Sm), fino, esbranquiçado, passando para sucessões rítmicas centimétricas de argilitos maciços (Facies $\mathrm{Fm}$ ) intercalados a arenitos maciços com superfície retrabalhada por onda (Facies Sm), finos, esbranquiçados, associados a siltitos laminados (Facies Fl), por vezes com finas lâminas ferrificadas (Figura 3.3e 3.15-A, B). Os topos dos ciclos são encerrados por bancos de arenito com estratificação cruzada tabular e/ou laminação plano-paralela truncadas por estruturas de onda (Facies Sp - Figura 3.3e 3.15-C), feldspáticos, grosso/muito grosso, localmente grânulos, muito silicificado, com ocorrência de lâminas de argila/silte, associados a conglomerados maciços (Facies Gm), com clastos/lâminas de argila (Figura 3.15- D). 

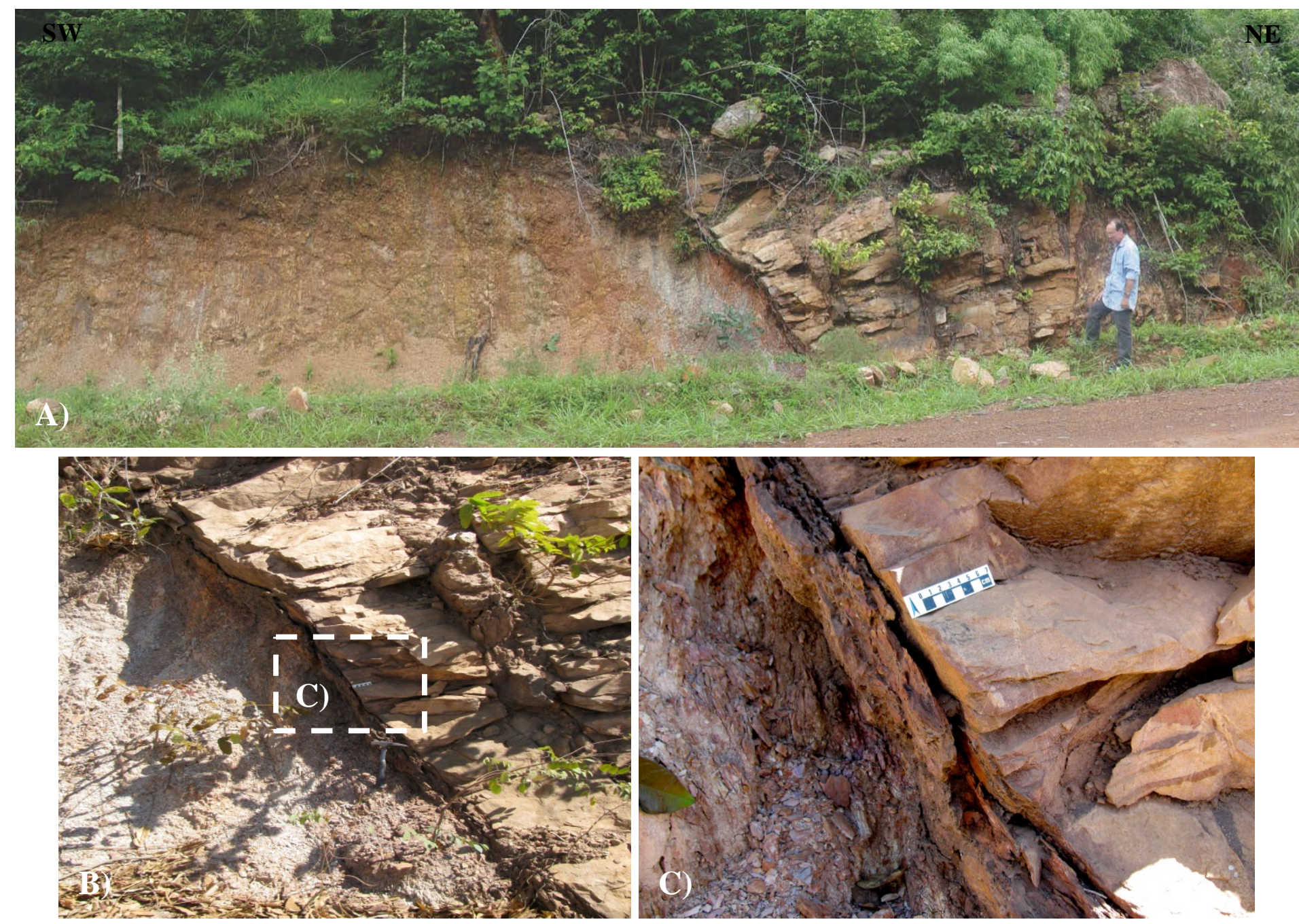

Figura 3.14: A) Seção panorâmica que registra contato brusco descrito entre o topo da Formação Serra Azul e base da Formação Raizama (Ciclo A), na região de Planalto da SerraMT (Ponto PS 43, ver Figura 3.3 e 3.4). B) Contato brusco que limita o topo da Formação Serra Azul e o aparecimento do primeiro grande banco de arenito grosso, muito silicificado (Ciclo A), que sustenta a base da Formação Raizama. C) Detalhe deste contato. 

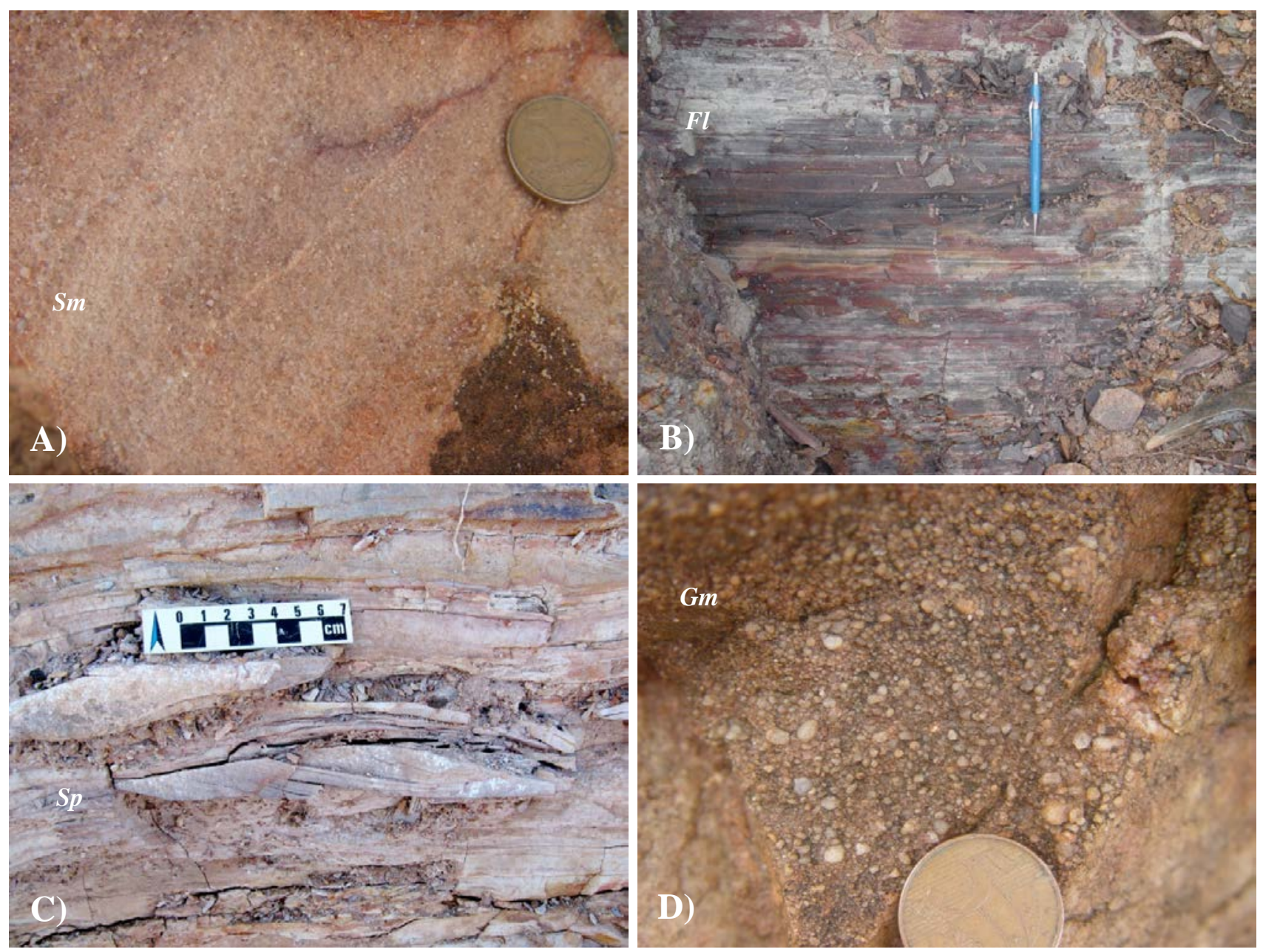

Figura 3.15: Formação Raizama; Ciclo A. A) Arenito maciço (Facies Sm), granulometria fina. B) Siltito finamente laminado (Facies Fl), com finas lâminas ferrificadas. C) Banco de arenito com estratificação cruzada tabular e/ou laminação plano-paralela truncadas por estruturas de ondas (Facies Sp), com ocorrência de finas lâminas de argila/silte. D) Conglomerado maciço (Facies Gm), com clastos de argila. 


\subsection{Ciclo B}

O 'Ciclo B' também encontra-se organizado em pequenos ciclos internos, alcançando cerca de $120 \mathrm{~m}$ de espessura (Figura 3.3 e 3.4). Sua base é marcada por camada (50 m) de siltito maciço (Facies Fm), muito alterado, que grada para ciclos formados por sucessões rítmicas centimétricas $(3-7 \mathrm{~cm}$ ) de siltito laminado (Facies Fl), argiloso, amarelado, micáceo, intercalado a finas lâminas de arenito maciço (Facies Sm), fino, esbranquiçado, com aumento da proporção/camadas de areia em direção ao topo (Figura 3.3e 3.16-A, B e C). Estas sucessões rítencerram-se ao topo dos ciclos com bancos arenosos, de espessura métrica (3 m), formadas por arenitos com estratificação/laminação plano-paralela (Facies Sp), quartzo-feldspáticos, grosso/muito grosso a conglomerático, branco-avermelhado (Figura 3.3, 3.4 e 3.16-A).

\subsection{Ciclo C}

O 'Ciclo C' é o mais espesso dos ciclos, alcançando cerca de $670 \mathrm{~m}$ de espessura (Figura 3.3 e 3.4). Consiste em sucessões pelíticas muito alteradas, em parte encobertas e/ou dobradas, logo sua descrição foi parcialmente prejudicada por conta da ausência de bons afloramentos. Entretanto, foi possível observar a ciclicidade e ritmicidade das sucessões, à semelhança dos ciclos basais (Ciclo A e B). Os ciclos internos são formados por intercalações de siltitos laminados (Facies Fl) e arenitos maciços (Facies Sm), fino/médio, com aumento da proporção/camadas de areia em direção ao topo, associados à ocorrência de níveis de argilitos finamente laminados (Facies Fl), esverdeados, encerrados ao topo por finas camadas $(0,5 \mathrm{~m})$ de arenito maciço (Facies Sm), médio/grosso, muito silicificado. Acima destes ciclos de granocrescência ascendente há espessa camada (300 m) de siltito maciço (Facies Fm), muito alterado e/ou dobrado. O pacote se encerra ao topo com ocorrência de significativo banco de arenito maciço (cerca de 18 m de espessura - Facies Sm), quartzo-feldspático, médio/grosso, silicificado, branco-avermelhado, fraturado, com ocorrência de finas lâminas siltosas no seu arcabouço (Figura 3.3 e 3.17).

\subsection{Ciclo D}

O 'Ciclo D' possui cerca de $125 \mathrm{~m}$ de espessura e marca o fim dos grandes ciclos encerrados por bancos arenosos (Figura 3.3 e 3.4). Este ciclo, a semelhança do 'Ciclo C', encontra-se em parte encoberto e/ou dobrado, sendo ainda possível observar a ciclicidade e ritmicidade das sucessões. Também organiza-se internamente em pequenos ciclos rítmicos 
formados por intercalações de siltito laminado (Facies Fl) com arenito maciço (Facies Sm), ambos ricos em mica, com aumento da proporção/camadas de areia em direção ao topo (Figura 3.3 e 3.18). Estes ciclos encerram-se em espessos bancos de arenito maciço (Facies Sm), com cerca de $4 \mathrm{~m}$ de espessura, quartzo-feldspático, grosso/muito grosso, bem silicificado, branco-avermelhado, com ocorrência de finas lâminas siltosas amareloesverdeado e placas de mica no seu arcabouço (Figura 3.3). Ao topo do último ciclo rítmico há ocorrência de três diques preenchidos por material caolinítico maciço, micáceo, medindo aproximadamente $50 \mathrm{~cm}$ cada.

Na Formação Raizama foram analisados em microscópio petrográfico apenas os arenitos maciços (Fáceis Sm), do primeiro grande banco de arenito do 'Ciclo A' (cerca de 14 m de espessura - Figura 3.3 e 3.14) e do arenito maciço que marca o topo do 'Ciclo B' (Figura 3.2 e 3.16). Estes arenitos encontram-se muito silicificados e são compostos essencialmente por grãos de quartzo detrítico, destes raros quartzos policristalinos e abundantes monocristalinos; feldspatos, raros feldspatos detríticos e alta ocorrência de plagioclásio detrítico e, rara ocorrência de mica e zircão detrítico (Figura 3.19-A, B, C e D). Nos arenitos da base, os feldspatos alcalinos apresentam ausência de geminação lamelar, ocorrência de textura pertítica e um caso isolado de mimerquita (Figura 3.19-C); os feldspatos potássicos encontram-se muito alterados para sericita, mica. Cimento é constituído principalmente por sílica (dissolução por pressão) e material caolinítico/sericítico (alteração dos feldspatos). Nos arenitos do topo do 'Ciclo B', os grãos de feldspato potássico encontramse bastante alterados, caolinitizados. Há presença de fina capa de óxido de Fe, que recobre alguns grãos de feldspato, e circunda grãos de quartzo e feldspato. Características microscópicas texturais: intervalos de tamanho de grão varia de areia muito fina $(0,10 \mathrm{~mm})$ a areia muito grossa $(1,37 \mathrm{~mm})$. Tamanho de grão modal: areia fina $(0,17 \mathrm{~mm})$, areia média $(0,31 \mathrm{~mm})$, areia grossa $(0,57 \mathrm{~mm})$. Arcabouço composto por grãos tamanho areia $(85 \%)$ e cascalho (15\%). Moderadamente selecionado (0,6\%). Esfericidade média, sub-arredondado devido à deformação, faturamento e dissolução por pressão. Fábrica com orientação caótica. Arcabouço suportado pelos próprios grãos. Empacotamento apertado (86). Contatos entre grãos são 54\% suturados, 26\% longos, 19\% côncavo-convexos, 0,5\% pontuais e 0,1\% do tipo grão/não-grão. O sistema poroso possui tamanho médio, com poros variando de 0.5-0.25 mm, intergranular, seleção ruim, distribuição heterogênea, não-orientados. Classificação textural: Arenito sub-arcóseo. 

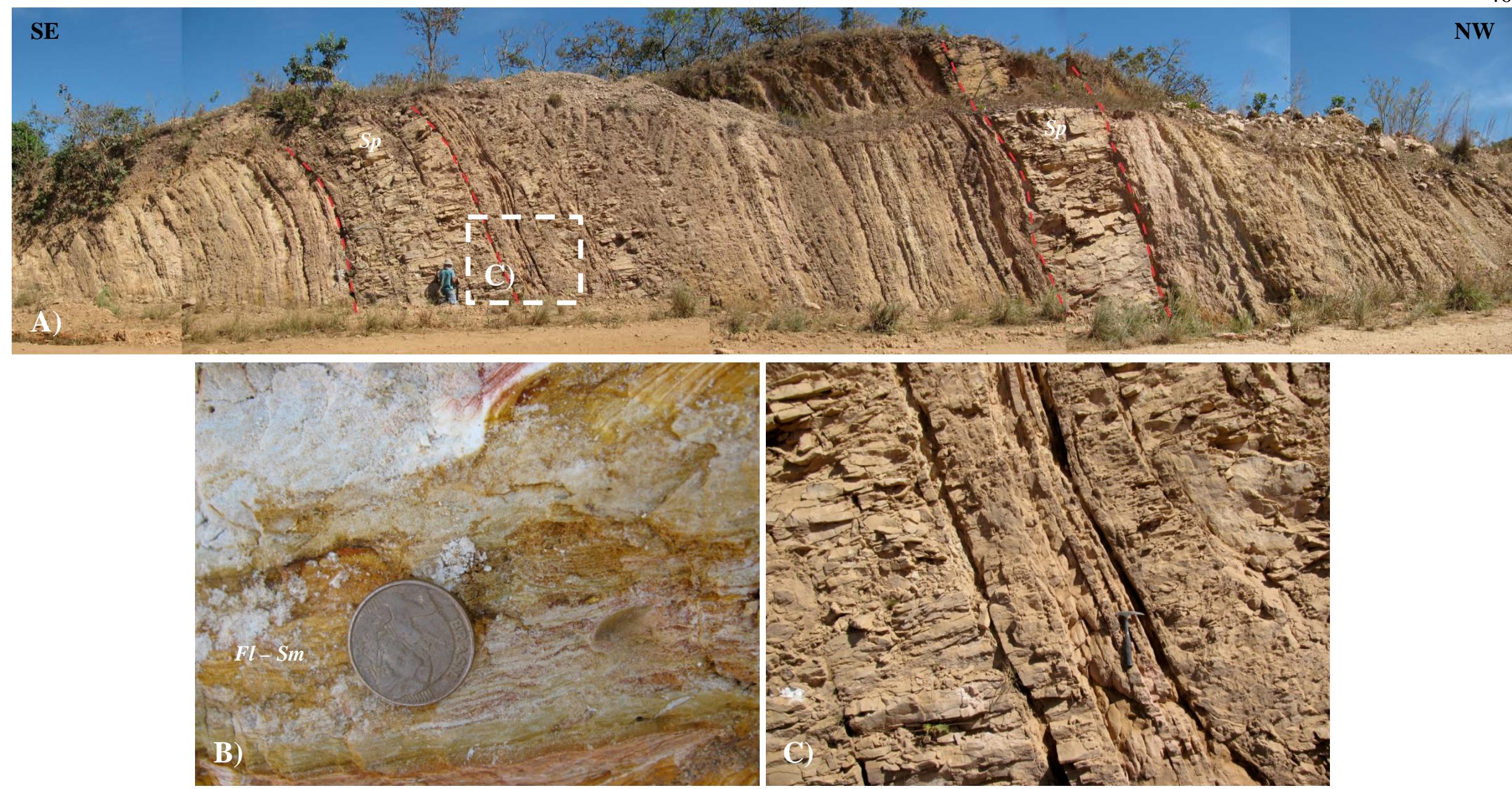

Figura 3.16: Formação Raizama; Ciclo B. A) Seção panorâmica que demonstra os ciclos internos compostos por sucessões rítmicas (Facies $F l$ - Sm) limitadas por grandes bancos de arenito com estratificação plano-paralela (Facies $S p$ ) destacados pelas linhas tracejadas em vermelho (base à direita). B) Detalhe das sucessões rítmicas centimétricas (3- $7 \mathrm{~cm}$ ) de siltito laminado (Facies Fl) intercalado com finas lâminas de arenito maciço (Facies Sm). C) Detalhe do contato entre estas sucessões rítmicas e banco arenoso composto por arenito com estratificação/laminação plano-paralela (Facies Sp), grosso/muito grosso. 


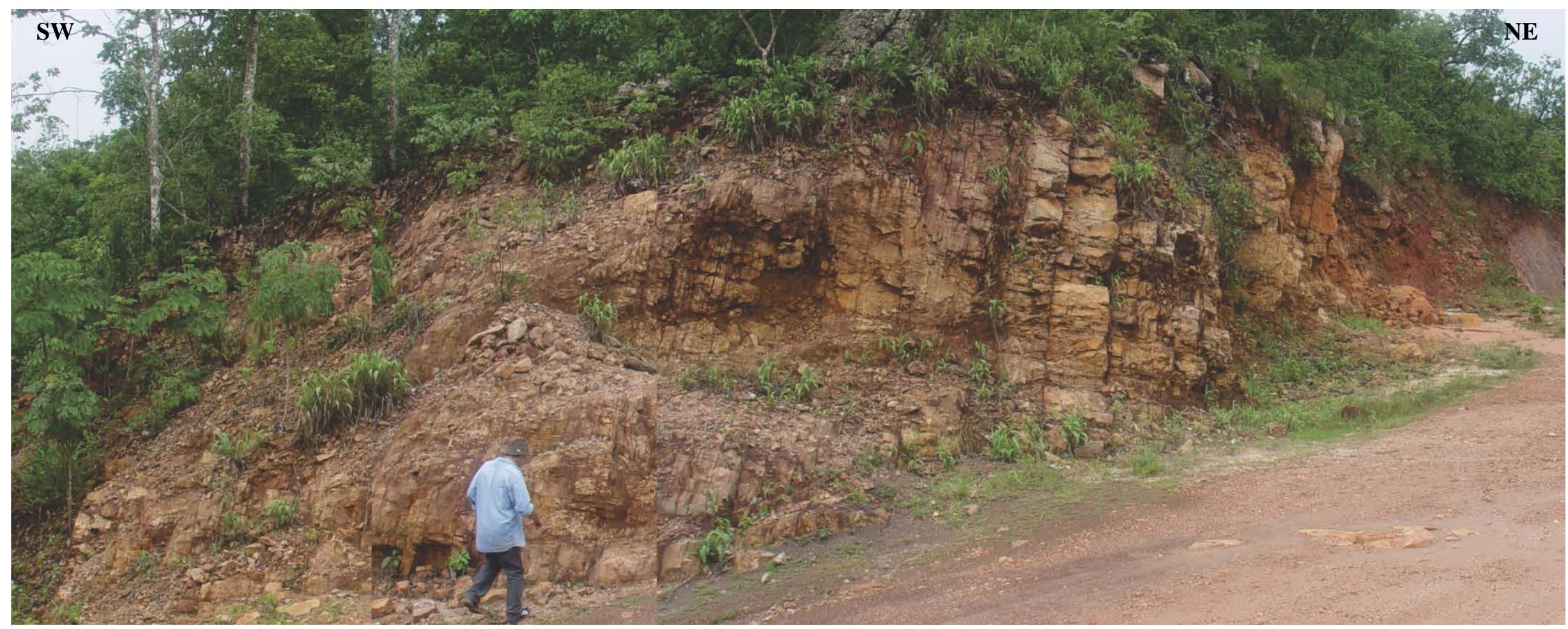

Figura 3.17: Formação Raizama; Ciclo C. Sessão panorâmica que demonstra banco de arenito maciço que marca o topo do Ciclo C (cerca de 18 m de espessura - Facies Sm), quartzo-felspático, médio-grosso, bem silicificado, fraturado (PS 59; ver Figura 3.3 e 3.4). 


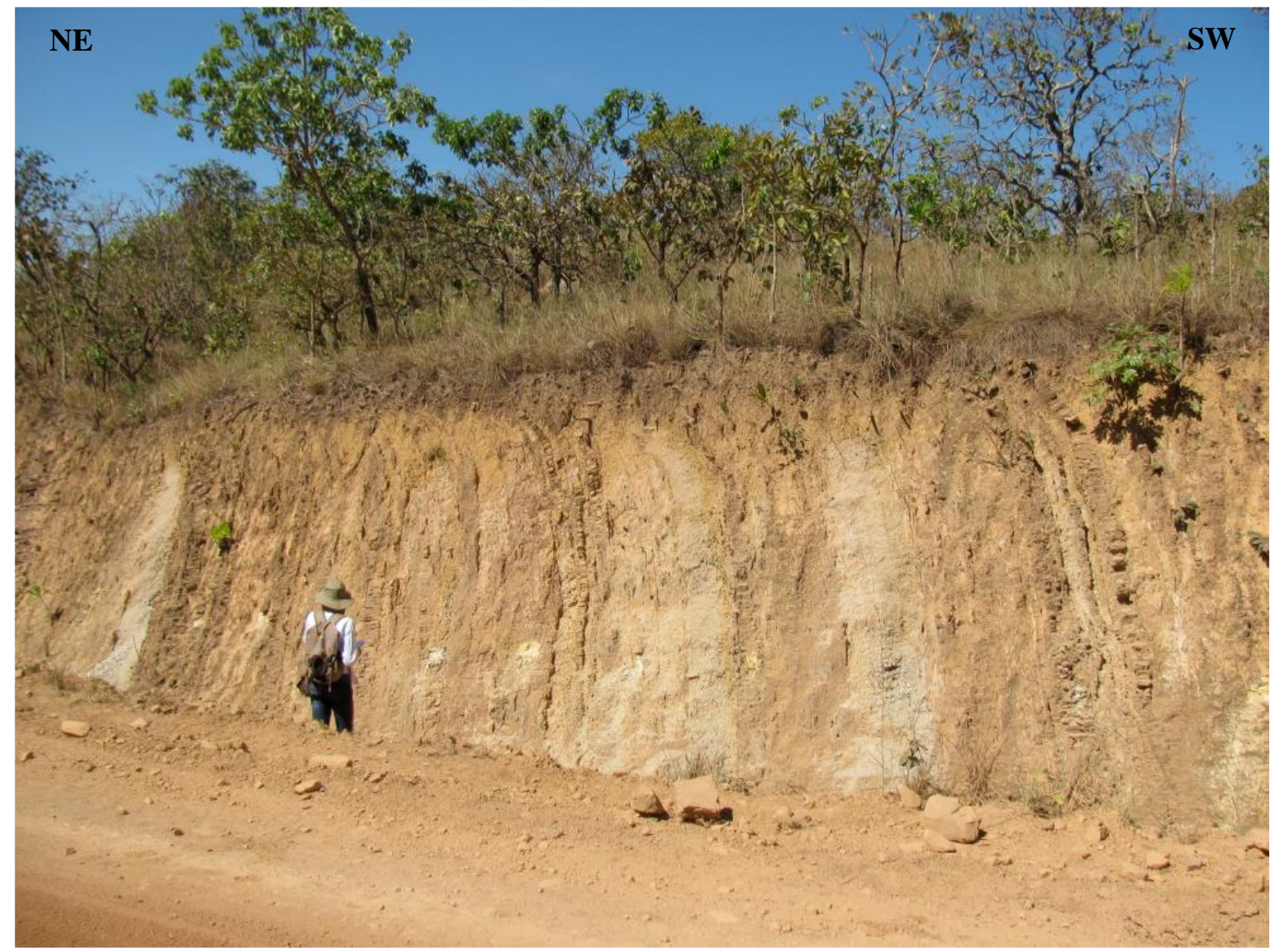

Figura 3.18: Formação Raizama; Ciclo D. Seção panorâmica que demonstra os ciclos rítmicos internos do 'Ciclo D', bastante intemperizado, formados por intercalações de siltito laminado (Facies Fl) com arenito maciço (Facies Sm - PS 77; ver Figura 3.3 e 3.4). 

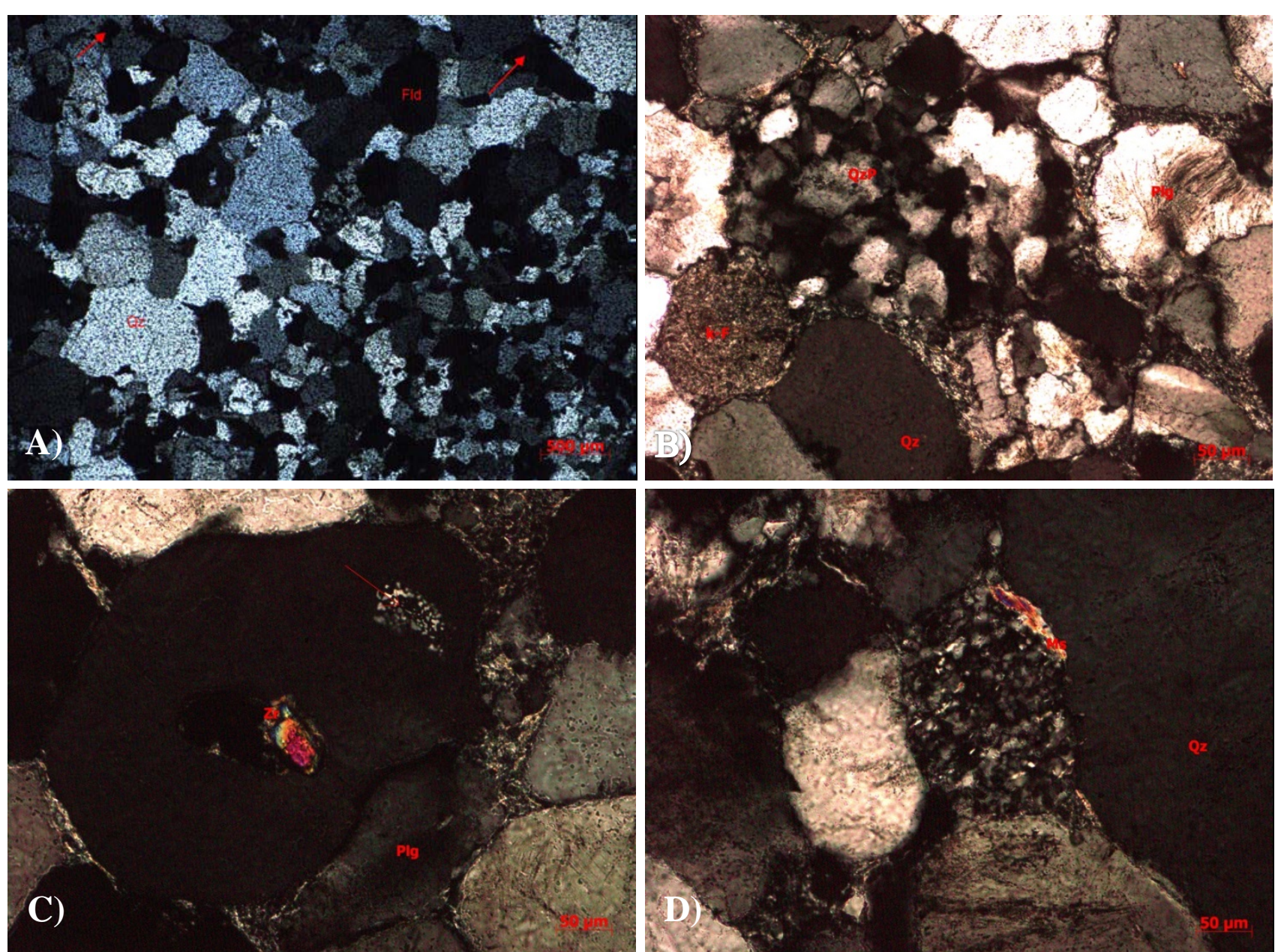

Figura 3.19: Formação Raizama. Arenito maciço (Facies Sm). A) Fotomicrografia do arenito maciço sob nicóis cruzados (óptica 5X). Setas indicam ocorrência de porosidade. B) Compõe-se principalmente por quartzo e feldspatos detríticos cimentados por sílica (Fotomicrografia sob nicóis cruzados, óptica 10X). D) Ocorrência de zircão detrítico e mimerquita. (Fotomicrografia sob nicóis cruzados, óptica 10X). D) Ocorrência de mica (Fotomicrografia sob nicóis cruzados, óptica 10X). Qz - Quartzo; Qzp - Quartzo policrisalino; Fld - Feldspato indiferenciado; K-F - Feldspato potássico; Plg - Plagioclásio; Ms - Muscovita; Zr - Zircão. 


\subsubsection{Formação Diamantino}

Estratos pertencentes à Formação Diamantino foram encontrados a noroeste do munícipio de Planalto da Serra (Figura 3.1, 3.2 e 3.4). São siltitos que recobrem de forma brusca a última ocorrência dos grandes bancos de arenito grosso muito silicificado que limita os ciclos de pelito/arenito da Formação Raizama (Figura 3.3), abrangendo área arrasada de relevo pouco acentuado (Seção 1 - Figura 3.4 e 3.20). Estes siltitos são laminados (Facies Fl), muito alterados, dispostos em escassos afloramentos pobremente preservados.

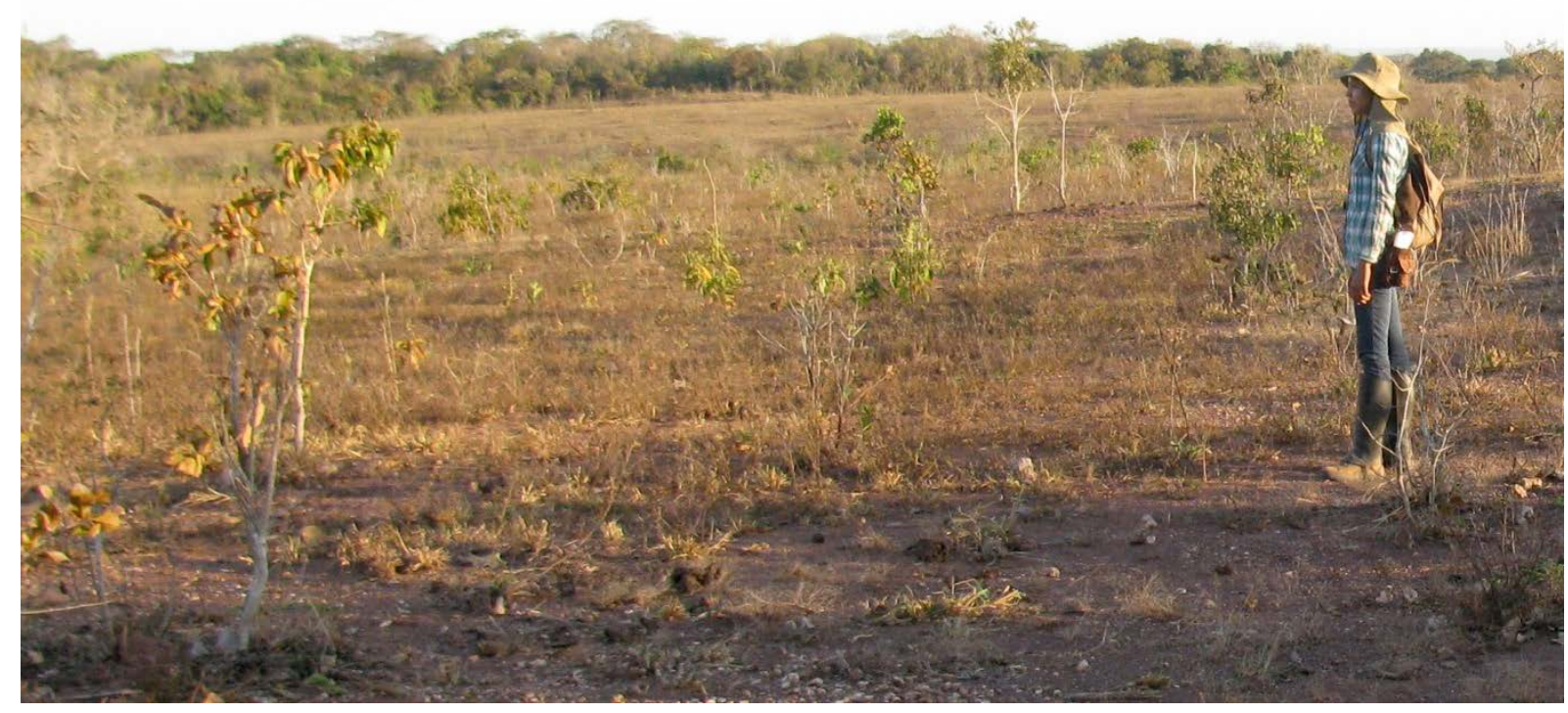

Figura 3.20: Formação Diamantino. Área arrasada de relevo pouco acentuado que marca a Formação Diamantino na região de Planalto da Serra-MT.

\subsection{REGIÃO DE “SETE PLACAS”}

$\mathrm{Na}$ localidade conhecida como "Sete Placas", foram encontrados estratos pertencentes às Formações Raizama e Diamantino (Figura 3.1 e 3.2 - Grupo Alto Paraguai). Duas seções foram estudadas, Seções 4 e 5 (Figura 3.1, 3.2, 3.21e 3.22), as quais apresentam bons afloramentos, porém descontínuos, dificultando a construção de uma seção vertical contínua. Dessa forma, segue adiante descrição detalhada destas formações.

\subsubsection{Grupo Alto Paraguai}

\subsubsection{Formação Raizama}

A Formação Raizama, na Seção 4, está disposta em camadas sub-horizontais ( $\mathrm{S}_{0}$ 150/15 Az) de arenitos com estratificação cruzada acanalada de médio porte (Facies St), quartzo-feldspáticos, grosso/muito grosso, vermelho-esbranquiçado, bases dos sets são 
conglomeráticos, com granodecrescência ascendente em direção aos foresets (Figura 3.23-A). O sentido da paleocorrente medida varia de $20^{\circ}$ a $50^{\circ}$ Az. Nos intervalos seguintes, as camadas mergulham em maior ângulo e, nesta ordem, há ocorrência de camadas arenosas com estratificação cruzada tabular de baixo ângulo (Facies Sp - Figura 3.23-B) e com estratificação cruzada acanalada (Facies St) com estrutura de onda ao topo (Figura 3.23-B). Entre estes intervalos há áreas sem afloramento, as quais são atribuídas ao domínio dos sedimentos finos. Seguido de faixa de não exposição, há ocorrência de um ciclo rítmico de material pelítico maciço (Facies $F m$ ), coloração de alteração avermelhada, intercalado a arenito maciço (Facies Sm), fino, micáceo, encerrado ao topo por arenito com estratificação cruzada hummocky (Facies Sh - Figura 3.23-C), quartzo-felspático, grosso/muito grosso, esbranquiçado, truncados bruscamente por estruturas de onda. Estes ciclos se repetem, porém com faixas alternadas parcialmente encobertas, dificultando a descrição e a localização do contato com a Formação Diamantino. 


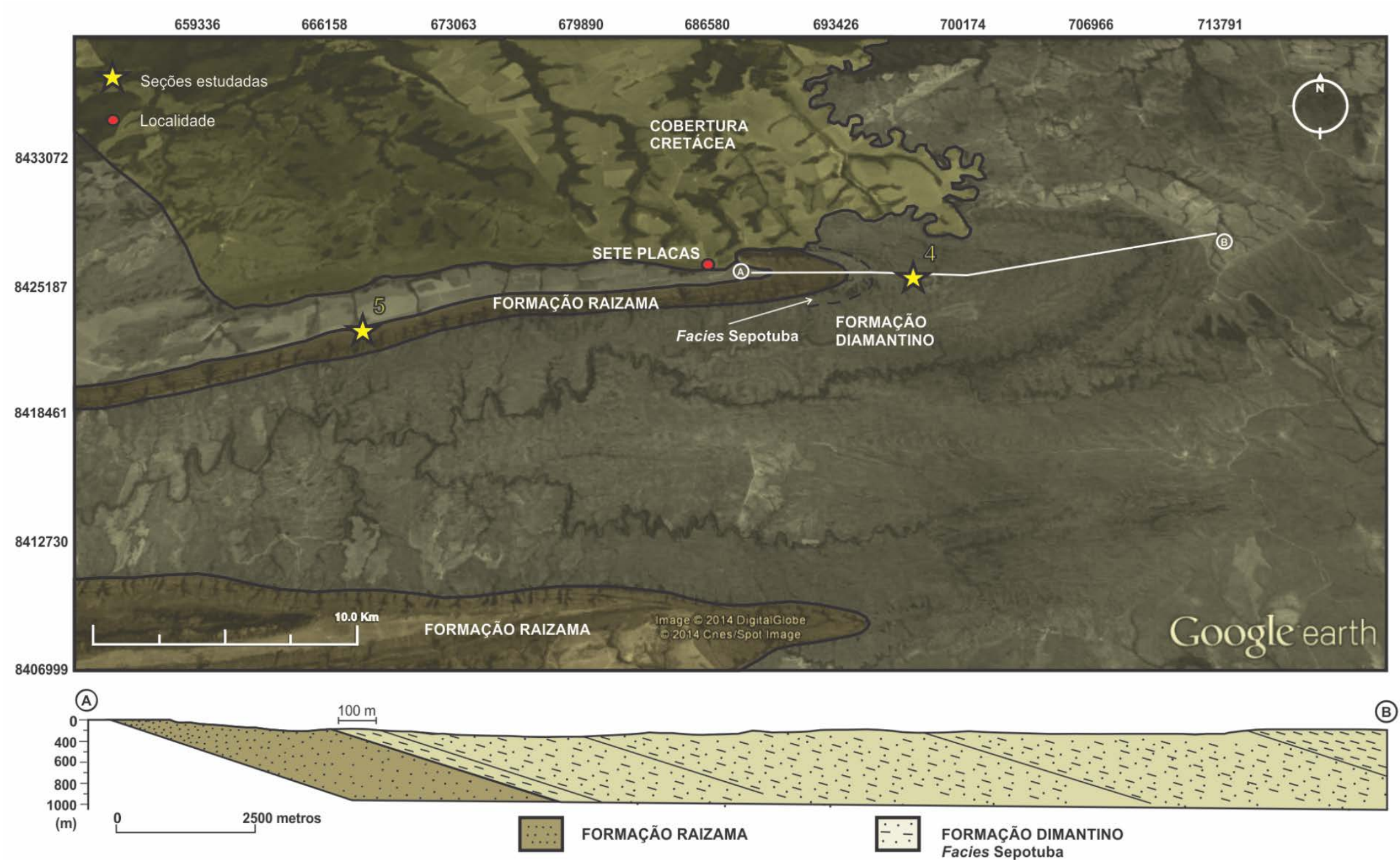

Figura 3.21: Imagem de satélite da região de "Sete Placas"; onde foram estudadas as Seções 4 (perfil A-B) e 5. O esboço marca o limite entre a Cobertura Cretácea, Formação Raizama e a Formação Diamantino. Abaixo, seção transversal esquemática da Seção 4 (perfil A-B), com espessura estimada das Formações Raizama e Diamantino (Zona UTM21; Imagen Digital Globe - Cnes/Spot Image, Google 2014). 


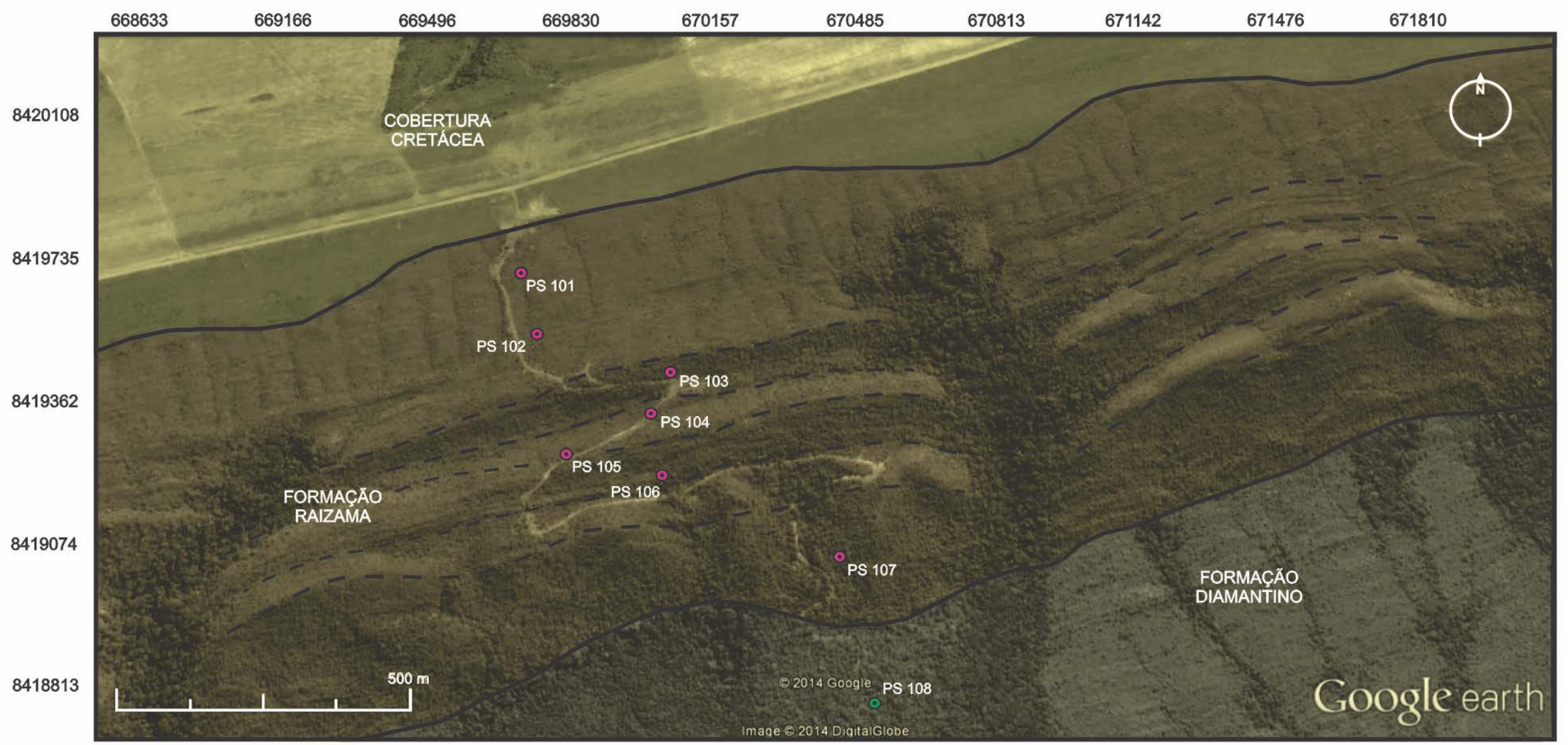

Figura 3.22: Imagem de satélite da região de “Sete Placas”. Detalhe da Seção 5 (ver Figura 3.1, 3.2 e 3.21) com a localização dos pontos descritos. O esboço marca o limite entre a Cobertura Cretácea, Formação Raizama e a Formação Diamantino. Na Formação Raizama os bancos de arenito que limitam os grandes ciclos sedimentares são bem nítidos e encontram-se destacados pelas linhas tracejadas (Zona UTM21; Imagen Digital Globe - Cnes/Spot Image, Google 2014). 

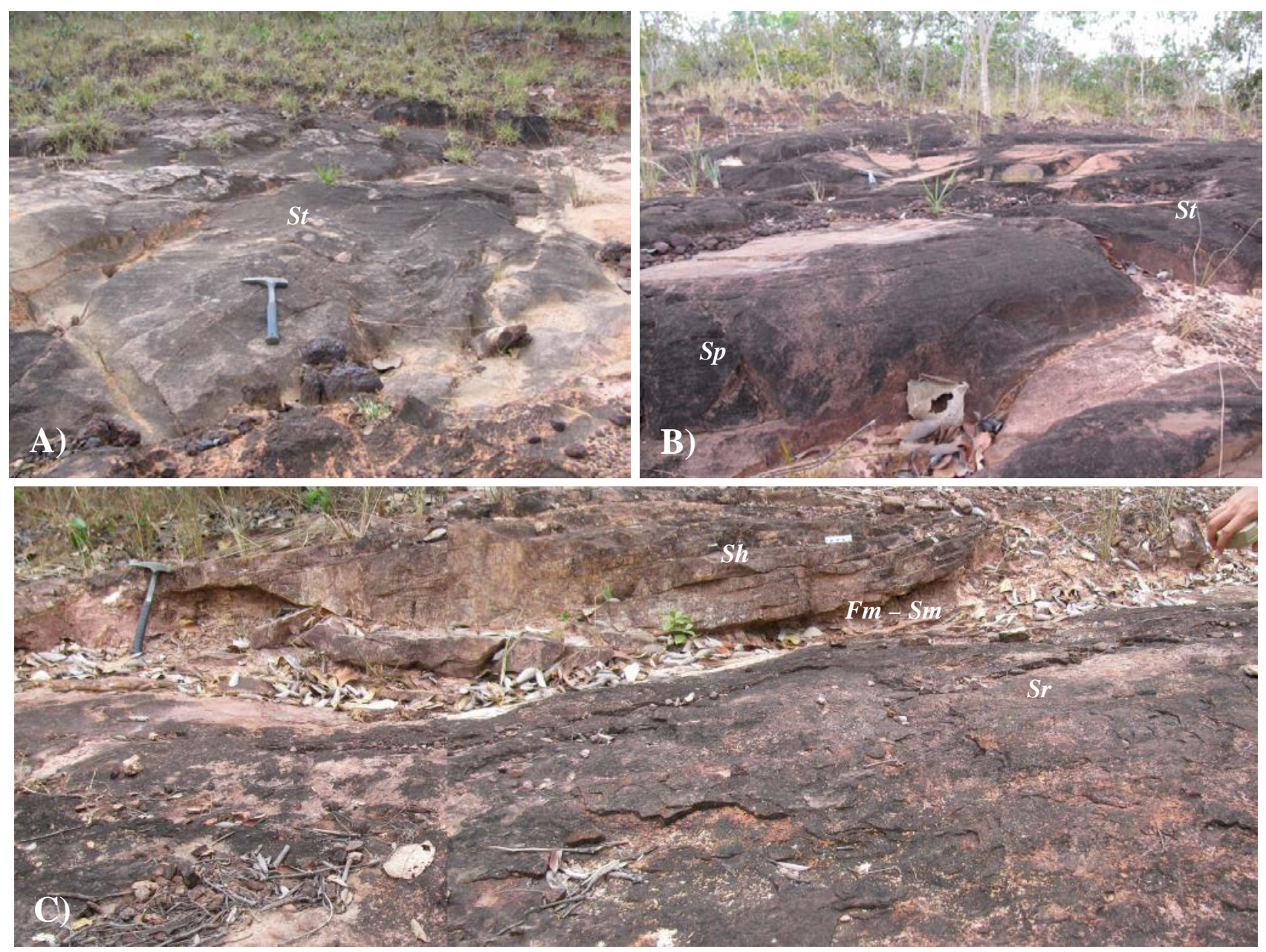

Figura 3.23:Formação Raizama, Seção 4. A) Camadas de arenito com estratificação cruzada acanalada com estrutura de onda ao topo (Facies St). B) Camadas de arenito com estratificação cruzada tabular de baixo ângulo (Facies $\mathrm{Sp}$ ). C) Base formada por camada de arenito com estrutura de onda (Facies $\mathrm{Sr}$ ), intercalado a um ciclo rítmico de pelito maciço (Facies Fm) com arenito maciço (Facies Sm), de granulometria fina, encerrado ao topo por arenito com estratificação cruzada hummocky (Facies Sh). 
Na Seção 5 ocorrem camadas sub-horizontais $\left(S_{0}\right.$ 150/38 Az) de arenito com estratificação cruzada incipiente (Facies Sp), quartzo-feldspático, micáceo, grosso/muito grosso, branco-avermelhado e conglomerático na base dos sets (Figura 3.24-A, B). Seguido por intercalações rítmicas $(0,5 \mathrm{~m})$ de pelito laminado (Facies $F l$ ), amarelo-esbranquiçado, com arenito maciço (Facies Sm), médio-grosso, micáceo, esbranquiçado, com o aumento da proporção/camadas de areia em direção ao topo (Figura 3.24-C, D). Estas intercalações rítmicas se repetem ao longo da seção, e são encerradas por camadas arenosas semelhantes à descrita no início da seção. Ao topo, encerrando estes ciclos, foi identificado contato brusco entre pelitos de topo da Formação Raizama e a ocorrência de arenito maciço (Facies Sm), arcoseano, grosso/muito grosso, com aspecto conglomerático, esbranquiçado, atribuído à Formação Diamantino.

\subsubsection{Formação Diamantino}

A Formação Diamantino, na Seção 4, tem sua base marcada por domínio de cerca de 10 m de siltito laminado (Facies Fl), com ocorrência esporádica de camadas arenosas maciças (0,2 m - Facies Sm), granulometria fina/muito fina, bastante alteradas, as quais repetem-se de metros e metros que seriam atribuídas a Facies Sepotuba (Figura 3.21). Acima afloram alguns ciclos de finas camadas sub-horizontais $\left(\mathrm{S}_{0}\right.$ 80/15 Az) de argilito/pelito finamente laminado (Facies Fl), de coloração amarelo-esverdeado, intercalados a arenito maciço (Facies Sm), quartzo-feldspático, granulometria fina/muito fina, micáceo, de coloração amareloesbranquiçado. Seguido por ciclo de siltito finamente laminado (Facies Fl), argiloso, coloração arroxeada, intercalado a arenito com estratificação cruzada (Facies Sp), argiloso, coloração amarelo-esbranquiçado, com ocorrência de placas de mica marcando o plano de estratificação (Figura 3.25-A). O topo deste ciclo é marcado por afloramento em forma de lajedo, constituído de arenito com ocasionais lentes de argilito, onde há marcas de ondas simétricas (Facies Sm - Figura 3.25-B) e ocorrência do fenômeno de esfoliação esferoidal no argilito (Facies Fm). Após faixa encoberta, aflora no leito de drenagem espessa camada de arenito maciço (Facies Sm), quartzo-feldpático, granulometria fina, micáceo, passando em direção ao topo para um paredão com camadas sub-horizontais de arenito maciço (Facies $S m$ ), granulometria fina, cinza-avermelhado, intercalado com lâminas centimétricas de argilito maciço esverdeado (Facies Fm - Figura 3.25-C). Muito próximo desta drenagem, aflora sucessão com níveis esverdeados, ricos em mica, com espessura centimétrica e contínua lateralmente, intercalados às camadas cíclicas de argilito-arenito (Figura 3.25-D). 
Na Seção 5, foi possível identificar contato brusco entre o topo da Formação Raizama e a base da Formação Diamantino (Figura 3.21). Este contato é marcado pelo término dos ciclos rítmicos da Formação Raizama, encerrado por banco arenoso que dá lugar a siltitos finamente laminados (Facies $F$ ), argilosos, coloração arroxeada, ricos em mica, os quais seriam atribuídos à Facies Sepotuba definida aqui como base da Formação Diamantino. 

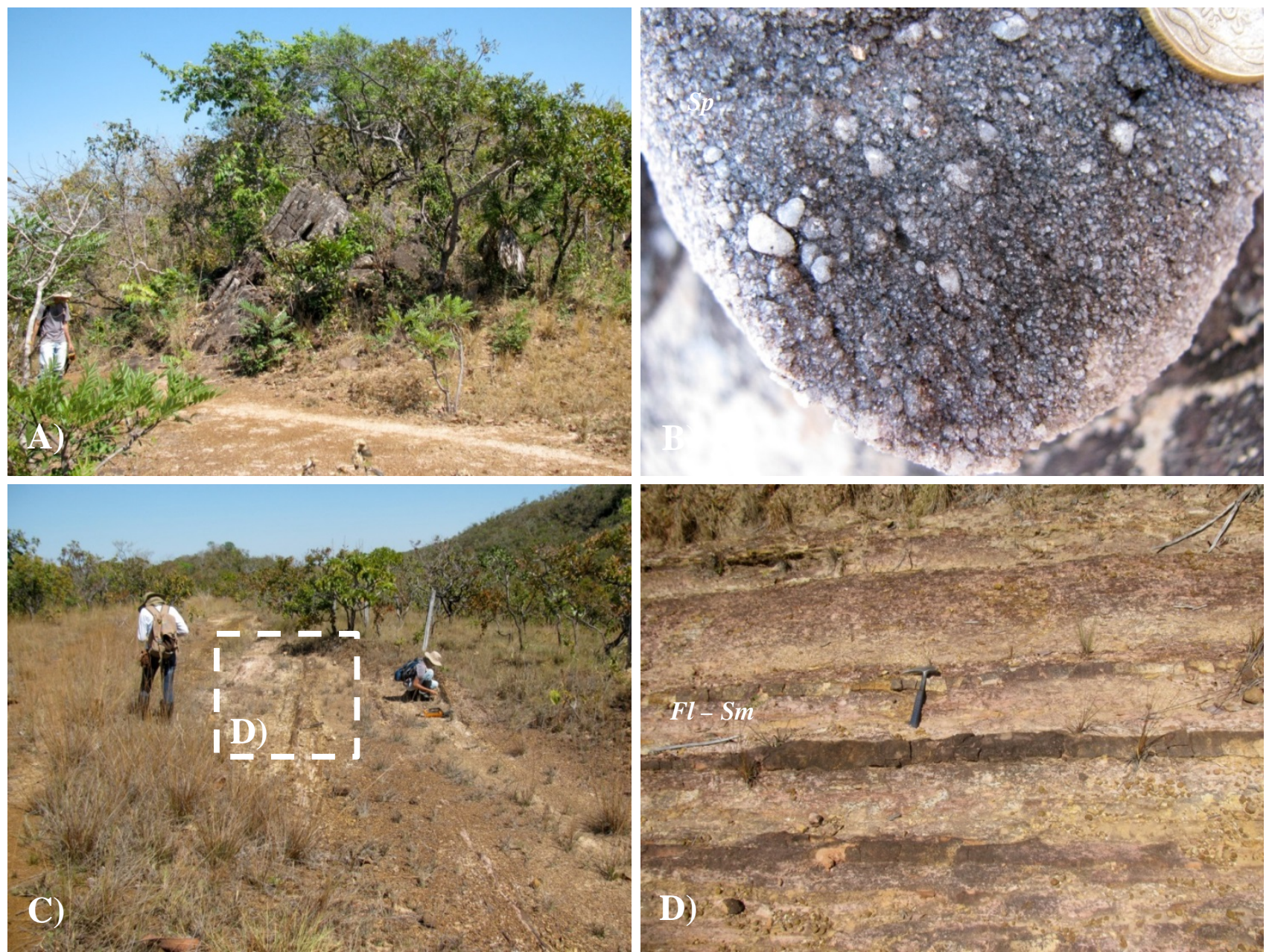

Figura 3.24: Formação Raizama, Seção 5. A) Banco de arenito com estratificação cruzada incipiente (Facies $S p$ ), conglomerático na base dos sets. B) Detalhe da Facies $S p$, com ocorrência de seixos e grânulos. C) Intercalações rítmicas $(\sim 0,5 \mathrm{~m})$ de pelito laminado (Facies $F l)$ com arenito maciço $($ Facies $S m)$. D) Detalhe destas intercalações rítmicas (Facies Fl/Sm). 

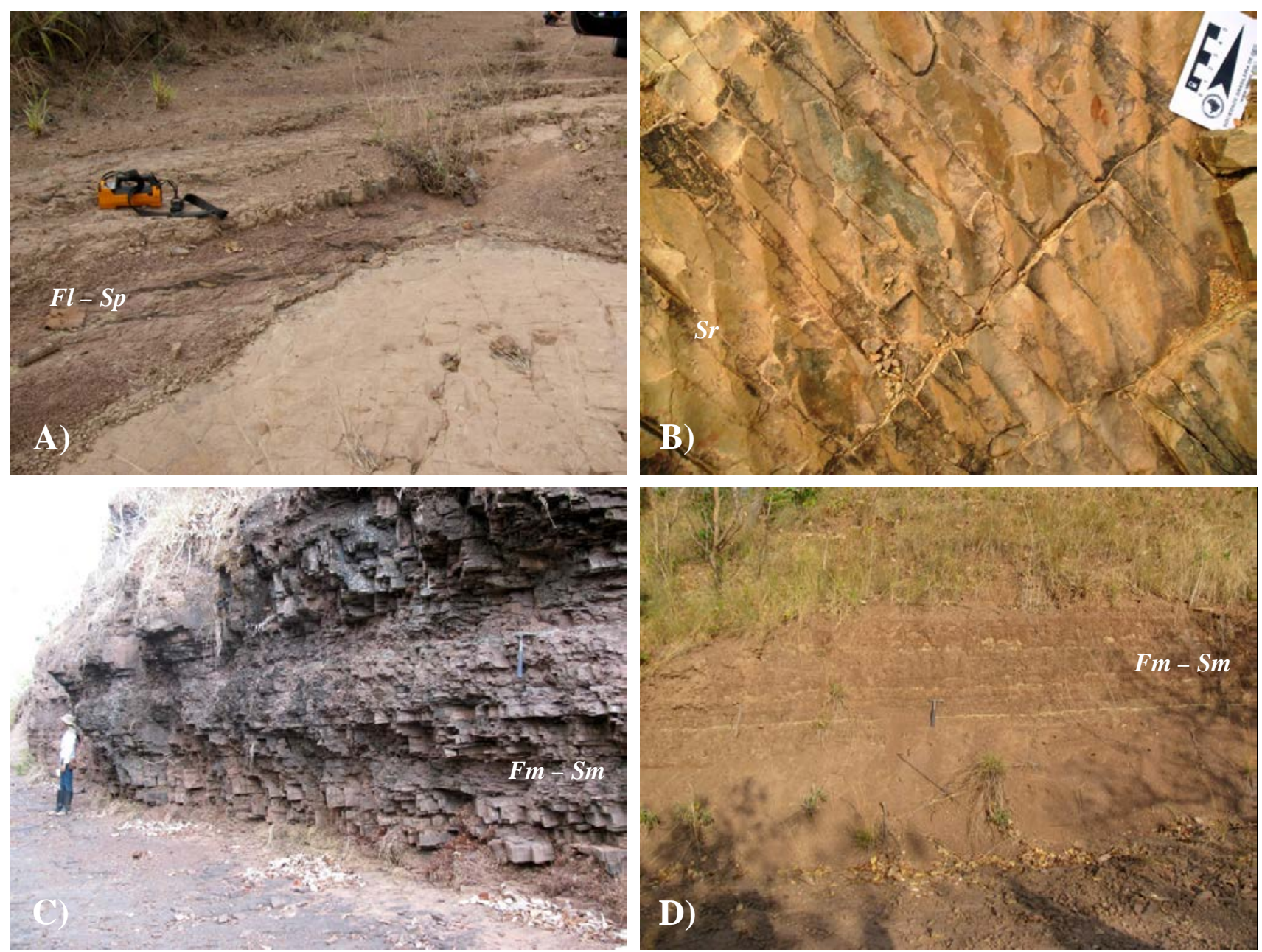

Figura 3.25: Formação Diamantino, Seção 4. A) Ciclo formado por siltito finamente laminado (Facies $F l$ ) e arenito com estratificação cruzada (Facies $S p$ ), com placas de mica marcando o plano de estratificação. B) Afloramento em forma de lajedo, constituído de arenito com ocasionais lentes de arglito, onde há marcas de ondas simétricas (Facies Sr). C) Paredão com camadas sub-horizontais de arenito maciço (Facies Sm) intercalado a lâminas centimétricas de argilito maciço esverdeado (Facies Fm). D) Sucessão com níveis esverdeados, ricos em mica, de espessura centimétrica e contínuos lateralmente, intercalados às camadas de argilito-arenito (Facies Fm - Sm). 


\section{QUIMIOESTRATIGRAFIA}

O estudo quimioestratigráfico foi realizado na Seção 3, nos $80 \mathrm{~m}$ de calcários estromatolíticos (Facies Ls) pertencentes à Facies Carbonática da Formação Pacu, unidade superior do Grupo Araras (Coordenadas UTM 0750899/8380324 - Figura 3.1 e 3.2). Esta seção foi sistematicamente medida e amostrada a cada 3 metros. As amostras foram selecionadas para análises isotópicas (C, $\mathrm{O}$ e Sr) e geoquímica elementar (Tabela 4.1) que foram utilizadas para produzir curvas quimioestratigráficas (Figura 4.1) que contribuirão no estudo de correlações quimioestratigráficas regionais no contexto da Faixa Paraguai Norte e Glaciação Gaskiers. Razões de ${ }^{87} \mathrm{Sr} /{ }^{86} \mathrm{Sr}$ foram obtidas a partir de amostras contendo teores acima de 1300 ppm de Sr, de forma a produzir dados confiáveis.

A análise geoquímica revelou que a seção calcária da Formação Pacu possui altas concentrações de Sr, que variam de 0 a 3500 ppm. Essas amostras também exibem um baixo conteúdo de $\mathrm{SiO}_{2}$ e $\mathrm{Al}_{2} \mathrm{O}_{3}$ (Tabela 4.1).

Os valores de $\delta^{13} \mathrm{C}$ para esta seção mostram na sua base o valor $+6,5 \%$ aumentando levemente ao longo de $54 \mathrm{~m}$ atingindo $+7,9 \%$, enquanto que nos últimos $20 \mathrm{~m}$ os valores encontrados estão entre $+8,4 \%$ e $+8,9 \%$ (Tabela 4.1 ). Os valores de $\delta^{18} \mathrm{O}$ encontrados são muito baixos, entre $-7,9 \%$ e $-4,7 \%$.

As razões isotópicas de ${ }^{87} \mathrm{Sr} /{ }^{86} \mathrm{Sr}$ foram obtidas em sete amostras e apresentam valores coerentes e homogêneos entre 0.70870 e 0.70877 (Tabela 4.1 e Figura 4.1). 
Tabela 4.1: Isótopos de C, O, Sr e geoquímica elementar dos calcários da Formação Pacu.

\begin{tabular}{|c|c|c|c|c|c|c|c|c|c|c|c|c|c|c|c|}
\hline $\mathrm{N}^{\mathbf{o}}$ & Amostra & Grupo & Formação & Nível (m) & Litologia & $\delta^{13} \mathrm{C} \%$ PDB & $\delta^{18} \mathrm{O} \%$ о PDB & $\mathrm{SiO}_{2} \%$ & $\mathrm{Al}_{2} \mathrm{O}_{3} \%$ & $\mathrm{Fe}_{2} \mathrm{O}_{3} \%$ & MnO & $\mathrm{CaO}$ & MgO & Sr ppm & ${ }^{87} \mathrm{Sr} /{ }^{86} \mathrm{Sr}$ \\
\hline 1 & PS 62A & & & 2 & Calcarenito & 6.5 & -5.3 & $2.5 \%$ & $1.0 \%$ & $0.3 \%$ & $0.0 \%$ & $53.3 \%$ & $0.5 \%$ & 2800 & $0.70873 \pm 1$ \\
\hline 2 & PS 62B & & & 3 & Calcarenito & 6.8 & -5.1 & $2.8 \%$ & $1.2 \%$ & $0.3 \%$ & $0.0 \%$ & $51.8 \%$ & $0.7 \%$ & 200 & \\
\hline 3 & PS 62C & & & 6 & Calcarenito & 6.8 & -4.7 & $6.3 \%$ & $1.2 \%$ & $0.2 \%$ & $0.0 \%$ & $50.5 \%$ & $0.6 \%$ & 3400 & \\
\hline 4 & PS 62D & & & 9 & Calcarenito & 7.0 & -6.3 & $2.8 \%$ & $1.2 \%$ & $0.4 \%$ & $0.0 \%$ & $52.9 \%$ & $0.5 \%$ & 3500 & $0.70870 \pm 1$ \\
\hline 5 & PS 62E & & & 12 & Calcarenito & 7.1 & -5.8 & $2.0 \%$ & $0.7 \%$ & $0.2 \%$ & $0.0 \%$ & $50.0 \%$ & $0.5 \%$ & 2900 & \\
\hline 6 & PS 62F & & & 15 & Calcarenito & 7.3 & -6.1 & $3.7 \%$ & $1.2 \%$ & $0.4 \%$ & $0.0 \%$ & $52.1 \%$ & $0.7 \%$ & 3200 & \\
\hline 7 & PS 62G & & & 18 & Calcarenito & 7.2 & -6.5 & $3.1 \%$ & $1.2 \%$ & $0.3 \%$ & $0.0 \%$ & $52.6 \%$ & $0.5 \%$ & 3400 & $0.70873 \pm 1$ \\
\hline 8 & PS $62 \mathrm{H}$ & & & 21 & Calcarenito & 7.4 & -6.8 & $4.8 \%$ & $1.1 \%$ & $0.2 \%$ & $0.0 \%$ & $51.5 \%$ & $0.5 \%$ & 3500 & \\
\hline 9 & PS 62I & & & 24 & Calcarenito & 7.6 & -6.6 & $3.5 \%$ & $1.1 \%$ & $0.3 \%$ & $0.0 \%$ & $52.1 \%$ & $0.4 \%$ & 3100 & \\
\hline 10 & PS 62J & ARARAS & PACU & 27 & Calcarenito & 7.3 & -6.7 & $2.9 \%$ & $1.2 \%$ & $0.3 \%$ & $0.0 \%$ & $52.6 \%$ & $0.5 \%$ & 3200 & \\
\hline 11 & PS $62 \mathrm{~K}$ & & & 30 & Calcarenito & 6.6 & -6.3 & $2.4 \%$ & $0.9 \%$ & $0.2 \%$ & $0.0 \%$ & $53.8 \%$ & $0.6 \%$ & 2800 & $0.70873 \pm 1$ \\
\hline 12 & PS 62L & & & 33 & Calcarenito & 7.1 & -7.1 & $3.1 \%$ & $1.4 \%$ & $0.4 \%$ & $0.0 \%$ & $52.0 \%$ & $0.5 \%$ & 3400 & \\
\hline 13 & PS 62M & & & 36 & Calcarenito & 7.2 & -6.8 & $2.8 \%$ & $1.7 \%$ & $0.2 \%$ & $0.0 \%$ & $54.6 \%$ & $0.5 \%$ & 3500 & $0.70871 \pm 1$ \\
\hline 14 & PS 62N & & & 39 & Calcarenito & 6.9 & -7.3 & $5.0 \%$ & $2.2 \%$ & $0.6 \%$ & $0.0 \%$ & $50.4 \%$ & $0.5 \%$ & 3400 & \\
\hline 15 & PS 620 & & & 42 & Calcarenito & 6.9 & -6.2 & $4.9 \%$ & $2.0 \%$ & $0.7 \%$ & $0.0 \%$ & $48.2 \%$ & $1.2 \%$ & 1300 & \\
\hline 16 & PS 62P & & & 45 & Calcarenito & 7.5 & -6.3 & $2.6 \%$ & $1.0 \%$ & $0.4 \%$ & $0.0 \%$ & $52.8 \%$ & $0.7 \%$ & 3000 & $0.70872 \pm 1$ \\
\hline 17 & PS 62R & & & 48 & Calcarenito & 7.0 & -5.8 & $3.5 \%$ & $0.8 \%$ & $0.4 \%$ & $0.0 \%$ & $51.9 \%$ & $1.3 \%$ & 0 & \\
\hline 18 & PS 62S & & & 51 & Calcarenito & 7.9 & -5.7 & $3.9 \%$ & $1.0 \%$ & $0.3 \%$ & $0.0 \%$ & $51.4 \%$ & $0.6 \%$ & 3100 & \\
\hline 19 & PS 63 & & & 54 & Calcarenito & 7.8 & -6.4 & $4.4 \%$ & $1.2 \%$ & $0.4 \%$ & $0.0 \%$ & $51.6 \%$ & $0.7 \%$ & 3100 & \\
\hline 20 & PS 64A & & & 61 & Calcarenito & 8.9 & -6.5 & $5.4 \%$ & $1.0 \%$ & $0.2 \%$ & $0.0 \%$ & $51.7 \%$ & $0.7 \%$ & 3100 & $0.70877 \pm 1$ \\
\hline 21 & PS 64B & & & 72 & Calcarenito & 8.5 & -7.0 & $5.2 \%$ & $1.9 \%$ & $0.7 \%$ & $0.0 \%$ & $49.8 \%$ & $1.2 \%$ & 2700 & \\
\hline 22 & PS 64C & & & 80 & Calcarenito & 8.4 & -7.9 & $6.1 \%$ & $1.2 \%$ & $0.2 \%$ & $0.0 \%$ & $49.6 \%$ & $0.6 \%$ & 3300 & \\
\hline
\end{tabular}




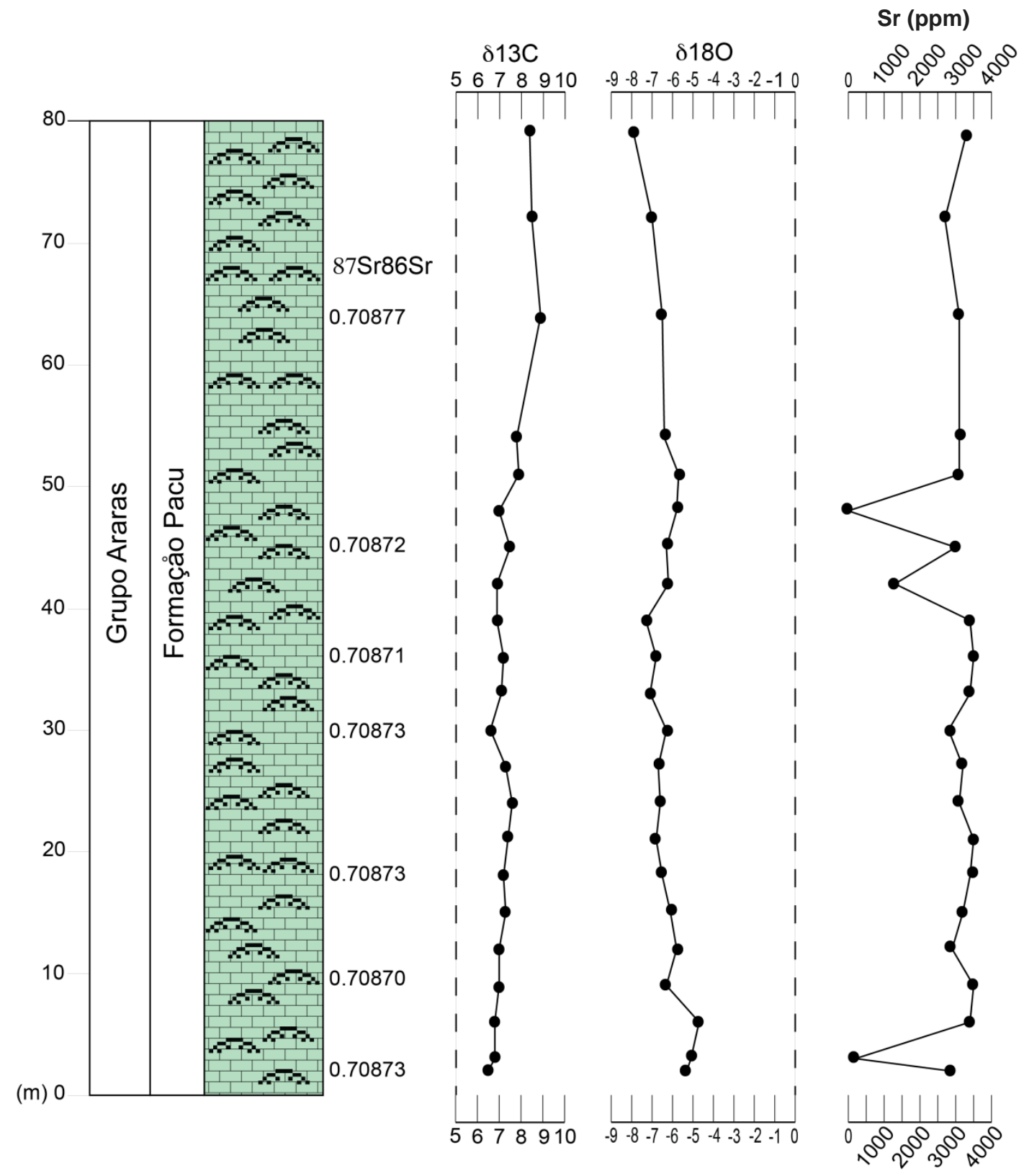

Figura 4.1: Curvas quimioestratigráficas de $\delta^{13} \mathrm{C}$ e $\delta^{18} \mathrm{O}$ e razões isotópicas de ${ }^{87} \mathrm{Sr} /{ }^{86} \mathrm{Sr}$ para a Facies Carbonática da Formação Pacu, Grupo Araras, região de Planalto da Serra (ver Figura 3.2 - Seção 3). 


\section{GEOCRONOLOGIA}

Seis amostras coletadas no Grupo Alto Paraguai foram selecionadas para análise de proveniência sedimentar, baseada em dados geocronológicos U-Pb obtidos em grãos de zircão detrítico.

\subsection{RESULTADOS}

A análise geocronológica gerou uma ampla faixa temporal, a partir da base até o topo do Grupo Alto Paraguai. As amostras PS 07 (arenito fino/médio), PS 08-A (arenito fino/médio), PS 40-C (arenito médio/grosso) e PS 22 (diamictito de matriz acinzentada) pertencem a Formação Serra Azul. As amostras PS 11 (arenito grosso) e PS 30 (arenito fino/médio) pertencem a Formação Raizama. A amostra PS 10 (arenito fino/médio) é da Formação Diamantino. Os grãos de zircão detríticos recuperados destas amostras variam granulométricamente de areia muito fina a tamanho silte, morfologicamente caracterizados por grãos bem arredondados, estando alguns quebrados e/ou com bordas agudas (subédricos). Tais características morfológicas estão diretamente relacionadas ao intemperismo, transporte e deposição. Dados geocronológicos são apresentados nas Figuras 5.1 e 5.2 e os dados analíticos são fornecidos na Tabela suplementar em Anexos. Idades são apresentadas utilizando a razão ${ }^{206} \mathrm{~Pb} /{ }^{238} \mathrm{U}$; todos desvios padrão são apresentados no nível sigma $1(1 \sigma)$ e médias ponderadas possuem 95\% de confiança.

\section{Formação Serra azul}

PS 07 (Arenito fino/médio). No total, 59 análises LA-ICP-MS foram obtidas de 54 grãos de zircão recuperados da amostra PS 07. A análise mais jovem, apenas um grão, $297 \pm$ 5 Ма (conc. 91\%) mostra uma herança Paleozóica. Os próximos dois grãos mais jovens registram idades 593 \pm 4 Ma (conc. 95\%) e 619 \pm 7 Ma (conc. 99,7\%). A maioria dos outros

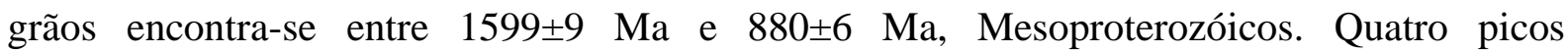
proeminentes ocorrem em $2737 \pm 7$ Ma, $2220 \pm 7$ Ma, 2042 \pm 5 Ma e $1861 \pm 8$ Ma, o primeiro pico Neoarqueano e os três últimos Paleoproterozóicos. 
PS 08-A (Arenito fino/médio). No total, 64 análises LA-ICP-MS foram obtidas de 46 grãos de zircão recuperados daamostra PS 08-A. A maioria das análises são concordantes e situam-se entre $2028 \pm 14$ Ma e $951 \pm 5$ Ma, principalmente Paleoproterozóicos e Mesoproterozóicos.

PS 40-C (arenito médio/grosso). No total, 58 análises LA-ICP-MS foram obtidas de 54 grãos de zircão recuperados da amostra PS 40-C. A maioria das análises são concordantes e se espalham principalmente entre $925 \pm 11$ Ma e 1835 \pm 9 Ma, com pico expressivo no

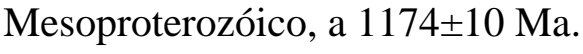

PS 22 (Diamictito matriz cinza). No total, 64 análises LA-ICP-MS foram obtidas de 58 grãos de zircão recuperados da amostra PS 22. A maioria das análises são concordantes e se espalham principalmente entre 906 \pm 7 Ma e 2023 \pm 7 Ma, com dois picos extremos, um a

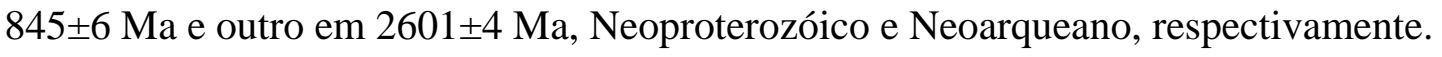

\section{Formação Raizama}

PS 11 (Arenito grosso). No total, 64 análises LA-ICP-MS foram obtidas de 57 grãos de zircão recuperados da amostra PS 11. As análises são predominantemente concordantes e situam-se entre $888 \pm 4$ Ma e $1915 \pm 8$ Ma, com dois picos expressivos em $1454 \pm 10$ e $1780 \pm 7$ Ma no Paleoproterozóico.

PS 30 (Pelito/Arenito médio-fino). No total, 64 análises LA-ICP-MS foram obtidas de 59 grãos de zircão recuperados da amostra PS 30. Quatro grupos de dados são evidentes.

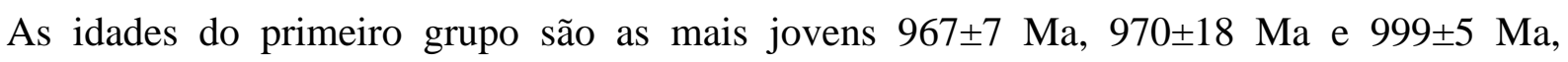
Neoproterozóicos. Enquanto que os três grupos principais de dados variam entre $1134 \pm 6 \mathrm{Ma}$

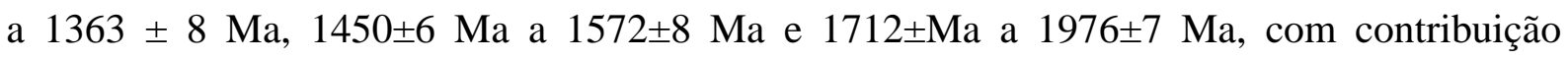

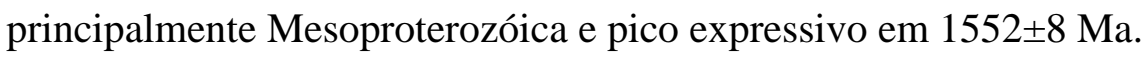

\section{Formação Diamantino}

PS 10 (Pelito/Arenito médio/fino). No total, 64 análises LA-ICP-MS foram obtidas de 57 grãos de zircão recuperados da amostra PS 10. As análises mais jovens, apenas dois grãos, $567 \pm 4$ Ma a $694 \pm 4$ Ma, mostram herança Ediacarana. Enquanto que a maioria dos outros grãos são Mesoproterozóicos com picos no Paleozóico e Neoarqueano. 

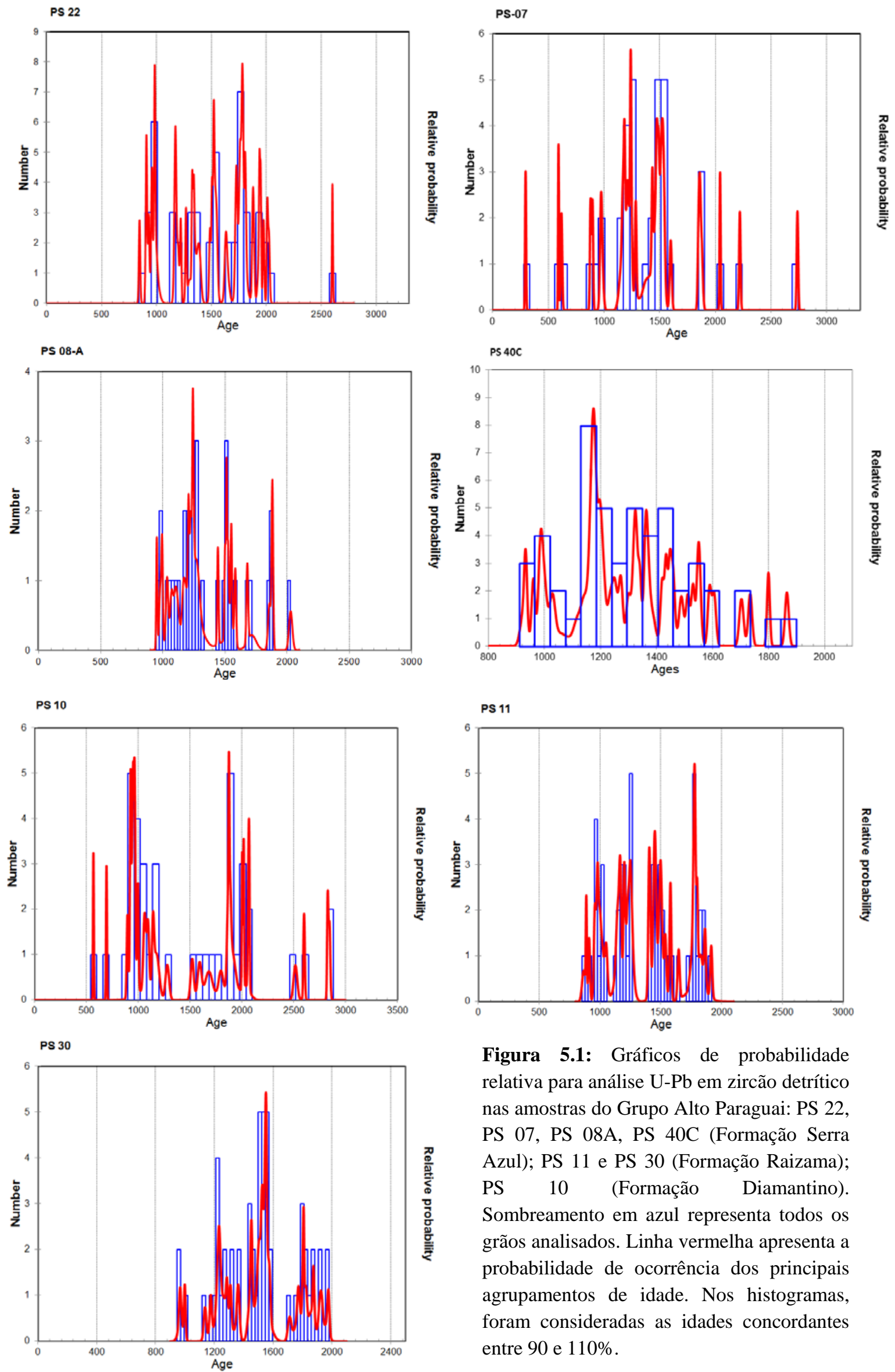

Figura 5.1: Gráficos de probabilidade relativa para análise $\mathrm{U}-\mathrm{Pb}$ em zircão detrítico nas amostras do Grupo Alto Paraguai: PS 22, PS 07, PS 08A, PS 40C (Formação Serra ग्ञ $\quad$ Azul); PS 11 e PS 30 (Formação Raizama); PS 10 (Formação Diamantino). Sombreamento em azul representa todos os grãos analisados. Linha vermelha apresenta a probabilidade de ocorrência dos principais agrupamentos de idade. Nos histogramas, foram consideradas as idades concordantes entre 90 e $110 \%$. 


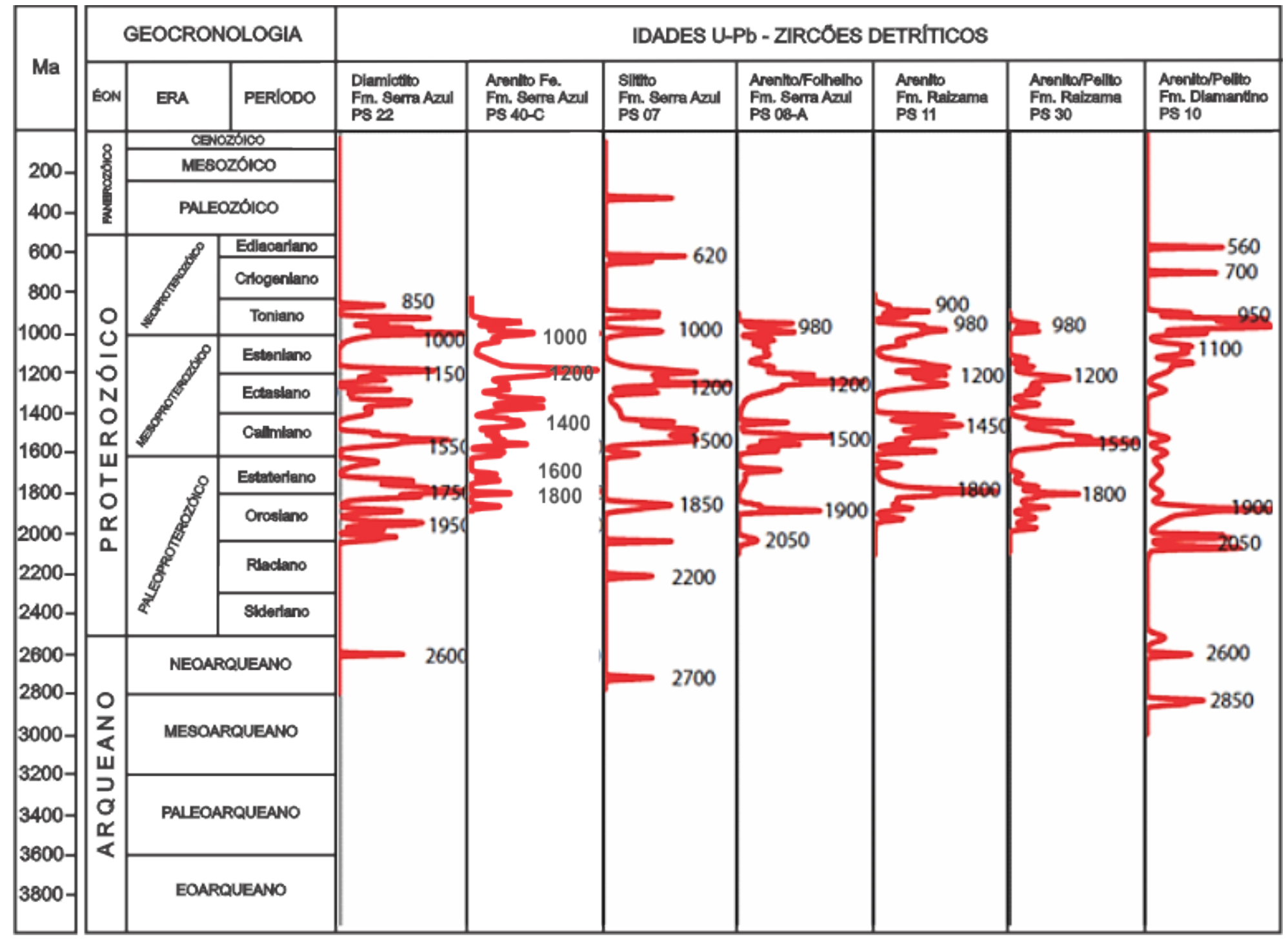

Figura 5.2: Probabilidade das idades relativas U-Pb obtidas em zircões detríticos das amostras coletadas nas formações Serra Azul, Raizama e Diamantino, Grupo Alto Paraguai. 


\section{DISCUSSÃO}

Este item foi desenvolvido a fim de integrar, em ordem cronológica, as análises paleoambientais e estratigráficas em combinação com os dados quimioestratigráficos e geocronológicos existentes, propiciando uma visão geral sobre a história geológica das unidades superiores do segmento E-W da Faixa Paraguai Norte.

\subsection{GRUPO ARARAS: Unidade Superior}

\subsubsection{Formação Pacu}

Uma nova unidade estratigráfica denominada Formação Pacu foi definida na Comunidade Pacu, sudeste de Planalto da Serra (Souza et al., 2012). Esta unidade foi subdividida em Facies Argilosa (base) e Facies Carbonática (topo). Na área estudada, a Facies Argilosa é representada por laminito (Facies $\mathrm{Lm}$ ) e argilito carbonático/silicificado laminado (Facies Fl), situada logo acima dos doloarenitos da Formação Nobres e, é interpretada como de ambiente marinho raso a transicional. O contato brusco entre esses doloarenitos e os laminitos/argilitos da Facies Argilosa sugere uma transgressão marinha (Souza et al., 2012). A Facies Carbonática, representada por calcários cinza escuros com estruturas estromatolíticas colunares (Facies Ls), possui espessura estimada em mais $200 \mathrm{~m}$ na sua área tipo e em torno de $80 \mathrm{~m}$ na área de estudo e são interpretados como representante de plataforma carbonática rasa.

A geoquímica elementar (Tabela 4.1) da Facies Carbonática caracteriza a seção carbonática como litológicamente homogênea, essencialmente calcítica, com baixa influência de terrígenos. Isotopicamente (Tabela 4.1) esta unidade difere-se em relação aos dados isotópicos classicamente descritos para o Grupo Araras (Formações Mirassol d'Oeste, Guia e Nobres). Os dados $\delta^{13} \mathrm{C}$ da Formação Pacu apresentam intervalo de valores positivos entre +6.5\% a +8.9\%o, que são distintos daqueles encontradas na base do Grupo Araras. Valores negativos variando entre $-10.5 \%$ e $-1.7 \%$ ocorrem na capa dolomítica da Formação Mirassol d'Oeste (Nogueira et al., 2003, 2007; Alvarenga et al., 2004, 2008; Font et al., 2006) e entre 5.4\% e +0.1\%o em calcário laminado e calcário argiloso da Formação Guia (Alvarenga et al., 2004, 2008; Nogueira et al., 2007; Figueiredo, 2006), enquanto que valores positivos mais altos de até $+9.6 \%$ foram descritos para a formação Nobres (Alvarenga et al., 2004, 2008). 
Há um padrão de aumento gradativo dos valores $\delta^{13} \mathrm{C}$ encontrados desde a Formação Mirassol d’Oeste até a Formação Nobres e esse padrão difere dos dados positivos constantes encontrados para a Formação Pacu. Os valores de $\delta^{18} \mathrm{O}$ encontrados para a Formação Pacu são muito baixos, entre -7,9\%o e -4,7\%. Na Formação Mirassol d'Oeste os valores variam entre -8,0\% e -1.9\%o (Alvarenga et al., 2008). Variam entre -10,6\% a -5,8\%o na Formação Guia (Alvarenga et al., 2004, 2008; Nogueira et al., 2007a). Para a Formação Nobres variam entre -6,7\%o a -0,1 \%o (Pinho et al., 2003; Alvarenga et al., 2004; Figueiredo, 2006; Nogueira et al., 2007a).

Os valores de ${ }^{87} \mathrm{Sr} /{ }^{86} \mathrm{Sr}$ dos calcários da Formação Pacu são semelhantes, com variações apenas na última casa decimal (0.70870-0.70877 - Tabela 4.1). Estes valores, comparados aos obtidos para a Formação Guia (0.70763-0.70780 - Alvarenga et al., 2004, 2008, 2010), exibem razões ligeiramente mais altas, indicando deposição em intervalos de idade mais jovens do Ediacarano, pós Glaciação Gaskiers. As razões ${ }^{87} \mathrm{Sr} /{ }^{86} \mathrm{Sr}$ obtidas para a Formação Pacu quando lançadas na curva de variação isotópica de ${ }^{87} \mathrm{Sr} /{ }^{86} \mathrm{Sr}$ da água do mar (Halverson et al., 2007, 2010 - Figura 6.1) também indicam idade de sedimentação pós Glaciação Gaskiers. Considerando o recobrimento desses calcários pelos diamictitos considerados correlatos à Glaciação Gaskiers (Formação Serra Azul, Grupo Alto Paraguai), globalmente datada em 582 Ma (Bowring et al., 2003; Knoll et al., 2004), seria de se esperar uma idade superior a 582 Ma para a Formação Pacu.

Dados de ${ }^{87} \mathrm{Sr} /{ }^{86} \mathrm{Sr}$ entre 0.7084 e 0.7085 descritos para os calcários da Formação Tamengo, Grupo Corumbá, Faixa Paraguai Sul (Boggiani, 1998; Boggiani et al., 2010; Alvarenga et al., 2011), local com ocorrência de assembleia de macrofósseis, característicos da transição final do Neoproterozóico-Cambriano, dominada por Corumbella werneri e Cloudina lucianoi, sugerem deposição entre 570 - 545 Ma (Boggiani et al., 2010). Valores de ${ }^{87} \mathrm{Sr} /{ }^{86} \mathrm{Sr}$ muito próximos aos da Formação Tamengo, entre 0.7086 e 0.7088 , também foram encontrados para a Formação Serra Azul (Figueiredo, 2006, 2010; Alvarenga et al., 2010). Essas informações, comparadas às razões encontradas para a Formação Pacu, revelam certa constância nos valores de ${ }^{87} \mathrm{Sr} /{ }^{86} \mathrm{Sr}$ e registram a necessidade de mais investigações, a fim de verificar se a curva global de valores de ${ }^{87} \mathrm{Sr} /{ }^{86} \mathrm{Sr}$ apresenta valores praticamente constantes entre 582 e 543 Ma. Os dados produzidos poderão ajudar a melhorar a resolução desta curva global (Halverson et al., 2007, 2010), sendo preciso aprimorar a calibração geocronológica das compilações existentes para estabelecer uma curva global com bom grau de confiabilidade. 


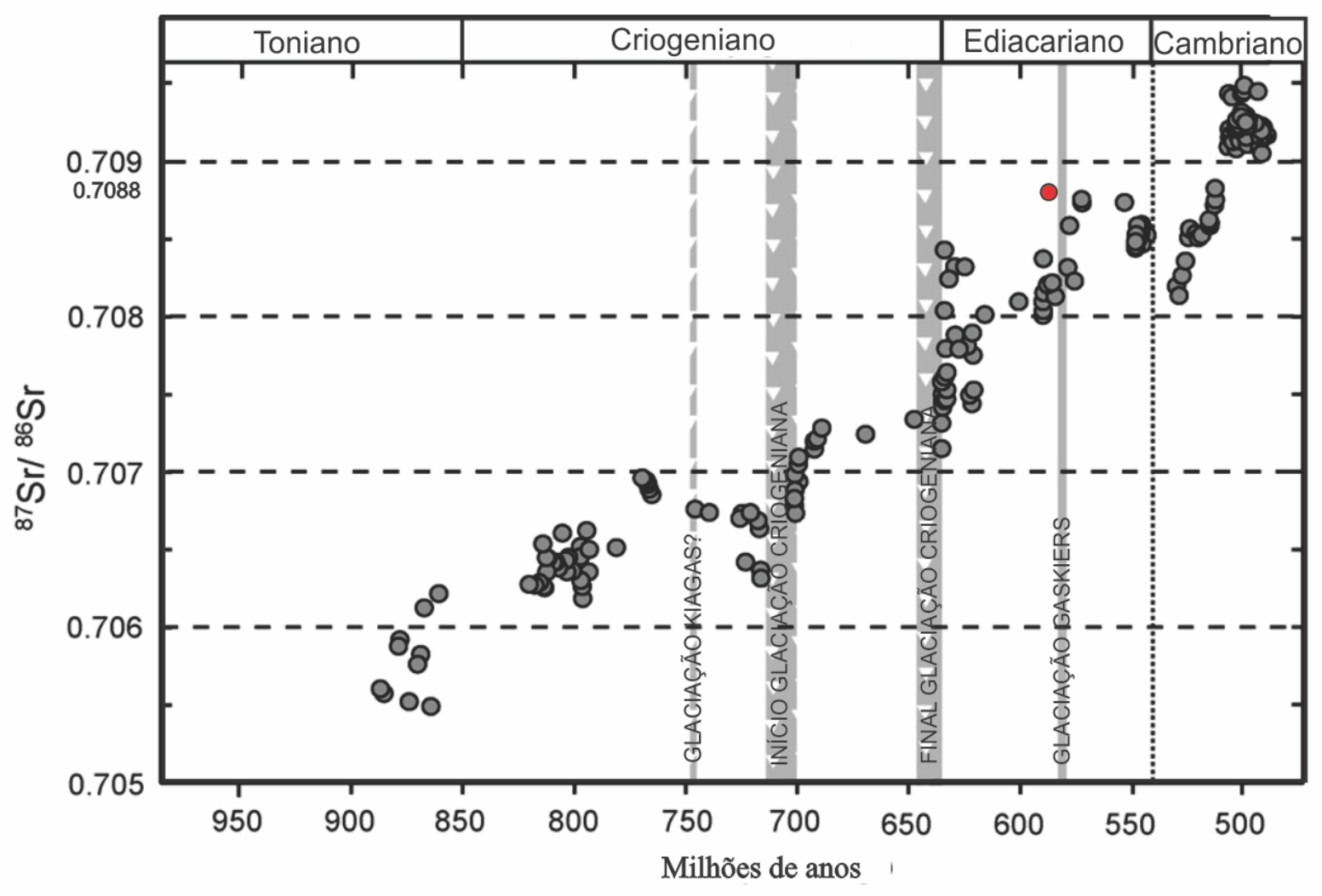

- Formação Pacu

Figura 6.1: Curva marinha de razões isotópicas de Sr para o Neoproterozóico e Cambriano (Adaptado de Halverson et al., 2007, 2010). Os calcários da Formação Pacu, estão estratigráficamente abaixo da Formação Serra Azul, e a plotagem das razões ${ }^{87} \mathrm{Sr} /{ }^{86} \mathrm{Sr}$ dessa formação levou em consideração que os diamictitos da Formação Serra Azul sejam correlatos à Glaciação Gaskiers.

Idades Pb-Pb obtidas nos carbonatos de capa da Formação Mirassol d’Oeste e, calcário laminado e calcário argiloso da Formação Guia apresentam idades de 627士32 Ma (Babinski et al., 2006) e 580 \pm 77 Ma (Figueiredo, 2010), respectivamente. A idade Pb-Pb de 633ะ25 Ma dos carbonatos de capa da Formação Mirassol d’Oeste, interpretada como idade máxima de deposição, permite uma boa correlação com a Glaciação Marinoana (635 Ma Hoffman et al., 2004; Condon et al., 2005) e, o alto erro analítico obtido para as razões isotópicas de $\mathrm{Pb}$ na Formação Guia restringe sua interpretação geocronológica, podendo esta idade representar tanto a idade de sedimentação, quanto a idade de deformação (Figueiredo, 2010). As idades Sm-Nd e idade modelo $T_{\mathrm{DM}}$ das formações Mirassol d'Oeste e Guia são similares, com valores de $\varepsilon_{\mathrm{Nd}}$ entre -8.2 a -11 e $\mathrm{T}_{\mathrm{DM}}$ em torno de 2 Ga (Dantas et al., 2009). Os doloarenitos da Formação Nobres apresentam valores de $\varepsilon_{\mathrm{Nd}}$ que variam entre -11.3 e 11.4 e idade modelo $\mathrm{T}_{\mathrm{DM}}$ de $2 \mathrm{Ga}$ (Dantas et al., 2009). Estas idades modelo $\mathrm{T}_{\mathrm{DM}}$ sugerem que rochas da Província Maroni-Itacaúnas (2.25 - 2.05 Ga), Cráton Amazônico (Tassinari \& 
Macambira, 1999; 2004), sejam a fonte dos sedimentos dos depósitos do Grupo Araras (Dantas et al., 2009 - Figura 6.2).

\subsection{GRUPO ALTO PARAGUAI}

\subsubsection{Formação Serra Azul}

A Formação Serra Azul foi primeiramente descrita próximo ao distrito de Marzagão, Mato Grosso (Figueiredo et al., 2004). Inserida na base do Grupo Alto Paraguai esta formação foi subdividida em cinco unidades informais, com espessura miníma entre 250 e 300 m (Figueiredo et al., 2004, 2008, 2011; Alvarenga et al., 2007). Na região de Planalto da Serra a Formação Serra Azul chega a alcançar 470 m de espessura e sua divisão interna (Unidade A e B) segue mesma divisão informal proposta por Alvarenga et al. (2007). A 'Unidade A' corresponde à porção basal desta formação e é preenchida por diamictitos maciços (Facies Dm), compostos por seixos/clastos de tamanho e composição variada (i.e. arenito, carbonato, granito) mergulhados em matriz silto-argilosa, com grandes blocos de quartzito e granito. Estas características sugerem que essa unidade pode ter sido originada durante processo de rain-out (chuva de detritos) a partir de "pluma” de sedimentos carreados por geleira sendo relacionada a ambiente glácio-marinho raso a transicional (Figueiredo et al., 2004, 2008). A ‘Unidade B’ corresponde à porção intermediária e superior da Formação Serra Azul e é formada por siltitos que gradam para intercalações rítmicas de pelito/arenito com superfícies onduladas/retrabalhadas por onda ao topo. Nesta unidade, intercalados aos ritmitos, ocorre alguns horizontes de arenito com estratificação cruzada tabular (Facies Sp) e conglomerados (Facies $\mathrm{Gm}$ ), estes quando ferruginosos têm valores anômalos positivos de Raio Gama, relacionados a grande quantidade de zircônio (3833 ppm). O contato brusco desta unidade com a 'Unidade A' sugere a interrupção da influência glacial, evidenciando uma passagem para ambiente marinho profundo esporadicamente influenciado por atividades de ondas.

O contato basal da Formação Serra Azul é brusco, tanto com a Formação Nobres (Grupo Araras) em sua seção tipo (Figueiredo et al., 2004, 2008, 2011; Alvarenga et al., 2007), quanto com a Formação Pacu na região de Planalto da Serra, sugerindo que houve um forte processo erosivo gerado pela deglaciação que suprimiu a Formação Pacu na área da seção tipo da Formação Serra Azul. A ausência da Formação Pacu nessa região pode também ser explicada pela sua não deposição ou variação lateral da espessura. O contato superior da Formação Serra Azul com a Formação Raizama foi descrito como gradacional em sua seção 
tipo (Figueiredo et al., 2004, 2008, 2011; Alvarenga et al., 2007), entretanto, na "Seção 1" (Figura 3.3) foi identificado contato brusco entre os ritmitos (Unidade B, Formação Serra Azul) e arenito grosso que marca o do primeiro banco arenoso que define a base dos grandes ciclos deposicionais que caracterizam a Formação Raizama.

Idades $\mathrm{Pb}-\mathrm{Pb}$ obtidas em lentes calcárias atribuídas a porção superior da Formação Serra Azul estabeleceu idade miníma de deposição de 570 Ma e máxima de 622 Ma (Figueiredo, 2010). Idades K-Ar obtidas em clastos vulcânicos recuperados nos diamictitos revelaram idades máximas de deposição em cerca de 730 e 1200 Ma (Figueiredo, 2010). Idade Ar-Ar obtida em muscovita detrítica forneceu idade máxima de deposição em torno de 640 Ma (McGee et al., 2015a). Idade U-Pb obtida em zircões detríticos forneceu idade máxima de deposição em 646 Ma (McGee et al., 2015b). Tais idades Ar-Ar e U-Pb levaram a interpretar que a Formação Serra Azul seria correlata tanto da Glaciação Marinoana quanto Gaskiers (McGee et al., 2015b), entretanto, zircões de 619 e 593 Ma encontrados neste trabalho sugerem deposição da Formação Serra Azul pós Glaciação Marinoana (635 Ma Hoffman et al., 2004; Condon et al., 2005). Dessa forma, com base nestes dados e outras evidências globais disponíveis é possível correlacionar a Formação Serra Azul com outros depósitos glaciais Ediacaranos, incluindo a Formação Gaskiers de Newfoundland-Canadá, dando mais robustez à hipótese da ocorrência de outro evento glacial na América do Sul, correlato da Glaciação Gaskiers (Figueiredo et al., 2004, 2008, 2011; Alvarenga et al., 2007; McGee et al., 2015a,b). Dados de Sm-Nd apresentam valores de $\varepsilon_{\mathrm{Nd}}$ entre -6.7 a -9.5 e idades modelo $\mathrm{T}_{\mathrm{DM}}$ de 2.0 e $1.6 \mathrm{Ga}$ (Figueiredo, 2010). Estas idades Sm-Nd $\mathrm{T}_{\mathrm{DM}}$ associadas aos outros dados radiométricos apresentados sugerem que as rochas das Províncias MaroniItacaiúnas (2.25 - 2.05 Ga), Ventuari-Tapajós (1.98 - 1.81 Ga) e Rio Negro-Juruena (1.78 1.55 Ga), Cráton Amazônico (Tasinari \& Macambira, 1999, 2004), podem ser as principais fontes de sedimentos para os depósitos da Formação Serra Azul. Entretanto, idades menores que 900 Ma, como por exemplo, a idade de 730 Ma obtida em clastos vulcânicos, não foram identificadas no Cráton Amazônico (Figueiredo, 2010), sugerindo que nessa época já havia uma parte de sedimentos provenientes de leste-sudeste, região do Maciço de Goiás e Faixa Brasília, onde são frequentes essas idades.

\subsubsection{Formação Raizama}

A Formação Raizama, estimada em 1600 m de espessura, foi definida na base do Grupo Alto Paraguai (Almeida, 1964a). Entretanto, os depósitos da Formação Serra Azul, 
devido ao seu posicionamento estratigráfico e características dos ambientes deposicionais, foram recentemente incluídos na base deste grupo (Figueiredo et al., 2008; Souza et al., 2012). Na região de Planalto da Serra, a Formação Raizama alcança cerca de 1140 m de espessura e foi individualizada em quatro grandes ciclos (Ciclos A-D - Figura 3.2) com base na proporção/ocorrência de domínios de bancos arenosos e de pelitos. Na região de "Sete Placas” (Figura 3.21 e 3.22) os afloramentos dessa formação são descontínuos, dificultando a sua individualização interna.

A oeste da Faixa Paraguai Norte, região de Nobres-MT, a Formação Raizama está disposta diretamente acima de uma superfície erosiva que marca o topo da Formação Nobres (Grupo Araras - Figueiredo, 2010). Isto indica que os estratos da Formação Pacu (Grupo Araras) e Formação Serra Azul foram removidos ou não foram depositados nesta região. O contato superior da Formação Raizama com a Formação Sepotuba foi descrito como gradacional (Almeida, 1984, Bandeira et al., 2012). Entretanto, na região de Planalto da Serra e na Região de "Sete Placas" este contato foi descrito como brusco. Na região de Planalto da Serra esse contato foi definido em função de uma mudança topográfica entre os arenitos grossos (Formação Raizama) que sustentam as maiores elevações da região e uma região aplainada sem afloramentos (Formação Diamantino). Em contrapartida, na região de "Sete Placas” os arenitos da Formação Raizama passam bruscamente para uma unidade de pelitos arroxeados atribuídos a Facies Sepotuba, intercalados com ocasionais arenitos arcoseanos finos da Formação Diamantino.

Os depósitos da Formação Raizama, compostos por intercalações rítmicas de pelitos e arenitos maciços e/ou com estratificação cruzada tabular/laminação plano-paralela retrabalhadas/truncadas por estrutura de onda de grande amplitude métrica (Figura 3.23-A) e estratificação cruzada hummocky (Figura 3.23-C), arranjados em grandes ciclos de raseamento ascendente (shallowing-upward) com tendência granocrescente ascendente (coarsening-upward), representam ambiente de shoreface inferior dominado por processos de onda e tempestade. Esta interpretação sugere que os eventos de tempestades que atuavam no shoreline eram episódicos, acomodando por decantação sedimentos finos em suspensão em períodos de tempo bom.

Idades Ar-Ar obtidas em muscovitas detríticas retiradas de arenito estabeleceu idade máxima de deposição em 924 Ma (McGee et al., 2015a). Idades U-Pb obtidas em zircões detríticos forneceram idades de máximo deposicional em 1002 Ma (Santos, 2014), 635 Ма (McGee et al., 2015b), 888 Ma e 967 Ma (este trabalho). Estes valores encontrados estão 
distantes da idade de deposição, considerando que esta formação é mais jovem que a Formação Serra Azul, tendo sido depositada em um intervalo de idade entre 622 Ma e 541 Ma (Figueiredo, 2010; Bandeira et al., 2012; Romero et al., 2013). A ocorrência de traços fósseis característicos do limite Neoproterozóico-Cambriano Inferior, pertencentes ao icnogênero Skólitos corroboram com a afirmação de que o limite mínimo de idade para a Formação Raizama estaria na transição Neoproterozóico-Cambriano Inferior (Santos, 2014). Dessa forma, tais idades indicam que os sedimentos da Formação Raizama seriam provenientes em parte do Cráton Amazônico e região do Maciço de Goiás e Faixa Brasília (Figura 6.2).

\subsubsection{Formação Diamantino}

A existência de uma perfeita continuidade entre os folhelhos da Formação Sepotuba e os arcóseos da Formação Diamantino (Scorza, 1960; Almeida, 1964a-b), associados à semelhança litológica de seus sedimentos pelíticos e o não reconhecimento de feições geológicas que definem a Formação Sepotuba, levaram a diversos autores considerarem ao topo do Grupo Alto Paraguai apenas a Formação Diamantino (Vieira, 1964; Figueiredo \& Olivatti, 1974; Ribeiro Filho et al.,1975; Alvarenga \& Saes, 1992; Souza et al., 2012). Desse modo a espessura dada para a Formação Sepotuba em torno de 900 m e para a Formação Diamantino estimada em 600 m (Almeida, 1964) é duvidosa, provavelmente devido à dificuldade em distinguir estas formações usando apenas critérios litológicos.

Na região de Planalto da Serra, os siltitos laminados da Formação Dimantino recobrem bruscamente a Formação Raizama e abrange área arrasada de relevo pouco acentuado. Na região de "Sete Placas”, na base da Formação Diamantino, pelitos arroxeados micáceos intercalados a arenitos muito finos com ocorrência de marcas de ondas simétricas alcançam cerca de $200 \mathrm{~m}$ de espessura e passam em direção ao topo para siltitos/pelitos intercalados a arcóseos finos com mais de 5000 m de espessura (Figura 3.21). Convencionouse nomear os pelitos arroxeados micáceos de Formação Sepotuba (Almeida, 1964a-b), entretanto, neste trabalho foram incluídos à base da Formação Diamantino como Facies Sepotuba. O limite superior da Formação Diamantino é marcado por contato brusco/erosivo com os depósitos Cretáceos do Grupo Parecis.

Na área de estudo, os afloramentos dessa formação são descontínuos, impedindo uma interpretação paleoambiental confiável. Todavia, há na literatura interpretações diversas, tais como: ambiente continental de clima quente (Figueiredo \& Olivatti, 1974), marinho sublitorâneo (Barros et al., 1982), basin plan em contexto de lago tectônico ou bacia de 
antefossa (Silva Jr \& Nogueira, 2010) e turbiditos distais sucedidos por depósitos lacustres/deltaicos em bacia foreland (Bandeira et al., 2012). Esta variedade de interpretações ressalta a complexidade desses depósitos e mostra a importância de maiores investigações.

Idades Rb-Sr obtidas nas rochas da porção basal e superior forneceram idades de 569 Ma e 660 Ma, respectivamente (Cordani et al., 1978). Idade Rb-Sr obtida em folhelhos da porção basal forneceu idade de $568 \mathrm{Ma}$, interpretada como idade diagenética (Bonhomme et al., 1982; Cordani et al., 1985). Idades Ar-Ar obtidas em muscovitas detríticas retiradas de arenito estabeleceu idade máxima de deposição em 544 Ma (McGee et al., 2015a). Idades U$\mathrm{Pb}$ obtidas em zircões detríticos forneceram idades máximas de deposição em $541 \mathrm{Ma}$ (Bandeira et al., 2012), 560 Ma (McGee et al., 2015b), 567 Ma e 694 Ma (este trabalho). Estes valores encontrados sugerem que a deposição no Grupo Alto Paraguai pode ter se estendido até o Cambriano Inferior. Dados de Sm-Nd apresentam valores de $\varepsilon_{\mathrm{Nd}}$ entre -4.9 a 9.7 e idades modelo $\mathrm{T}_{\mathrm{DM}}$ de 1.5 a $1.8 \mathrm{Ga}$ (Dantas et al., 2009). Estas idades Sm-Nd $\mathrm{T}_{\mathrm{DM}}$ associadas aos outros dados radiométricos indicam uma mudança de área fonte, sugerindo que os sedimentos antes provenientes de norte-noroeste (Cráton Amazônico), teriam derivado de uma fonte mais jovem provavelmente a leste-sudeste nas rochas Neoproterozóicas do Maciço de Goiás e Faixa Brasília (Coelho et al., 2008; Giustina, 2010; Nilson et al., 1997; Pimentel et al., 1991, 1998, 2000; Pimentel \& Fuck, 1992, 1994), inferindo inversão tectônica da bacia (Dantas et al., 2009; Bandeira et al., 2012; McGee et al., 2015a,b).

\subsection{MODELO TECTÔNICO E CONTEXTO EVOLUTIVO DA FAIXA PARAGUAI NORTE}

A interpretação das prováveis áreas fontes para os depósitos da Faixa Paraguai tem implicação direta na sua história evolutiva, pois a Faixa Paraguai considerada como representante do evento Brasiliano (940-630 Ma - Cordani et al., 2009), segundo evidenciado nos dados aqui descritos pode ser consideravelmente mais jovem que outros orógenos envolvidos na sutura do Gondwana (i.e. Trindade et al., 2006; McGee et al., 2015a,b).

O modelo proposto para a deposição das unidades basais da Faixa Paraguai Norte (Formação Puga, grupos Cuiabá e Araras) é de um ambiente de margem passiva (Alvarenga \& Trompette, 1992), com sedimentos provenientes principalmente do Cráton Amazônico. Este período de deposição foi seguido por um período glacial responsável pela deposição da Formação Serra Azul (Figueiredo et al., 2004, 2008, 2011; Alvarenga et al., 2007; McGee et al., 2015a,b), já com alguma contribuição sedimentar provinda de leste-sudeste (Maciço de 
Goiás e Faixa Brasília). Em seguida, a deposição da Formação Raizama foi controlada tectônicamente devido ao início do soerguimento da bacia, registrando sedimentação derivada tanto de norte-noroeste, Cráton Amazônico, como de leste-sudeste, Maciço de Goiás e da Faixa Brasília (Dantas et al., 2009; Bandeira et al., 2012; McGee et al., 2015a,b). A atividade tectônica e deformação flexural da litosfera associada à inversão da bacia gerou uma bacia foreland que foi preenchida pelos depósitos da Formação Diamantino, com sedimentos essencialmente provenientes de leste-sudeste da região do Maciço de Goiás e Faixa Brasília (Dantas et al., 2009; Bandeira et al., 2012; McGee et al., 2015a,b). Estes depósitos registraram a erosão do órogeno em cerca de 540-530 Ma, estando de acordo com a idade da intrusão de granitos pós-orôgenicos em cerca de 518 Ma (Ferreira, 2009; Godoy et al., 2010; McGee et al., 2012). 


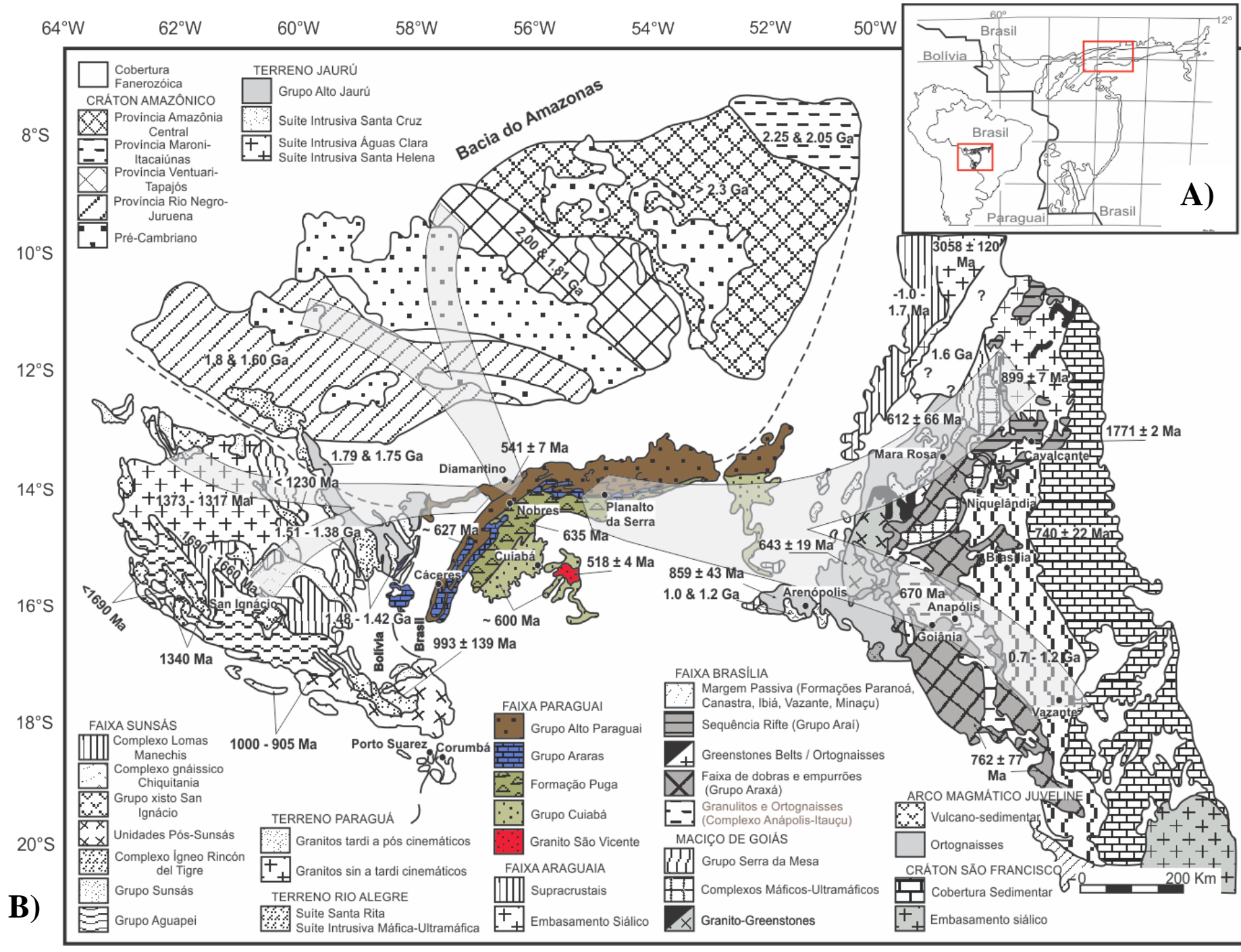

S. C. R. Souza
Figura 6.2: A) Mapa com a localização da Faixa Paraguai dentro do contexto da Placa Sul-Americana e área de estudo área em vermelho - adaptado a partir de Figueiredo et al., 2008). B) Мара simplificado do SW do Cráton Amazônico, Faixas Paraguai e Brasília indicando as potenciais áreas fontes para os depósitos superiores da Faixa Paraguai Norte (Grupo Alto Paraguai). Os sedimentos das Formações Serra Azul e Raizama são provenientes principalmente de NNW e para a Formação Diamantino são provenientes principalmente de ESE, como indicado pelas faixas cinzas. Cráton Amazônico (Tassinari \& Macambira, 1999, 2004). Cráton São Francisco cobertura sedimentar (Babinski \& Kaufman, 2003). Faixa Brasília - margem passiva (Coelho et al., 2008); Sequência Rift, Greenstons Belts, Faixa de dobras e empurrões (Pimentel et al., 1991; 1998; 2000); Complexo Anápolis-Itaçu (Giustina, 2010). Maciço de Goiás Grupo Serra da Mesa (Pimentel et al., 1991; Pimentel \& Fuck, 1992); Complexo máfico-ultramáfico (Nilson et al., 1997); Granito-Greenstones (Pimentel \& Fuck, 1994; Nilson et al., 1997). Arco magmático Juvenile - Vulcano-sedimentar (Viana et al., 1995); Ortognaisses (Pimentel et al., 1997). Faixa Araguaia Supracrustais (Moura et al., 2008); Embasamento siálico (Pimentel et al., 2000). Faixa Paraguai - Grupo Cuiabá, Formação Puga, Grupo Araras, Grupo Alto Paraguai (Cordani et al., 1978, 1985; Bonhomme et al., 1982; Nogueira, 2003; Nogueira et al., 2003; Babinski et al., 2006, 2007; Figueiredo, 2006; Dantas et al., 2009; Bandeira et al., 2012; McGee et al., 2015a,b; este trabalho).

$I G-U n B$ 


\section{CONCLUSÕES}

O estudo do limite Neoproterozóico-Cambriano Inferior do segmento E-W da Faixa Paraguai Norte, região de Planalto da Serra e “Sete Placas”, Mato Grosso, revelaram novas informações sob o ponto de vista estratigráfico, isotópico, geocronológico e tectônico. As principais conclusões foram:

- A unidade superior do Grupo Araras, representada pela Formação Pacu, exibe valores $\delta^{13} \mathrm{C}(+6.5 \%$ a $+8.9 \%), \delta^{18} \mathrm{O}\left(-7,9 \%\right.$ e $-4,7 \%$ ) e razões ${ }^{87} \mathrm{Sr} /{ }^{86} \mathrm{Sr}(0.7087-0.7088)$ distintos daqueles encontrados no restante do grupo (formações Mirassol d'Oeste, Guia e Nobres).

- Os altos valores positivos $\delta^{13} \mathrm{C}$ encontrados na Formação Pacu diferem daqueles obtidos para as formações basais do Grupo Araras, com valores negativos.

- As razões ${ }^{87} \mathrm{Sr} /{ }^{86} \mathrm{Sr}$ quando comparados aos encontrados para as demais formações do Grupo Araras revelaram grande diferença entre esses intervalos estratigráficos, mostrando a existência de águas com distintas razões isotópicas de Sr.

- A atual curva global marinha de razões isotópicas de Sr, coloca os valores encontrados como compatíveis com o final do Ediacarano, mais jovem que a Glaciação Gaskiers, entretanto esses calcários estão imediatamente abaixo da Formação Serra Azul, unidade considerada correlata dessa glaciação, sugerindo a necessidade de reavaliação e ampliação do banco de dados para uma melhor aferição geocronológica desta curva global.

- O contato basal da Formação Serra Azul, com o topo da Formação Pacu é discordante e pode ser bem marcado em campo. Enquanto que o seu contato superior com a base da Formação Raizama, descrito como gradacional para a região de Marzagão, se apresenta claramente como tipo brusco na região de Planalto da Serra.

- A ausência das formações Pacu e Serra Azul na região de Rosário d’Oeste-Nobres e, a ausência da Formação Pacu na região de Marzagão, conferem evidências de descontinuidades estratigráficas entre as unidades superiores da Faixa Paraguai Norte.

- Na base da Formação Raizama foi definida uma discordância. Evidenciada pelo contato dessa formação com os doloarenitos da Formação Nobres na região de Rosário 
d’Oeste-Nobres, enquanto que em Marzagão-Planalto da Serra esta formação está diretamente sobre a Formação Serra Azul.

- A Formação Raizama, na região de Planalto da Serra, possui boa continuidade estratigráfica, o que permitiu na "Seção 1" a individualização de quatro grandes ciclos (Ciclos A-D) com base na proporção/ocorrência de domínios de bancos arenosos e de pelitos.

- Idades U-Pb, em zircões detríticos da Formação Diamantino, confirmam mudança significativa de área fonte, sugerindo que a fonte principal desses sedimentos derivaram de leste-sudeste, regiões do Maciço de Goiás e da Faixa Brasília, corroborando com o modelo de inversão tectônica da bacia com o estabelecimento de bacia foreland. 


\section{REFERÊNCIAS}

ALMEIDA, F. F. M. Geologia do centro-oeste mato-grossense. Rio de Janeiro, DNPM, Boletim da Divisão de Geologia e Mineralogia 215, p. 1-54. 1964a.

ALMEIDA, F. F. M. Glaciação eocambriana em Mato Grosso. Notas Prel. e Est. Rio de Janeiro, DNPM, Boletim da Divisão de Geologia e Mineralogia Rio de Janeiro 117, p. 1-11. 1964b.

ALMEIDA, F. F. M. Geologia da Serra da Bodoquena (Mato Grosso). Rio de Janeiro, DNPM, Boletim da Divisão de Geologia e Mineralogia 219, p. 1-96. 1965 a.

ALMEIDA, F. F. M. Geossiclíneo Paraguaio. $1^{\text {a }}$ Semana de Debates Geológicos, Centro Acad. Est. Geol. Porto Alegre, p. 88-109. 1965b.

ALMEIDA, F. F. M. Sistema tectônico marginal do cráton do Guaporé. In: CONGR. BRÁS. GEOL., 28. Porto Alegre, 1974. Anais... Porto Alegre, SBG. v. 4, p. 11-17.

ALMEIDA, F. F. M. \& MANTOVANI, M. S. M. Geologia e geocronologia do Granito São Vicente, Mato Grosso. Anais da Academia Brasileira de Ciências, 47: 451-458. 1975.

ALMEIDA, F. F. M. Província Tocantins, setor Sudoeste. In: ALMEIDA, F. F. M. \& HASUI, Y. (coord.). O Pré-Cambriano do Brasil. São Paulo, Edgard Blücher, 1984. p. 265-281.

ALVARENGA, C. J. S. Dobramentos da Faixa Paraguai na borda sudeste do Cráton Amazônico. In: CONGR. BRÁS. GEOL., 33. Rio de Janeiro, 1984. Anais... Rio de Janeiro, 1984. SBG. v. 7, p. 3258-3271.

ALVARENGA, C. J . S. 1985. Evidências de fácies turbidíticas grosseiras no Grupo Cuiabá, MT. In: SIMP. GEOL. CENTRO-OESTE, 2. Goiânia, 1985. Atas... Goiânia, SBG. p. 256-266.

ALVARENGA, C. J. S. Turbiditos e a glaciação do final do Proterozóico superior no Cinturão Paraguai, Mato Grosso. Revista Brasileira de Geociências, v. 18, p. 323-327, 1988.

ALVARENGA, C. J. S. 1990. Phénomenes sédúnentaires, structuraux et circulation de fluides développés à la rransition chane-craton: Example de la Quote Paraguai d'age Proterozoque Supérieur, Mato Grosso, Brésil. Marseille. 177 p. (These Doc., Sei. Univ. d'Aix Marseille HI). 
ALVARENGA, C. J. S. \& SAES, G. S. 1992. Estratigrafia e sedimentologia do Proterozóico Médio e Superior da região sudeste do Cráton Amazônico. Rev. Bras. Geoc., 22 (4): 493-499.

ALVARENGA, C. J. S. \& TROMPETTE, R. 1988. Upper Proterozoic glacial environment ofthe border of Amazonian Craton and its evolution towards the adjacent Paraguay Belt (Mato Grosso, Brazil). In: Meeting Earth's Glacial Record-Proj. 260. Cuiabá 1988. Abstracts and Field Trip... Cuiabá, IGCP-UNESCO/UFMT. p. 31-44.

ALVARENGA, C. J. S. \& TROMPETTE, R. 1992. Glacially influenced sedimentation in the Late Proterozoic of Paraguai Belt (Mato Grosso, Brasil). Palaegeogr. Paleoclimatol. Paleoecol., 92: 85-105.

ALVARENGA, C. J. S. \& TROMPETTE, R., 1993. Evolução tectônica Brasiliana da Faixa Paraguai: a estruturação da Região de Cuiabá. Rev. Bras. Geociênc. 23, 18-30.

ALVARENGA, C. J. S.; MOURA, C. A. V; GORAYEB, P. S. S.; ABREU, F. A. M., 2000. Paraguay and Araguaia belts. In: U.G. CORDANI, E. J.; MILANI, A.; THOMAZ FILHO \& CAMPOS, D. A. Tectonic Evolution of South America, p. 183-193, Rio de Janeiro, 31st International Geological Congress.

ALVARENGA, C. J. S.; SANTOS, R. V. \& DANTAS, E. L. 2004. C-O-Sr isotopic stratigraphy of cap carbonates overlying Marinoan-age glacial diamictites in the Paraguay Belt, Brazil. Precambrian Research, 131, 1-21.

ALVARENGA, C. J. S.; FIGUEIREDO, M. F.; BABINSKI, M. \& PINHO, F. E. C. 2007. Glacial diamictites of Serra Azul Formation (Ediacaran, Paraguay Belt): evidence of the Gaskiers glacial event in Brazil. Journal of South American Earth Science, 23, 236-241.

ALVARENGA, C. J. S.; DARDENNE, M. A. et al. 2008. Isotope stratigraphy of Neoproterozoic cap carbonate in the Araras Group, Brazil. Gondwana Research, 13, 469-479.

ALVARENGA, C. J. S.; BOGGIANI, P. C.; BABINSKI, M.; DARDENE, M. A.; FIGUEIREDO, M. F. F.; SANTOS, R. V.; DANTAS, E. The Amazonian Palaeocontinent. In: K. C. CONDIE, editor: Developments in Precambrian Geology, Vol 16, Neoproterozoic-Cambrian Tectonics, Global Change and Evolution: Focus on South Western Gondwana, GAUCHER C.; SIAL, A. N.; HALVERSON, G. P. and FRIMMEL, H. E. The Netherlands: Elsevier, 2010, pp. 15 - 28. ISBN: 978-0-44453249-7.

ALVARENGA, C. J. S.; BOGGIANI, P. C.; BABINSKI, M.; DARDENE, M. A.; FIGUEIREDO, M. F. F.; DANTAS, E.; UHLEIN, A.; SANTOS, R. V.; SIAL, A. N. \& TROMPETTE, R. Chapter 45 Glacially influenced sedimentation of the Puga Formatin, Cuiabá Group and Jacadigo Group, and associated carbonates of the Araras and 
Corumbá groups, Paraguay Belt, Brazil. Geological Society, London, Memoirs. 2011; v. 36; p. 487-497.

ARAÚJO, H. J. T.; SANTOS NETO, A.; TRINDADE, C. A. H.; PINTO, J. C. A.; MONTALVÃO, R. M. G.; DOURADO, T. D. C.; PALMEIRA, R. C. B.; TASSINARI, C. C. G. 1982. Folha SF. 21 Campo Grande, Geologia. In: RADAMBRASIL. Rio de Janeiro, MME. p. 23-124. (Levantamento de Recursos Naturais 28).

BABINSKI, M.; KAUFMAN, A. J. 2003. First direct dating of a Neoproterozoic post-glacial cap carbonate. IVth SouthAmerican Symposiumon Isotope Geology, short papers, pp. 321-323.

BABINSKI, M.; TRINDADE, R. I. F.; ALVARENGA, J. C. S.; BOGGIANI, P. C.; LIU, D.; SANTOS, R. V. 2006. Geocronological constrains on the neoproterozoic glaciations in Brazil. Snowball Earth Conference, Ascona, Switzerland.

BABINSKI, M.; VIEIRA, L. C.; TRINDADE, R. I. F. 2007. Direct dating of the Sete Lagoas cap carbonate (Bambuí Group, Brazil) and implications for the Neoproterozoic glacial events. Terra Nova, 19:401-406.

BANDEIRA, J. 2006. Fácies e Estratigrafia da Formação Sepotuba: Registro da última incursão marinha na transição Neoproterozóico-Cambriano da Faixa Paraguai Norte, Mato Grosso. Dissertação (Mestrado). Manaus: UFAM.

BANDEIRA, J. 2011. Fácies e Estratigrafia do Grupo Alto Paraguai: NeoproterozóicoCambriano da Faixa Paraguai Norte, Mato Grosso. Tese (Doutorado). Belém: CG/UFPA.

BANDEIRA, J.; NOGUEIRA, A. C. R.; PETRI, S. ; RICCOMINI, C.; TRINDADE, R. I. F.; SIAL, A. N.; RIDALGO, R. L. Depósitos litorâneos neoproterozóicos do Grupo Alto Paraguai no sudoeste do Cráton Amazônico, região de Mirassol d’Oeste, Mato Grosso. Revista Brasileira de Geociências, v. 37, p. 595-606, 2007.

BANDEIRA, J.; MCGEE, B.; NOGUEIRA, A. C. R.; COLLINS, A. S.; TRINDADE, R. 2012. Sedimentological and provenance response to Cambrian closure of the Clymene ocean: The upper Alto Paraguai Group, Paraguay Belt, Brazil. Gondwana Research 21: 323-340.

BARROS, A. M.; SILVA, R. H.; CARDOSO, O. R. F. A.; FREIRE, A. F.; SOUZA, JR, J. J.; RIVETTI, M.; LUZ, D. S.; PALMEIRA, R. C. B.; TASSINARI, C. C. G. 1982. Geologia da Folha SD. 21-Cuiabá. Rio de Janeiro, Projeto Radambrasil, DNPM, Levantamento de Recursos Naturais, 26, p. 25-192. 
BOGGIANI, P. C. Análise estratigráfica da bacia Corumbá (neoproterozóico)-Mato Grosso do Sul. São Paulo, 1998. 181 f. Tese (Doutorado em Geologia Sedimentar)Universidade de São Paulo, Instituto de Geociências, São Paulo, 1997.

BOGGIANI, P. C.; FERREIRA, V. P. et al. 2003. The cap carbonate of the Puga hill (central South America) in the context of the Post-Varanger glaciation. In: South American Symposium on Isotope Geology, 4, Salvador, Brazil, Short Papers, 324-327.

BOGGIANI, P. C.; GAUCHER, C.; SIAL, A. N.; BABINSKI, M.; SIMON, C. M.; RICCOMINI, C.; FERREIRA, V. P.; FAIRCHILD, T. R. 2010. Chemostratigraphy of the Tamengo Formation (Corumba Group, Brazil): A contribuition to the calibration of the Ediacaran carbon-isotope curve Precambrian Res., doi: 10.1016/j.precramres.2010.06.003.

BONHOMME, M. G.; CORDANI, U. G.; KAWASHITA, K.; MACEDO, M. H. F.; THOMAS FILHO, A. 1982. Radiochronological age and correlation of Proterozoic sediments in Brazil. Precamb. Res., 18: 103-118.

BOWRING, S.; MYROW, P.; LANDING, E.; RAMEZANI, J.; GROTZINGER, J. 2003. Geochronological constraints on terminal Neoproterozoic events and the rise of metazoans. Journal of Geophysical Research Abstracts 5, 13219.

BÜHN, B.; PIMENTEL, M. M.; MATTEINI, M.; DANTAS, E. L. 2009. High spatial resolution analysis of $\mathrm{Pb}$ and $\mathrm{U}$ isotopes for geochronology by laser ablation multicollector inductively plasma mass spectrometry (LA-MC-ICP-MS). Anais da Academia Brasileira de Ciências 81 (1): 99-114.

CARTO, S. L. \& EYLES, N. 2011. The deep-marine glaciogenic Gaskiers Formation. Newfoundland, Canada. In: ARNALD, E.; HALVERSON, G. P. \& SHIELDS-ZHOU, G. (eds) The Geological Record of Neoproterozoic Glaciations, Geological Society, London, Memoirs, 36, 467-473.

CASTELnAU, F. Expeditiondans lês parties centrales de l'Amerique du sud. Paris: COUSSOT, P. \& MEUNIER, 1857. 15 vol., 7 partes.

CATUNEANU, O. 2006. Principles of Sequence Stratigraphy: 1-345. First edition. Elsevier, Canadá.

COELHO, J. C. C.; MARTINS-NETO, M. A.; MARINHO, M. S. 2008. Estilos estruturais e evolução tectônica da porção mineira da bacia proterozóica do São Francisco. Revista Brasileira de Geociências 38 (2), 149-165.

CONDON, D.; ZHU, M.; BOWRING, S.; WANG, W.; YANG, A.; JIN, Y. 2005. U-Pb ages from the Neoproterozoic Doushantuo Formation, China. Science 308, 95-98. 
CORREAA, J. A.; CORREIA FILHO, F. C. L.; SCISLEWSKI, G.; NETO, C.; CAVALLON, L. A.; CERQUEIRA, N. L. S.; NOGUEIRA, V. L. Projeto Bodoquena: Geologia das regiões centro e oeste de Mato Grosso do Sul. Brasília: CPRM/DNPM, 1979. 111 p.

CORDANI, U. G.; KAWASHITA, K.; THOMAZ FILHO, A. 1978. Applicability of the rubidium-strontium methods to shales and related rocks. In: COHEE, G. V.; GLAESSNER, M. F.; HEDBERG, H. D. (Eds.). Contributions to the geologic time scale. Am. Assoc. Petrol. Geol., Studies in Geologie, 6, p. 93-117.

CORDANI, U. G.; THOMAZ FILHO, A.; BRITO NEVES, B. B.; KAWASHITA, K. 1985. On the applicability of the Rb-Sr method to argillaceous sedimentary rocks: some examples from Precambrian sequences of Brazil. Giornale Geol., 471:253-280.

CORDANI, U. G.; TEIXEIRA, W.; D’AGRELLA, M. S. and TRINDADE, R. I. 2009. The position of the Amazonian Craton in supercontinents. Gondwana Res., 15, 396-407.

DANTAS, E. L.; ALVARENGA, C. J. S.; SANTOS, R. V. \& PIMENTEL, M. M. 2009. Using $\mathrm{Nd}$ isotopes to understand the provenance of sedimentary rocks from a continental margin to a foreland basin in the Neoproterozoic Paraguay Belt, Central Brazil. Precambrian Research, 170, 1-12.

DEL'ARCO, J. O.; SILVA, R. H.; TARAPANOFF, L; FREIRE, F. A; PEREIRA, L. G. M.; SOUZA, S. L.; LUZ, L. G.; PALMEIRA, R. C. B.; TASSINARI, C. C. G. 1982. Folha SE. 21 Corumbá e Parte da Folha SE. 20, Geologia. In: RADAMBRASIL. Rio de Janeiro, MME. p. 25- 160. (Levantamento de Recursos Naturais 27).

EVANS, J. W. 1894. The geology of Mato Grosso (Particularly the region drained by the upper Paraguay), Quart. Journal Soc. London, Londres, 50(2): 85-104.

EYLES, C. H.; EYLES, N.; MIALL, A. D. 1985. Models of glacio-marine sedimentation and their application on the interpretation of ancient glacial sequences. Palaeogeo. Palaeoclim. Palaeoeco., 51:15-84.

FERREIRA, C. O. 2009. Constraints of the Neoproterozoic-Cambrian magmatism along the Transbrasiliano Lineament, central Brazil. A study based on U-Pb, Lu-Hf (LA-CICPMS) and Nd isotopic signature. Universidade de Brasília, Brasília.

FIGUEIREDO, A. J. A. \& OLIVATTI, O. 1974. O Projeto Alto - Guaporé. Relatório final integrado. Goiânia, DNPM/CPRM, 11. (Relatório do arquivo técnico da DGM, 2323).

FIGUEIREDO, A. J. A.; EULALIO, A.; RODRIGUES, A. P.; BARRETO, B. F.; PIMENTEL, G. B.; COUTO, J. G. P.; REISCHL, J. L.; COSTA, S. A. G.; RESENDE FILHO, S. T.; PASTORE JUNIOR, W. P.; RIBEIRO FILHO, W. Projeto Alto 
Guaporé. Relatório Final. Folha Tangará da Serra SD. 21-YB. Goiânia: DNPM/CPRM, 1974. v.1.

FIGUEIREDO, M. F; BABINSKI, M.; ALVARENGA, C. J. S.; PINHO, F. E. C. 2004. Diamictites overlying Marinoan-age carbonates of Araras Formation, Paraguay belt, Brazil: evidence of a new glaciation?. In: Symposium on Neoproterozoic-Early Paleozoic Events in SW-Gondwana, 1, Extended Abstracts, IGCP Project 478, Second Meeting, Brazil, p. 18-19.

FIGUEIREDO, M. F. Quimioestratigrafia das rochas ediacaranas do extremo norte da Faixa Paraguai, Mato Grosso. 2006. Dissertação (Mestrado) - Instituto de Geociências, Universidade de São Paulo, São Paulo, 105p.

FIGUEIREDO, M. F.; BABINSKI, M.; ALVARENGA, C. J. S. \& PINHO, F. E. C. 2008. Nova unidade litoestratigráfica registra glaciação ediacarana em Mato Grosso: Formação Serra Azul. Geologia USP, 8, 65-75.

FIGUEIREDO, M. F. 2010. Quimiestratigrafia isotópica (C, O, S e Sr), Geocronologia (Pb$\mathrm{Pb}$ e K-Ar) e Proveniência (Sm-Nd) das rochas da Faixa Paraguai Norte, Mato Grosso. Tese (Doutorado). São Paulo: Universidade de São Paulo, Instituto de Geociências.

FIGUEIREDO, M. F.; BABINSKI, M.; ALVARENGA, C. J. S. 2011. The Serra Azul Formation, Paraguay Belt, Brazil. Geological Society, London, Memoirs 2011; v. 36; p. 499-502.

FOLK, R. L. 1974. The petrology of sedimentary rocks. 182 p., Hemphill Publishing Co., Austin, Texas, USA.

FONT, E.; NE'DE'LEC, A.; TRINDADE, R. I. F.; MACOUIN, M. \& CHARRIÈRE, A. 2006. Chemostratigraphy of the Neoproterozoic Mirassol d'Oeste cap dolostone (Mato Grosso, Brazil): an alternative model for Marinoan cap dolostone formation. Earth and Planetary Science Letters, 250, 89-103.

GAUCHER, C.; BOGGIANI, P. C.; SPRECHMANN, P.; SIAL, A. N. \& FAIRCHILD, T. 2003. Integrated correlation of the Vendian to Cambrian Arroyo del Soldado and Corumba' Groups (Uruguay and Brazil): palaeogeography, palaeoclimatic and palaeobiologic implications. Precambrian Research, 120, 241-278.

GIUSTINA, M. E. S. 2010. Geocronologia e significado tectônico de rochas máficas de alto grau metamórfico da Faixa Brasília. Tese (Doutorado em Geologia) - Programa de PósGraduação em Geologia Sedimentar. Universidade de Brasília, Brasília. pp. 116. 
GODOY, A. M.; PINHO, F. E. C.; MANZANO, J. C.; ARAÚJO, L. M. B.; SILVA, J. A.; FIGUEIREDO, M. Estudos Isotópicos das Rochas Granitóides Neoproterozóicas da Faixa de Dobramento Paraguai. Rev. Bras. Geoc., v. 40 (3): 380-391, 2010.

HALVERSON, G. P.; HOFFMAN, P. F.; SCHRAF, D. P.; MALOOF, A. C. Toward a neoproterozoic composite carbon-isotope record. Bulletin of the Geological Society of America, v. 117, p. 1181-1207, 2005.

HALVERSON, G. P.; DUDAS, F. O.; MALOOF, A. C.; BOWRING, S. A. 2007. Evolution of the 87Sr/86Sr composition of Neoproterozoic seawater. Palaeogeogr. Palaeoclimatol. Palaeoecol. 256, 103-129.

HALVERSON, G. P.; HURTGEN, M. T.; PORTER, S. M.; COLlinS, A. C. 2010. Neoproterozoic-Cambrian biogeochemical evolution. In: GAUCHER, C.; SIAL, A. N.; HALVERSON, G. P.; FRIMMEL, H. (Eds.), Neoproterozoic-Cambrian Tectonics, Global Change and Evolution: A Focus on Southwestern Gondwana, Dev. Precambrian Geol., vol. 16. Elsevier, pp. 351-356.

HASUI, Y. \& ALMEIDA, F. F. M. 1970. Geocronologia do Centro-Oeste brasileiro. Bol. Soc. Bras. Geol., 19(1): 1-26.

HENNIES, W. T. 1966. Geologia do Centro-Norte Mato-Grossense. Tese de Doutoramento, Escola Politécnica, Universidade de São Paulo, 65p.

HOFFMAN, K. H.; SCHRAG, D. P. 2002. The snowball Earth hypothesis: testing the limits of global change. Terra Nova, 14: 129-155.

HOFFMANN, K. H.; CONDON, D. J.; BOWRING, S. A.; CROWLEY, J. L. 2004. U-Pb zircon date from the Neoproterozoic Ghaub Formation, Namibia: constraints on Marinoan glaciation. Geology 32, 817-820.

JACKSON, S. E.; PEARSON, N. J.; GRIFFIN, W. L. \& BELOUSOVA, E. A. 2004. The application of laser ablation inductively coupled plasma mass spectrometry to in situ U$\mathrm{Pb}$ zircon geochronology. Chem Geol 211: 47-69.

KENNEDY, M. J.; CHRISTIE-BLICK, N.; SOHL, L. E. 2001. Are Proterozoic cap carbonates and isotopic excursions a record of a gas hydrate destabilization following Earth’s coldest intervals? Geology, 29: 443-446.

KNOLL, A. H.; WALTER, M. R.; NARBONNE, G. M.; CHRISTIE-BLICK, N., 2004. A new period for the geologic time scale. Science 305, 621-622.

LACERDA FILHO, J. V.; ABREU FILHO, W.; VALENTE, C. R.; OLIVEIRA, C. C.; ALBUQUERQUE, M. C. (Organizadores); 2004. Geologia e Recursos Minerais do Estado de Mato Grosso - SIG: texto explicativo dos mapas Geológico e Tectônico e de 
Recursos Minerais do Estado do Mato Grosso. Escala 1:1.000.000: 1-252. CPRM, Cuiabá.

LITHERLAND, M.; ANNELS, R. N. et al. 1986. The Geology and Mineral Resources of the Bolivian Precambrian Shield. British Geological Survey, Overseas Memoir, 9.

LUDWIG, K. R. User's manual for Isoplot 3.0: a geochronological toolkit for Microsoft Excel. Berkeley Geochronology Center, 2003. 71 p. (Special Publication, 4).

LUZ, J. S.; OLIVEIRA, A. M.; LEMOS, D. B.; ARGOLO, J. L.; SOUZA, N. B.; ABREU FILHO, W. 1978. Projeto Província Serrana. Goiânia, DNPM/ CPRM. v. l, 105 p. (Relatório Final).

LUZ, J. S.; OLIVEIRA, A. M.; SOUZA, J. O.; MOTTA, J. J. I. M.; TANNO, L. C.; CARMO, L. S.; SOUZA, N. B. 1980. Projeto Coxipó. Goiânia, DNPM/CPRM. v. l, 136 p. (Relatório Final).

MCGEE, B.; COLLINS, A. S. and TRINDADE, R. I. F. 2012. G'day Gondwana - the final accretion of a supercontinent: U-Pb ages from the post-orogenic São Vicente Granite, northern Paraguay Belt, Brazil. Gondwana Research, 21: 316-322.

MCGEE, B.; COLLINS, A. S. and TRINDADE, R. I. F. 2015a. Age and Provenance of the Cyrogenian to Cambrian passive margin to foreland basin sequence of the northern Paraguay Belt, Brazil. Bull. Geol. Soc. Am., 127: 76-86.

MCGEE, B.; COLLINS, A. S.; TRINDADE, R. I. F. and JOURDAN, F. 2015b. Investigating mid-Ediacarian glaciation and final Gondwana amalgamation using coupled sedimentology and ${ }^{40} \mathrm{Ar} /{ }^{39} \mathrm{Ar}$ detrital muscovite provenance from the Paraguay Belt, Brazil. International Association of Sedimentologists, Sedimentology, 62: 130-154.

MINISTÉRIO DO PLANEJAMENTO, ORÇAMENTO E GESTÃO; IBGE. Mapa Político do Estado do Mato Grosso. Diretoria de Geociências. 2009. Escala 1:1.500.000.

MOURA, C. A. V.; PINHEIRO, B. L. S.; NOGUEIRA, A. C. R.; GORAYEB, P. S. S.; GALARZA, M. A. 2008. Sedimentary provenance and palaeoenvironment of the Baixo Araguaia Supergroup: constraints on the palaeogeographical evolution of the Araguaia belt and assembly of West Gondwana. Geological Society, London, Special Publications 294, 173-196.

MYROW, P. M. \& KAUFMAN, A. J. 1999. A newly discovered cap carbonate above Varanger age glacial deposits in Newfoundland. Journal of Sedimentary Petrology, 69, 784-793. 
NICOLS. G.; 2009. Sedimentology and Stratigraph, Second Edition: 1-432. Wiley-Blackwell, UK.

NILSON, A. A.; GIOIA, S.; PIMENTEL, M. M. 1997. Idade Sm-Nd do Complexo MáficoUltramáfico de Americano do Brasil, Goiás e características isotópicas das rochas encaixantes. Anais, VI Congresso Brasileiro de Geoquímica, SBGq, pp. 643-645.

NOGUEIRA, V. L. \& OLIVEIRA, C. C. 1978. Projeto Bonito Aquidauana. Goiânia, DNPM/CPRM. 121 p. (Relatório Final 1).

NOGUEIRA, A. C. R.; RICCOMINI, C.; SIAL, A. N.; MOURA, C. A. V. \& FAIRCHILD, T. R. 2003. Soft-sediment deformation at the base of Neoproterozoic Puga cap carbonate (southwestern Amazon craton, Brazil): confirmation of rapid icehouse to greenhouse transition in snowball Earth. Geology, 31, 613-616.

NOGUEIRA, A. C. R. \& RICCOMINI, C. 2006. O Grupo Araras (Neoproterozóico) na parte norte da Faixa Paraguai e sul do Cráton Amazônico, Brasil. Rev. Bras. Geoc., 36: 623640.

NOGUEIRA, A. C. R.; RICCOMINI, C.; SIAL, A. N.; MOURA, C. A. V.; TRINDADE, R. I. F. \& FAIRCHILD, T. R. 2007. Carbon and strontium isotope fluctuations and paleoceanographic changes in the late Neoproterozoic Araras carbonate platform, southern Amazon craton, Brazil. Chemical Geology, 80, 168-190.

OLIVA, L. A.; OLIVATTI, O.; RIBEIRO FILHO, W.; SCHOBBENHAUS FILHO, C. 1979. Folha SD21 Cuiabá. Brasília, DNPM. (Carta geológica do Brasil ao milionésimo).

PIMENTEL, M. M. \& FUCK, R. A. 1992. Neoproterozoic crustal accretion in central Brazil. Geology 20 (4), 375-379.

PIMENTEL, M. M.; FUCK, R. A. 1994. Geocronologia Rb-Sr da porção sudoeste do Maciço Mediano de Goiás. Revista Brasileira de Geociências 24 (2), 104-111.

PIMENTEL, M. M.; HEAMAN, L.; FUCK, R. A. 1991. U-Pb zircon and sphene geochronology of late Proterozoic volcanic arc rock units from southwestern Goiás, central Brazil. Journal of South American Earth Sciences 4, 329-339.

PIMENTEL, M. M.; WHITEHOUSE, M. J.; VIANA, M. G.; FUCK, R. A.; MACHADO, N. 1997. The Mara Rosa arc in the Tocantins Province: further evidence for Neoproterozoie crustal accretion in central Brazil. Precambrian Research 81, 299-310.

PIMENTEL, M. M.; FUCK, R. A.; JUNGES, S. 1998. New Sm-Nd isotopic constraints for the age of metamorphic events in the Neoproterozoie Brasilia belt, Central Brazil. Abstracts, 14. International Conference on Precambrian and Craton Tectonics - 
International Conference on Basement Tectonics. UFOP-International Basement Tectonics Association, Ouro Preto, pp. 50-52.

PIMENTEL, M. M.; FUCK, R. A.; GIOIA, S. M. C. L. 2000. The Neoproterozoic Goiás magmatic arc, central Brazil: a review and new Sm-Nd isotopic data. Revista Brasileira de Geociências 30 (1), 035-039.

PINHO, F. E. C.; SIAL, A. N.; FIGUEIREDO, M. F.; 2003. Contribution to the Neoproterozoic C- and O-isotopic record: carbonate rocks from the Paraguay belt, Mato Grosso, Brazil. In: South American Symposium on Isotope Geology, 4, Short Papers, Salvador, Brazil. p. 390-393.

PLINT, A. G. 2010. Wave-and Storm-Dominated Shoreline and Shallow-Marine Systems. In: JAMES, N. P. \& DALRYMPLE, 2010, R. W. (Autors), Facies Models 4 (167-194). Toronto: Geological Association of Canada.

RIBEIRO FILHO, W. \& FIGUEIREDO, A. J. A. 1974. Reconhecimento geológico da região oeste de Mato Grosso. In: SBG, Cong. Bras. Geol., 28, Porto Alegre. Anais, p.27-35.

RIBEIRO FILHO, W.; LUZ, J. S.; ABREU FILHO, W. 1975. Projeto Serra Azul, relatório final. Departamento Nacional de Produção Mineral e Companhia de Pesquisa de Recursos Minerais, Goiânia. 1:104 p.

RICCOMINI, C. \& NOGUEIRA, A. C. R. A deformação sinsedimentar no Grupo Araras (Neoproterozóico) no contexto da margem sul-sudeste do Cráton Amazônico. In: XLII Congresso Brasileiro de Geologia, 2004, Araxá, MG. Anais. Araxá, MG: Sociedade Brasileira de Geologia, Núcleo Minas Gerais, 2004. p. S07-319-S07-319.

RICCOMINI, C.; NOGUEIRA, A. C. R. \& SIAL, A. N. 2007. Carbon and oxygen isotope geochemistry of Ediacaran outer platform carbonates, Paraguay Belt, central Brazil. Anais da Academia Brasileira de Ciências, 79, 519-527.

RODRIGUES, R.; AZEVEDO, R. L. M.; ESTRADA, N. M.; REHIM, H. A. A.; SATO, K.; KAWASHITA, K.; SOLIANI JR., E. Inferências cronoestratigráficas para carbonatos da Bacia dos Parecis, com base em dados da razão 87SR/86Sr. In: CONGRESSO BRASILEIRO DE GEOLOGIA, 38, 1994, Camboriu. 1994. Anais ... Camboriu: SBG, 1994. v.3, p.286-287.

ROMERO, J. A. S.; LAFON, J. M.; NOGUEIRA, A. C. R.; SOARES, J. L. 2013. Sr isotope geochemistry and $\mathrm{Pb}-\mathrm{Pb}$ geocronology of the Neoproterozoic cap carbonates, Tangará da Serra, Brazil. Inter. Geo. Rev., 55:1-19.

SANTOS, H. P. 2014. Fácies e Proveniência de depósitos costeiros da Formação Raizama: Evidências do registro Ediacarano-Cambriano na Faixa Paraguai, Região de Nobre, 
Mato Grosso. Dissertação (Mestrado em Geologia) - Programa de Pós-Graduação em Geologia e Geoquímica. Universidade Federal do Pará, Belém. pp. 95.

SCHOBBENHAUS FILHO, C. \& OLIVA, L. A. 1979. Folha SE2J Corumbá. Brasília, DNPM. (Carta Geológica do Brasil ao Milionésimo).

SCHOBBENHAUS FILHO, C. \& SOARES, M. E. S. 1979. Folha SF21 Rio Apa. Brasília, DNPM. (Carta Geológica do Brasil ao Milionésimo).

SCHOBBENHAUS, C.; CAMPOS, D. A.; DERZE, G. R. \& ASMUS, H. E. 1981. Mapa geológico do Brasil e da Área Oceânica Adjacente Incluindo Depósitos Minerais, esc. 1: 2.500.000, MME - DNPM.

SCORZA, E. P. 1960. Geologia de Dimantino, Estado de Mato Grosso. Div. De Geol. E Miner., Noras Prel. e Estudos, nº 113, 11 págs. Rio de Janeiro.

SILVA JR., J. B. C. \& NOGUEIRA, A. C. R. Depósitos progradantes da Formação Diamantino: os últimos estágios de sedimentação da Faixa Paraguai Norte, Região de Diamantino, Estado de Mato Grosso. In: CONGRESSO BRASILEIRO DE GEOLOGIA , 45., 26 set.- 01 out. 2010, Belém. Anais... Belém: SBG, 2010. p.303. Depósitos sedimentares Pré-cambrianos.

SOUZA, J. O.; et al. Projeto Planalto da Serra, Folhas Paranatinga, Cacimba, Brasilândia e Caiana. Organizado por João Olímpio Souza; Débora Regina Vieira dos Santos; Felicíssimo Rosa Borges; Karine Gollmann. Escala 1:100.000. Goiânia: CPRM, 2012. CPRM........p. il.; + mapas.

STACEY, J. S. \& KRAMERS, J. D. 1975. Approximation of terrestrial lead isotope evolution by a two-stage model. Earth Planet Sc Lett 26: 207-221.

TASSINARI, C. C. G. \& MACAMBIRA, M. J. B. 1999. Geocronological Provinces of the Amazonian Craton. Episodes, 22(3):174-182.

TASSINARI, C. C. G. \& MACAMBIRA, M. J. B. 2004. A evolução tectônica do Cráton Amazônico. In: Mantesso-Neto V. et al. 2004. Geologia do continente Sul Americano: uma evoluçãoda obra de Fernando Flávio Marques de Almeida. São Paulo: Beca. P. 471-488.

TRINDADE, R. I. F.; D’AGRELLA-FILHO, M. S.; EPOF, I. and BRITO NEVES, B. B. 2006 Paleomagnetism of Early Cambrian Itabaiana mafic dikes (NE Brazil) and the final assembly of Gondwana. Earth Planet. Sci. Lett., 244, 361-377.

TUCKER, M. E. \& WRIGHT, V. P. Carbonate Sedimentology. 1. ed. London: Blackwell Science, 1990, 482p. 
TUCKER, M. E. 2003. Sedimentary Rocks in the Field. Third Edition: 1-234. Departmente of Geological Scienses. University of Durham. John Wiley \& Sons, Ltd., UK.

VIANA, M. G.; PIMENTEL, M. M.; WHITEHOUSE, M. J.; FUCK, R. A.; MACHADO, N. 1995. O Arco Magmático de Mara Rosa, Goiás: geoquímica e geocronologia e suas implicações regionais. Revista Brasileira de Geociências 25 (2), 111-123.

VIEIRA, A. J. Geologia do Centro-Oeste de Mato Grosso. Ponta Grossa, Petrobrás - DEBSP, 1964, Boletim 303. 79p.

WALKER, R. G.; 1976. Facies Models - 3.Sandy Fluvial Systems. Geoscience Canada 3: 101-109.

WALKER, R. G.; 1984. Facies Models, Second Edition: 1-317. Geoscience Canada, Canada.

WALKER, R. G. \& JAMES, N. P. (editors); 1992. Facies models: response to sea level change: 1-409. Geological Association of Canada, Ontario.

WIEDENBECK, M.; ALLE, P.; CORFU, F.; GRIFFIN, W. L.; MEIER, M.; OBERLI, F.; VON QUADT, A.; RODDICK, J. C.; SPIEGEL, W. 1995. 3 natural zircon standards for U-Th-Pb, Lu-Hf, trace-element and REE analyses. Geostandards Newsletter 19: 123. 


\section{ANEXOS}

\section{CAPÍTULO 5}

Tabela suplementar:

\section{Formação Serra Azul}

\begin{tabular}{|c|c|c|c|c|c|c|c|c|c|c|c|c|c|c|c|}
\hline \multirow[b]{2}{*}{ Amostra } & \multicolumn{7}{|c|}{ Razões Radiogênicas } & \multirow[b]{2}{*}{ Rho } & \multicolumn{6}{|c|}{ Estimativa de Idade (Ma) } & \multirow[b]{2}{*}{ Conc. (\%) } \\
\hline & $\mathrm{Th} / \mathrm{U}$ & ${ }^{207} \mathrm{~Pb} /{ }^{206} \mathrm{~Pb}$ & $\pm 1 \sigma$ & ${ }^{206} \mathrm{~Pb} /{ }^{238} \mathrm{U}$ & $\pm 1 \sigma$ & ${ }^{207} \mathrm{~Pb} /{ }^{235} \mathrm{U}$ & $\pm 1 \sigma$ & & ${ }^{207} \mathrm{~Pb} /{ }^{206} \mathrm{~Pb}$ & $\pm 1 \sigma$ & ${ }^{206} \mathrm{~Pb} /{ }^{238} \mathrm{U}$ & $\pm 1 \sigma$ & ${ }^{207} \mathrm{~Pb} /{ }^{235} \mathrm{U}$ & $\pm 1 \sigma$ & \\
\hline \multirow{18}{*}{ PS 07} & 0,278 & 0,053 & 3,671 & 0,047 & 1,603 & 0,344 & 4,005 & 0,649 & 327 & 83 & 297 & 5 & 300 & 10 & 90,7 \\
\hline & 0,152 & 0,087 & 4,266 & 0,055 & 6,839 & 0,661 & 8,06 & 0,848 & 1359 & 82 & 346 & 23 & 515 & 33 & 25,5 \\
\hline & 0,162 & 0,06 & 0,905 & 0,084 & 0,791 & 0,689 & 1,202 & 0,626 & 589 & 20 & 519 & 4 & 532 & 5 & 88,2 \\
\hline & 1,157 & 0,061 & 3,933 & 0,096 & 0,676 & 0,805 & 3,992 & 0,29 & 628 & 83 & 593 & 4 & 600 & 18 & 94,4 \\
\hline & 0,622 & 0,06 & 1,025 & 0,101 & 1,13 & 0,84 & 1,525 & 0,727 & 621 & 22 & 619 & 7 & 619 & 7 & 99,7 \\
\hline & 0,4 & 0,063 & 0,969 & 0,112 & 1,093 & 0,969 & 1,461 & 0,734 & 707 & 21 & 682 & 7 & 688 & 7 & 96,5 \\
\hline & 0,454 & 0,063 & 1,796 & 0,114 & 1,144 & 0,989 & 2,129 & 0,755 & 712 & 38 & 694 & 8 & 698 & 11 & 97,4 \\
\hline & 0,159 & 0,071 & 0,446 & 0,137 & 0,606 & 1,332 & 0,753 & 0,759 & 943 & 9 & 828 & 5 & 860 & 4 & 87,7 \\
\hline & 0,472 & 0,078 & 0,998 & 0,139 & 2,012 & 1,501 & 2,257 & 0,967 & 1151 & 20 & 840 & 16 & 931 & 14 & 73 \\
\hline & 0,288 & 0,071 & 1,464 & 0,146 & 0,712 & 1,425 & 1,628 & 0,651 & 947 & 30 & 880 & 6 & 899 & 10 & 92,9 \\
\hline & 0,864 & 0,082 & 5,22 & 0,147 & 4,356 & 1,654 & 6,799 & 0,64 & 1237 & 102 & 884 & 36 & 991 & 43 & 71,4 \\
\hline & 1,856 & 0,07 & 1,102 & 0,149 & 0,704 & 1,445 & 1,307 & 0,741 & 934 & 23 & 897 & 6 & 908 & 8 & 96 \\
\hline & 0,439 & 0,075 & 1,443 & 0,163 & 0,954 & 1,68 & 1,729 & 0,53 & 1062 & 29 & 974 & 9 & 1001 & 11 & 91,7 \\
\hline & 0,214 & 0,074 & 1,5 & 0,164 & 1,419 & 1,673 & 2,065 & 0,678 & 1036 & 30 & 981 & 13 & 998 & 13 & 94,7 \\
\hline & 0,459 & 0,087 & 2,584 & 0,173 & 0,77 & 2,08 & 2,697 & 0,475 & 1363 & 49 & 1029 & 7 & 1142 & 18 & 75,5 \\
\hline & 0,383 & 0,09 & 1,128 & 0,18 & 1,886 & 2,222 & 2,197 & 0,855 & 1415 & 22 & 1067 & 19 & 1188 & 15 & 75,4 \\
\hline & 0,309 & 0,079 & 0,453 & 0,185 & 0,71 & 2,011 & 0,843 & 0,816 & 1171 & 9 & 1093 & 7 & 1119 & 6 & 93,4 \\
\hline & 0,152 & 0,078 & 1,025 & 0,185 & 0,876 & 2,001 & 1,348 & 0,624 & 1153 & 20 & 1097 & 9 & 1116 & 9 & 95,1 \\
\hline
\end{tabular}




\begin{tabular}{|c|c|c|c|c|c|c|c|c|c|c|}
\hline 0,303 & 0,082 & 0,792 & 0,188 & 0,94 & 2,109 & 1,229 & 0,746 & 1235 & 16 & 1108 \\
\hline 0,256 & 0,079 & 0,312 & 0,189 & 0,59 & 2,066 & 0,668 & 0,85 & 1185 & 6 & 1113 \\
\hline 0,224 & 0,08 & 0,871 & 0,189 & 0,639 & 2,097 & 1,081 & 0,539 & 1204 & 17 & 1119 \\
\hline 0,233 & 0,079 & 1,115 & 0,191 & 0,651 & 2,088 & 1,292 & 0,682 & 1183 & 22 & 1125 \\
\hline 0,415 & 0,082 & 0,258 & 0,192 & 0,498 & 2,166 & 0,561 & 0,835 & 1240 & 5 & 1133 \\
\hline 0,238 & 0,082 & 0,631 & 0,196 & 0,756 & 2,207 & 0,984 & 0,737 & 1234 & 12 & 1155 \\
\hline 0,229 & 0,083 & 2,408 & 0,197 & 0,536 & 2,261 & 2,467 & 0,336 & 1274 & 47 & 1159 \\
\hline 0,327 & 0,081 & 0,484 & 0,2 & 0,694 & 2,22 & 0,846 & 0,789 & 1212 & 10 & 1174 \\
\hline 0,196 & 0,082 & 0,436 & 0,2 & 0,674 & 2,263 & 0,803 & 0,809 & 1243 & 9 & 1177 \\
\hline 0,359 & 0,084 & 0,346 & 0,202 & 0,623 & 2,326 & 0,713 & 0,843 & 1285 & 7 & 1184 \\
\hline 0,351 & 0,097 & 0,877 & 0,218 & 1,741 & 2,917 & 1,95 & 0,963 & 1572 & 16 & 1269 \\
\hline 0,421 & 0,088 & 1,419 & 0,218 & 1,559 & 2,637 & 2,109 & 0,733 & 1374 & 27 & 1273 \\
\hline 0,286 & 0,094 & 0,71 & 0,227 & 0,7 & 2,922 & 0,996 & 0,662 & 1498 & 13 & 1317 \\
\hline 0,34 & 0,092 & 0,359 & 0,23 & 1,548 & 2,925 & 1,589 & 0,973 & 1473 & 7 & 1334 \\
\hline 0,248 & 0,094 & 3,445 & 0,232 & 0,93 & 3,002 & 3,571 & 0,246 & 1508 & 64 & 1343 \\
\hline 0,361 & 0,092 & 2,229 & 0,235 & 0,765 & 2,981 & 2,357 & 0,525 & 1465 & 42 & 1362 \\
\hline 0,497 & 0,092 & 0,604 & 0,242 & 0,722 & 3,052 & 0,942 & 0,733 & 1460 & 11 & 1395 \\
\hline 0,517 & 0,1 & 2,268 & 0,245 & 1,829 & 3,39 & 2,92 & 0,622 & 1629 & 42 & 1413 \\
\hline 0,176 & 0,093 & 0,453 & 0,246 & 0,662 & 3,158 & 0,802 & 0,791 & 1488 & 9 & 1419 \\
\hline 0,104 & 0,095 & 0,458 & 0,247 & 0,625 & 3,23 & 0,778 & 0,764 & 1528 & 9 & 1421 \\
\hline 0,17 & 0,09 & 0,335 & 0,249 & 1,009 & 3,099 & 1,063 & 0,945 & 1434 & 6 & 1431 \\
\hline 0,176 & 0,093 & 0,565 & 0,254 & 0,817 & 3,259 & 0,993 & 0,801 & 1487 & 11 & 1460 \\
\hline 0,147 & 0,094 & 0,479 & 0,257 & 0,738 & 3,341 & 0,879 & 0,814 & 1515 & 9 & 1474 \\
\hline 0,256 & 0,096 & 0,504 & 0,26 & 0,667 & 3,421 & 0,836 & 0,76 & 1540 & 9 & 1487 \\
\hline 0,399 & 0,09 & 1,468 & 0,263 & 0,831 & 3,27 & 1,699 & 0,464 & 1429 & 28 & 1505 \\
\hline 0,214 & 0,095 & 1,233 & 0,268 & 0,616 & 3,493 & 1,379 & 0,395 & 1519 & 23 & 1531 \\
\hline 0,474 & 0,094 & 0,77 & 0,279 & 2,147 & 3,634 & 2,281 & 0,94 & 1514 & 15 & 1588 \\
\hline 0,357 & 0,099 & 0,496 & 0,282 & 1,057 & 3,833 & 1,167 & 0,898 & 1599 & 9 & 1600 \\
\hline 0,489 & 0,12 & 0,638 & 0,294 & 0,884 & 4,872 & 1,09 & 0,792 & 1960 & 11 & 1660 \\
\hline
\end{tabular}




$\begin{array}{cccccccccccccccc}0,163 & 0,115 & 0,559 & 0,301 & 0,77 & 4,768 & 0,952 & 0,783 & 1877 & 10 & 1697 & & 11 & 1779 & 8 & 90,4 \\ 0,57 & 0,122 & 2,393 & 0,317 & 0,869 & 5,337 & 2,546 & 0,321 & 1989 & 43 & 1774 & & 13 & 1875 & 22 & 89,2 \\ 0,256 & 0,113 & 0,445 & 0,322 & 1,64 & 5,019 & 1,699 & 0,964 & 1850 & 8 & 1798 & & 26 & 1822 & 14 & 97,2 \\ 0,38 & 0,114 & 0,418 & 0,324 & 0,656 & 5,084 & 0,778 & 0,81 & 1861 & 8 & 1809 & 10 & 1834 & 7 & 97,2 \\ 0,415 & 0,126 & 0,265 & 0,34 & 1,78 & 5,91 & 1,8 & 0,989 & 2042 & 5 & 1888 & & 29 & 1963 & 16 & 92,4 \\ 0,413 & 0,139 & 0,378 & 0,385 & 0,626 & 7,397 & 0,731 & 0,822 & 2220 & 7 & 2099 & 11 & 2161 & 7 & 94,6 \\ 0,006 & 0,189 & 0,396 & 0,481 & 0,75 & 12,567 & 0,848 & 0,866 & 2737 & 7 & 2533 & & 16 & 2648 & 8 & 92,6\end{array}$

Razões Radiogênicas

Estimativa de Idade (Ma)

\begin{tabular}{|c|c|c|c|c|c|c|c|c|c|c|c|c|c|c|c|}
\hline \multirow[b]{2}{*}{ Amostra } & \multirow[b]{2}{*}{$\mathrm{Th} / \mathrm{U}$} & & & & & & & \\
\hline & & $207 \mathrm{~Pb} / 206 \mathrm{~Pb}$ & $\pm 1 \sigma$ & $206 \mathrm{~Pb} / 238 \mathrm{U}$ & $\pm 1 \sigma$ & $207 \mathrm{~Pb} / 235 \mathrm{U}$ & $\pm 1 \sigma$ & Rho & $207 \mathrm{~Pb} / 206 \mathrm{~Pb}$ & $\pm 1 \sigma$ & $206 \mathrm{~Pb} / 238 \mathrm{U}$ & $\pm 1 \sigma$ & $207 \mathrm{~Pb} / 235 \mathrm{U}$ & $\pm 1 \sigma$ & Conc. \\
\hline \multirow[t]{19}{*}{ PS 08-A } & 0,187 & 0,073 & 0,709 & 0,159 & 0,532 & 1,611 & 0,887 & 0,751 & 1028 & 14 & 951 & 5 & 975 & 6 & 92,6 \\
\hline & 0,141 & 0,078 & 1,26 & 0,16 & 0,847 & 1,712 & 1,518 & 0,529 & 1135 & 25 & 958 & 8 & 1013 & 10 & 84,3 \\
\hline & 0,222 & 0,075 & 1,922 & 0,164 & 0,948 & 1,689 & 2,143 & 0,422 & 1059 & 39 & 980 & 9 & 1005 & 14 & 92,6 \\
\hline & 0,171 & 0,073 & 0,62 & 0,167 & 0,603 & 1,684 & 0,865 & 0,831 & 1021 & 13 & 994 & 6 & 1003 & 6 & 97,4 \\
\hline & 0,2 & 0,074 & 0,424 & 0,171 & 0,633 & 1,733 & 0,761 & 0,901 & 1034 & 9 & 1015 & 6 & 1021 & 5 & 98,2 \\
\hline & 0,412 & 0,076 & 0,68 & 0,173 & 0,692 & 1,822 & 0,97 & 0,856 & 1100 & 14 & 1031 & 7 & 1053 & 6 & 93,7 \\
\hline & 0,174 & 0,075 & 0,588 & 0,178 & 2,103 & 1,843 & 2,184 & 0,962 & 1070 & 12 & 1056 & 20 & 1061 & 14 & 98,7 \\
\hline & 0,214 & 0,079 & 0,579 & 0,18 & 1,38 & 1,953 & 1,496 & 0,919 & 1165 & 11 & 1067 & 14 & 1099 & 10 & 91,6 \\
\hline & 0,364 & 0,077 & 0,85 & 0,183 & 0,974 & 1,939 & 1,297 & 0,735 & 1121 & 17 & 1081 & 10 & 1094 & 9 & 96,5 \\
\hline & 0,256 & 0,074 & 2,06 & 0,183 & 1,742 & 1,878 & 2,698 & 0,639 & 1055 & 41 & 1083 & 17 & 1073 & 18 & 102,6 \\
\hline & 0,352 & 0,081 & 0,788 & 0,187 & 0,999 & 2,082 & 1,272 & 0,769 & 1220 & 15 & 1103 & 10 & 1143 & 9 & 90,4 \\
\hline & 0,329 & 0,08 & 0,706 & 0,189 & 0,66 & 2,077 & 0,967 & 0,636 & 1186 & 14 & 1118 & 7 & 1141 & 7 & 94,3 \\
\hline & 0,22 & 0,089 & 2,906 & 0,193 & 1,337 & 2,376 & 3,199 & 0,408 & 1411 & 56 & 1137 & 14 & 1235 & 23 & 80,6 \\
\hline & 0,403 & 0,084 & 2,622 & 0,194 & 1,796 & 2,231 & 3,178 & 0,559 & 1284 & 51 & 1140 & 19 & 1191 & 22 & 88,8 \\
\hline & 0,371 & 0,08 & 1,63 & 0,195 & 0,942 & 2,159 & 1,883 & 0,733 & 1201 & 32 & 1150 & 10 & 1168 & 13 & 95,7 \\
\hline & 2,024 & 0,088 & 4,337 & 0,195 & 1,487 & 2,36 & 4,585 & 0,556 & 1373 & 83 & 1151 & 16 & 1231 & 33 & 83,9 \\
\hline & 0,348 & 0,08 & 0,277 & 0,196 & 0,684 & 2,173 & 0,738 & 0,912 & 1207 & 5 & 1154 & 7 & 1173 & 5 & 95,7 \\
\hline & 0,526 & 0,108 & 0,939 & 0,197 & 3,407 & 2,924 & 3,589 & 0,964 & 1760 & 17 & 1159 & 37 & 1388 & 27 & 65,9 \\
\hline & 0,193 & 0,081 & 0,365 & 0,197 & 0,525 & 2,206 & 0,64 & 0,757 & 1225 & 7 & 1160 & 6 & 1183 & 4 & 94,7 \\
\hline
\end{tabular}




\begin{tabular}{|c|c|c|c|c|c|c|c|c|c|c|c|c|c|c|}
\hline 0,343 & 0,083 & 1,315 & 0,199 & 1,014 & 2,277 & 1,661 & 0,591 & 1271 & 26 & 1169 & 11 & 1205 & 12 & $\begin{array}{c}87 \\
91,9\end{array}$ \\
\hline 0,161 & 0,082 & 0,928 & 0,2 & 1,275 & 2,268 & 1,577 & 0,8 & 1255 & 18 & 1173 & 14 & 1203 & 11 & 93,5 \\
\hline 0,252 & 0,082 & 0,223 & 0,201 & 0,803 & 2,263 & 0,834 & 0,959 & 1240 & 4 & 1179 & 9 & 1201 & 6 & 95,1 \\
\hline 0,24 & 0,083 & 1,432 & 0,203 & 0,578 & 2,32 & 1,544 & 0,321 & 1267 & 28 & 1191 & 6 & 1218 & 11 & 94 \\
\hline 0,223 & 0,083 & 1,025 & 0,203 & 0,725 & 2,34 & 1,256 & 0,537 & 1281 & 20 & 1193 & 8 & 1225 & 9 & 93,1 \\
\hline 0,29 & 0,095 & 1,091 & 0,205 & 1,448 & 2,684 & 1,813 & 0,792 & 1530 & 21 & 1200 & 16 & 1324 & 13 & 78,5 \\
\hline 0,544 & 0,088 & 1,153 & 0,209 & 0,914 & 2,548 & 1,471 & 0,822 & 1390 & 22 & 1224 & 10 & 1286 & 11 & 88 \\
\hline 0,199 & 0,082 & 0,283 & 0,209 & 0,469 & 2,369 & 0,548 & 0,779 & 1246 & 6 & 1226 & 5 & 1233 & 4 & 98,4 \\
\hline 0,509 & 0,087 & 8,486 & 0,213 & 2,776 & 2,545 & 8,935 & 0,545 & 1351 & 156 & 1246 & 32 & 1285 & 63 & 92,3 \\
\hline 0,338 & 0,093 & 3,24 & 0,238 & 1,85 & 3,065 & 3,737 & 0,49 & 1494 & 60 & 1377 & 23 & 1424 & 28 & 92,2 \\
\hline 0,345 & 0,094 & 0,302 & 0,238 & 1,516 & 3,078 & 1,545 & 0,98 & 1501 & 6 & 1378 & 19 & 1427 & 12 & 91,8 \\
\hline 0,239 & 0,095 & 0,342 & 0,241 & 0,776 & 3,154 & 0,848 & 0,902 & 1523 & 6 & 1394 & 10 & 1446 & 7 & 91,5 \\
\hline 0,341 & 0,085 & 2,076 & 0,242 & 1,154 & 2,847 & 2,375 & 0,724 & 1321 & 40 & 1398 & 15 & 1368 & 18 & 105,9 \\
\hline 0,26 & 0,096 & 0,977 & 0,243 & 1,275 & 3,209 & 1,606 & 0,785 & 1541 & 18 & 1404 & 16 & 1459 & 12 & 91,1 \\
\hline 0,111 & 0,091 & 0,287 & 0,244 & 1,025 & 3,049 & 1,065 & 0,96 & 1443 & 5 & 1405 & 13 & 1420 & 8 & 97,4 \\
\hline 0,203 & 0,094 & 0,196 & 0,246 & 0,599 & 3,189 & 0,63 & 0,936 & 1512 & 4 & 1415 & 8 & 1455 & 5 & 93,6 \\
\hline 0,366 & 0,098 & 3,145 & 0,247 & 0,785 & 3,339 & 3,242 & 0,223 & 1590 & 59 & 1421 & 10 & 1490 & 25 & 89,3 \\
\hline 0,291 & 0,098 & 0,37 & 0,258 & 0,812 & 3,48 & 0,893 & 0,898 & 1582 & 7 & 1480 & 11 & 1523 & 7 & 93,5 \\
\hline 0,992 & 0,119 & 0,929 & 0,264 & 2,257 & 4,32 & 2,441 & 0,924 & 1937 & 17 & 1510 & 30 & 1697 & 20 & 78 \\
\hline 0,248 & 0,096 & 0,293 & 0,265 & 0,819 & 3,509 & 0,87 & 0,934 & 1551 & 5 & 1514 & 11 & 1529 & 7 & 97,6 \\
\hline 0,334 & 0,103 & 0,366 & 0,284 & 0,833 & 4,036 & 0,91 & 0,904 & 1679 & 7 & 1612 & 12 & 1641 & 7 & 96 \\
\hline 0,266 & 0,105 & 1,937 & 0,287 & 2,437 & 4,159 & 3,12 & 0,927 & 1715 & 35 & 1627 & 35 & 1666 & 25 & 94,8 \\
\hline 0,501 & 0,115 & 0,345 & 0,294 & 1,869 & 4,663 & 1,9 & 0,983 & 1879 & 6 & 1663 & 27 & 1761 & 16 & 88,5 \\
\hline 0,808 & 0,119 & 0,323 & 0,295 & 1,221 & 4,847 & 1,27 & 0,965 & 1944 & 6 & 1667 & 18 & 1793 & 11 & 85,7 \\
\hline 0,353 & 0,115 & 0,331 & 0,306 & 0,734 & 4,853 & 0,805 & 0,896 & 1883 & 6 & 1719 & 11 & 1794 & 7 & 91,3 \\
\hline 0,456 & 0,114 & 0,627 & 0,309 & 0,851 & 4,836 & 1,057 & 0,914 & 1857 & 11 & 1735 & 13 & 1791 & 9 & 93,4 \\
\hline 0,238 & 0,125 & 0,769 & 0,339 & 1,371 & 5,848 & 1,579 & 0,867 & 2028 & 14 & 1884 & 22 & 1954 & 14 & 92,9 \\
\hline
\end{tabular}


Razões radiogênicas

Estimativa de Idade (Ma)

\begin{tabular}{|c|c|c|c|c|c|c|c|c|c|c|c|c|c|c|c|}
\hline Amostra & $\mathrm{Th} / \mathrm{U}$ & ${ }^{207} \mathrm{~Pb} /{ }^{206} \mathrm{~Pb}$ & $\pm 1 \sigma$ & ${ }^{206} \mathrm{~Pb} /{ }^{238} \mathrm{U}$ & $\pm 1 \sigma$ & ${ }^{207} \mathrm{~Pb} /{ }^{235} \mathrm{U}$ & $\pm 1 \sigma$ & Rho & ${ }^{207} \mathrm{~Pb} /{ }^{206} \mathrm{~Pb}$ & $\pm 1 \sigma$ & ${ }^{206} \mathrm{~Pb} /{ }^{238} \mathrm{U}$ & $\pm 1 \sigma$ & ${ }^{207} \mathrm{~Pb} /{ }^{235} \mathrm{U}$ & $\pm 1 \sigma$ & Conc. \\
\hline \multirow[t]{27}{*}{ PS 22} & 0,627 & 0,069 & 1,396 & 0,14 & 0,787 & 1,333 & 1,396 & 0,766 & 900 & 24 & 845 & 6 & 860 & 8 & 93,9 \\
\hline & 1,422 & 0,073 & 3,013 & 0,151 & 0,59 & 1,517 & 3,013 & 0,316 & 1014 & 60 & 905 & 5 & 937 & 18 & 89,3 \\
\hline & 0,211 & 0,07 & 1,053 & 0,151 & 0,795 & 1,453 & 1,053 & 0,728 & 924 & 14 & 906 & 7 & 911 & 6 & 98,1 \\
\hline & 0,312 & 0,07 & 0,757 & 0,151 & 0,661 & 1,458 & 0,757 & 0,846 & 925 & 8 & 908 & 6 & 913 & 5 & 98,2 \\
\hline & 0,33 & 0,073 & 0,877 & 0,155 & 0,716 & 1,552 & 0,877 & 0,787 & 1007 & 10 & 928 & 6 & 951 & 5 & 92,1 \\
\hline & 0,311 & 0,074 & 1,633 & 0,16 & 1,552 & 1,624 & 1,633 & 0,949 & 1031 & 10 & 957 & 14 & 979 & 10 & 92,8 \\
\hline & 0,243 & 0,073 & 0,816 & 0,16 & 0,638 & 1,61 & 0,816 & 0,739 & 1013 & 10 & 957 & 6 & 974 & 5 & 94,5 \\
\hline & 0,139 & 0,073 & 0,8 & 0,165 & 0,648 & 1,656 & 0,8 & 0,772 & 1013 & 9 & 983 & 6 & 992 & 5 & 97 \\
\hline & 0,229 & 0,073 & 0,735 & 0,165 & 0,58 & 1,664 & 0,735 & 0,735 & 1019 & 9 & 984 & 5 & 995 & 5 & 96,6 \\
\hline & 1,686 & 0,074 & 2,027 & 0,166 & 1,492 & 1,697 & 2,027 & 0,728 & 1042 & 28 & 991 & 14 & 1007 & 13 & 95,1 \\
\hline & 0,002 & 0,073 & 1,886 & 0,171 & 1,41 & 1,706 & 1,886 & 0,739 & 1000 & 25 & 1016 & 13 & 1011 & 12 & 101,6 \\
\hline & 0,244 & 0,079 & 0,865 & 0,192 & 0,711 & 2,084 & 0,865 & 0,792 & 1169 & 10 & 1130 & 7 & 1144 & 6 & 96,6 \\
\hline & 0,208 & 0,079 & 0,806 & 0,192 & 0,707 & 2,089 & 0,806 & 0,855 & 1172 & 8 & 1131 & 7 & 1145 & 6 & 96,5 \\
\hline & 0,021 & 0,08 & 0,73 & 0,194 & 0,545 & 2,143 & 0,73 & 0,677 & 1196 & 10 & 1145 & 6 & 1163 & 5 & 95,8 \\
\hline & 0,233 & 0,079 & 1,194 & 0,198 & 1,094 & 2,158 & 1,194 & 0,91 & 1171 & 9 & 1166 & 12 & 1168 & 8 & 99,6 \\
\hline & 0,24 & 0,081 & 0,726 & 0,2 & 0,651 & 2,233 & 0,726 & 0,873 & 1220 & 6 & 1176 & 7 & 1191 & 5 & 96,4 \\
\hline & 0,181 & 0,084 & 1,492 & 0,208 & 0,981 & 2,425 & 1,492 & 0,637 & 1303 & 22 & 1220 & 11 & 1250 & 11 & 93,6 \\
\hline & 0,18 & 0,086 & 0,984 & 0,213 & 0,932 & 2,522 & 0,984 & 0,943 & 1338 & 6 & 1243 & 11 & 1278 & 7 & 92,9 \\
\hline & 0,863 & 0,105 & 1,169 & 0,214 & 0,887 & 3,103 & 1,169 & 0,739 & 1721 & 14 & 1248 & 10 & 1434 & 9 & 72,5 \\
\hline & 0,029 & 0,083 & 0,586 & 0,214 & 0,504 & 2,448 & 0,586 & 0,801 & 1268 & 6 & 1250 & 6 & 1257 & 4 & 98,6 \\
\hline & 0,218 & 0,085 & 0,669 & 0,22 & 0,617 & 2,589 & 0,669 & 0,901 & 1324 & 5 & 1281 & 7 & 1297 & 5 & 96,7 \\
\hline & 0,847 & 0,098 & 7,156 & 0,232 & 1,294 & 3,136 & 7,156 & 0,335 & 1590 & 131 & 1343 & 16 & 1441 & 55 & 84,4 \\
\hline & 0,317 & 0,093 & 0,708 & 0,233 & 0,59 & 2,979 & 0,708 & 0,789 & 1486 & 7 & 1348 & 7 & 1402 & 5 & 90,7 \\
\hline & 0,167 & 0,089 & 0,994 & 0,234 & 0,692 & 2,853 & 0,994 & 0,845 & 1393 & 14 & 1354 & 8 & 1370 & 7 & 97,2 \\
\hline & 0,425 & 0,095 & 1,392 & 0,241 & 0,613 & 3,155 & 1,392 & 0,388 & 1527 & 24 & 1392 & 8 & 1446 & 11 & 91,1 \\
\hline & 0,274 & 0,086 & 0,884 & 0,242 & 0,642 & 2,879 & 0,884 & 0,678 & 1347 & 12 & 1395 & 8 & 1376 & 7 & 103,6 \\
\hline & 0,309 & 0,095 & 0,716 & 0,243 & 0,604 & 3,175 & 0,716 & 0,899 & 1521 & 7 & 1404 & 8 & 1451 & 6 & 92,3 \\
\hline
\end{tabular}




\begin{tabular}{|c|c|c|c|c|c|c|c|c|c|c|c|c|c|c|}
\hline 0,553 & 0,095 & 0,821 & 0,247 & 0,69 & 3,248 & 0,821 & 0,914 & 1534 & 8 & 1424 & 9 & 1469 & 6 & 92,9 \\
\hline 0,871 & 0,104 & 1,889 & 0,25 & 0,745 & 3,592 & 1,889 & 0,602 & 1699 & 32 & 1439 & 10 & 1548 & 15 & 84,7 \\
\hline 0,351 & 0,088 & 0,929 & 0,251 & 0,611 & 3,034 & 0,929 & 0,6 & 1374 & 13 & 1444 & 8 & 1416 & 7 & 105,1 \\
\hline 0,263 & 0,094 & 0,76 & 0,254 & 0,709 & 3,282 & 0,76 & 0,92 & 1505 & 5 & 1458 & 9 & 1477 & 6 & 96,9 \\
\hline 0,361 & 0,095 & 0,701 & 0,255 & 0,633 & 3,332 & 0,701 & 0,879 & 1520 & 6 & 1466 & 8 & 1488 & 5 & 96,5 \\
\hline 0,376 & 0,1 & 0,991 & 0,272 & 0,81 & 3,768 & 0,991 & 0,912 & 1630 & 11 & 1553 & 11 & 1586 & 8 & 95,2 \\
\hline 0,219 & 0,096 & 0,83 & 0,278 & 0,686 & 3,675 & 0,83 & 0,897 & 1548 & 9 & 1579 & 10 & 1566 & 7 & 102 \\
\hline 0,488 & 0,106 & 0,766 & 0,278 & 0,577 & 4,046 & 0,766 & 0,694 & 1723 & 9 & 1582 & 8 & 1644 & 6 & 91,8 \\
\hline 0,793 & 0,108 & 1,038 & 0,28 & 0,886 & 4,185 & 1,038 & 0,838 & 1774 & 10 & 1591 & 12 & 1671 & 9 & 89,7 \\
\hline 0,502 & 0,107 & 0,883 & 0,285 & 0,718 & 4,209 & 0,883 & 0,783 & 1753 & 9 & 1615 & 10 & 1676 & 7 & 92,1 \\
\hline 0,371 & 0,101 & 1,484 & 0,285 & 1,127 & 3,977 & 1,484 & 0,747 & 1644 & 18 & 1618 & 16 & 1629 & 12 & 98,4 \\
\hline 0,225 & 0,121 & 1,427 & 0,296 & 1,365 & 4,938 & 1,427 & 0,96 & 1970 & 7 & 1672 & 20 & 1809 & 12 & 84,9 \\
\hline 0,523 & 0,106 & 0,824 & 0,296 & 0,683 & 4,323 & 0,824 & 0,797 & 1728 & 8 & 1673 & 10 & 1698 & 7 & 96,8 \\
\hline 0,775 & 0,109 & 0,997 & 0,302 & 0,773 & 4,52 & 0,997 & 0,884 & 1775 & 12 & 1701 & 12 & 1735 & 8 & 95,8 \\
\hline 0,725 & 0,115 & 0,875 & 0,304 & 0,74 & 4,837 & 0,875 & 0,822 & 1884 & 8 & 1713 & 11 & 1791 & 7 & 90,9 \\
\hline 0,594 & 0,11 & 2,525 & 0,305 & 2,052 & 4,644 & 2,525 & 0,809 & 1808 & 27 & 1715 & 31 & 1757 & 21 & 94,9 \\
\hline 0,320 & 0,108 & 0,86 & 0,308 & 0,778 & 4,571 & 0,86 & 0,891 & 1762 & 7 & 1729 & 12 & 1744 & 7 & 98,2 \\
\hline 0,681 & 0,109 & 0,789 & 0,308 & 0,718 & 4,622 & 0,789 & 0,893 & 1778 & 6 & 1732 & 11 & 1753 & 7 & 97,4 \\
\hline 0,713 & 0,109 & 0,723 & 0,311 & 0,534 & 4,671 & 0,723 & 0,829 & 1779 & 9 & 1748 & 8 & 1762 & 6 & 98,2 \\
\hline 0,508 & 0,11 & 0,848 & 0,312 & 0,764 & 4,751 & 0,848 & 0,885 & 1806 & 7 & 1752 & 12 & 1776 & 7 & 97 \\
\hline 0,618 & 0,111 & 0,758 & 0,313 & 0,548 & 4,774 & 0,758 & 0,811 & 1809 & 10 & 1756 & 8 & 1780 & 6 & 97,1 \\
\hline 0,368 & 0,106 & 1,196 & 0,316 & 0,583 & 4,634 & 1,196 & 0,425 & 1737 & 19 & 1771 & 9 & 1755 & 10 & 102 \\
\hline 0,746 & 0,115 & 0,782 & 0,318 & 0,663 & 5,033 & 0,782 & 0,816 & 1876 & 7 & 1781 & 10 & 1825 & 7 & 94,9 \\
\hline 0,185 & 0,119 & 0,675 & 0,32 & 0,617 & 5,245 & 0,675 & 0,891 & 1937 & 5 & 1792 & 10 & 1860 & 6 & 92,5 \\
\hline 0,573 & 0,109 & 0,694 & 0,329 & 0,619 & 4,95 & 0,694 & 0,864 & 1787 & 6 & 1831 & 10 & 1811 & 6 & 102,5 \\
\hline 0,865 & 0,121 & 0,77 & 0,334 & 0,686 & 5,579 & 0,77 & 0,869 & 1975 & 6 & 1856 & 11 & 1913 & 7 & 94 \\
\hline 0,365 & 0,119 & 0,738 & 0,344 & 0,686 & 5,661 & 0,738 & 0,915 & 1948 & 5 & 1905 & 11 & 1925 & 6 & 97,8 \\
\hline 0,7 & 0,124 & 0,789 & 0,347 & 0,723 & 5,906 & 0,789 & 0,903 & 2008 & 6 & 1919 & 12 & 1962 & 7 & 95,5 \\
\hline 0,334 & 0,125 & 0,802 & 0,36 & 0,682 & 6,189 & 0,802 & 0,911 & 2023 & 7 & 1984 & 12 & 2003 & 7 & 98,1 \\
\hline
\end{tabular}




\begin{tabular}{|c|c|c|c|c|c|c|c|c|c|c|c|c|c|c|}
\hline 0,296 & 0,118 & 1,616 & 0,384 & 1,442 & 6,269 & 1,616 & 0,888 & 1933 & 13 & 2094 & 26 & 2014 & 14 & $\underset{108,3}{9}$ \\
\hline 0,376 & 0,174 & 1,29 & 0,482 & 1,263 & 11,604 & 1,29 & 0,978 & 2601 & 4 & 2537 & 26 & 2573 & 12 & 97,5 \\
\hline
\end{tabular}

\begin{tabular}{|c|c|c|c|c|c|c|c|c|c|c|c|c|c|c|c|}
\hline \multirow[b]{2}{*}{ Amostra } & \multirow[b]{2}{*}{$\mathrm{Th} / \mathrm{U}$} & \multicolumn{6}{|c|}{ Razões Radiogênicas } & \multirow[b]{2}{*}{ Rho } & \multicolumn{6}{|c|}{$\begin{array}{l}\text { Estimativa } \\
\text { de Idade } \\
\text { (Ma) }\end{array}$} & \multirow[b]{2}{*}{ Conc. } \\
\hline & & $207 \mathrm{~Pb} / 206 \mathrm{~Pb}$ & $\pm 1 \sigma$ & $206 \mathrm{~Pb} / 238 \mathrm{U}$ & $\pm 1 \sigma$ & $207 \mathrm{~Pb} / 235 \mathrm{U}$ & $\pm 1 \sigma$ & & $207 \mathrm{~Pb} / 206 \mathrm{~Pb}$ & $\pm 1 \sigma$ & $206 \mathrm{~Pb} / 238 \mathrm{U}$ & $\pm 1 \sigma$ & $207 \mathrm{~Pb} / 235 \mathrm{U}$ & $\pm 1 \sigma$ & \\
\hline \multirow[t]{21}{*}{ PS 40-C } & 0,155 & 0,076 & 0,446 & 0,166 & 0,864 & 1,730 & 0,972 & 0,876 & 1086 & 9 & 989 & 8 & 1020 & 6 & 91,1 \\
\hline & 0,211 & 0,081 & 0,460 & 0,191 & 0,936 & 2,146 & 1,043 & 0,887 & 1233 & 9 & 1127 & 10 & 1164 & 7 & 91,4 \\
\hline & 0,131 & 0,087 & 0,370 & 0,222 & 0,725 & 2,676 & 0,814 & 0,871 & 1368 & 7 & 1293 & 8 & 1322 & 6 & 94,5 \\
\hline & 0,078 & 0,086 & 0,294 & 0,221 & 0,819 & 2,624 & 0,870 & 0,933 & 1340 & 6 & 1288 & 10 & 1307 & 6 & 96,2 \\
\hline & 0,237 & 0,080 & 0,440 & 0,192 & 1,383 & 2,122 & 1,451 & 0,951 & 1197 & 9 & 1135 & 14 & 1156 & 10 & 94,8 \\
\hline & 0,065 & 0,079 & 0,354 & 0,189 & 0,854 & 2,063 & 0,925 & 0,914 & 1179 & 7 & 1115 & 9 & 1137 & 6 & 94,6 \\
\hline & 0,110 & 0,085 & 0,305 & 0,223 & 0,922 & 2,628 & 0,971 & 0,944 & 1326 & 6 & 1298 & 11 & 1309 & 7 & 97,9 \\
\hline & 0,099 & 0,080 & 0,574 & 0,200 & 0,730 & 2,201 & 0,928 & 0,755 & 1198 & 11 & 1173 & 8 & 1182 & 6 & 97,9 \\
\hline & 0,153 & 0,084 & 0,390 & 0,228 & 0,686 & 2,645 & 0,789 & 0,844 & 1299 & 8 & 1322 & 8 & 1313 & 6 & 101,8 \\
\hline & 0,166 & 0,071 & 0,394 & 0,165 & 0,724 & 1,617 & 0,824 & 0,857 & 958 & 8 & 985 & 7 & 977 & 5 & 102,8 \\
\hline & 0,223 & 0,092 & 0,321 & 0,249 & 0,957 & 3,142 & 1,009 & 0,943 & 1459 & 6 & 1432 & 12 & 1443 & 8 & 98,2 \\
\hline & 0,167 & 0,071 & 0,545 & 0,154 & 1,271 & 1,500 & 1,383 & 0,915 & 944 & 11 & 925 & 11 & 930 & 8 & 97,9 \\
\hline & 0,175 & 0,095 & 0,324 & 0,283 & 1,057 & 3,711 & 1,106 & 0,953 & 1530 & 6 & 1606 & 15 & 1574 & 9 & 105,0 \\
\hline & 0,411 & 0,114 & 0,372 & 0,355 & 1,133 & 5,581 & 1,192 & 0,947 & 1865 & 7 & 1958 & 19 & 1913 & 10 & 105,0 \\
\hline & 0,470 & 0,106 & 0,376 & 0,308 & 1,040 & 4,503 & 1,106 & 0,936 & 1734 & 7 & 1729 & 16 & 1732 & 9 & 99,7 \\
\hline & 0,125 & 0,079 & 0,387 & 0,217 & 0,823 & 2,353 & 0,909 & 0,892 & 1164 & 8 & 1265 & 9 & 1228 & 6 & 108,6 \\
\hline & 0,210 & 0,078 & 0,538 & 0,198 & 0,786 & 2,124 & 0,952 & 0,802 & 1141 & 11 & 1165 & 8 & 1157 & 7 & 102,2 \\
\hline & 0,102 & 0,085 & 0,455 & 0,241 & 0,826 & 2,835 & 0,943 & 0,860 & 1323 & 9 & 1391 & 10 & 1365 & 7 & 105,1 \\
\hline & 0,255 & 0,083 & 0,350 & 0,237 & 0,679 & 2,715 & 0,764 & 0,866 & 1273 & 7 & 1370 & 8 & 1333 & 6 & 107,7 \\
\hline & 0,203 & 0,080 & 0,358 & 0,214 & 0,665 & 2,360 & 0,755 & 0,855 & 1198 & 7 & 1249 & 8 & 1230 & 5 & 104,3 \\
\hline & 0,177 & 0,098 & 0,335 & 0,200 & 1,201 & 4,034 & 1,247 & 0,961 & 1589 & 6 & 1682 & 18 & 1641 & 10 & 105,9 \\
\hline \multicolumn{2}{|c|}{ S. C. R. Souza } & & & & & & 2015 & & & & & & & & $I G-U n B$ \\
\hline
\end{tabular}




$\begin{array}{llll}0,314 & 0,079 & 0,473 & 0,269 \\ 0,216 & 0,093 & 0,407 & 0,282 \\ 0,192 & 0,104 & 0,414 & 0,321 \\ 0,242 & 0,083 & 0,789 & 0,211 \\ 0,039 & 0,075 & 1,505 & 0,194 \\ 0,155 & 0,075 & 0,497 & 0,175 \\ 0,202 & 0,072 & 1,433 & 0,184 \\ 0,166 & 0,079 & 0,491 & 0,213 \\ 0,110 & 0,099 & 0,369 & 0,289 \\ 0,357 & 0,074 & 0,440 & 0,167 \\ 0,124 & 0,088 & 0,591 & 0,237 \\ 0,194 & 0,096 & 0,421 & 0,279 \\ 0,151 & 0,085 & 0,435 & 0,237 \\ 0,251 & 0,087 & 0,553 & 0,234 \\ 0,048 & 0,073 & 0,440 & 0,161 \\ 0,296 & 0,091 & 1,146 & 0,235 \\ 0,158 & 0,074 & 0,458 & 0,172 \\ 0,137 & 0,081 & 0,382 & 0,210 \\ 0,127 & 0,082 & 0,438 & 0,206 \\ 0,163 & 0,094 & 0,374 & 0,272 \\ 0,122 & 0,079 & 0,357 & 0,212 \\ 0,425 & 0,096 & 0,326 & 0,268 \\ 0,165 & 0,091 & 0,282 & 0,251 \\ 0,166 & 0,072 & 0,539 & 0,172 \\ 0,348 & 0,110 & 0,270 & 0,329 \\ 0,141 & 0,090 & 0,322 & 0,259 \\ 0,274 & 0,079 & 0,401 & 0,202 \\ 0,272 & 0,078 & 0,560 & 0,191 \\ & & & \\ 0,139\end{array}$

$\begin{array}{ll}0,972 & 2,184 \\ 1,052 & 3,453 \\ 1,492 & 4,618 \\ 1,538 & 2,401 \\ 1,541 & 1,995 \\ 0,659 & 1,815 \\ 2,705 & 1,833 \\ 1,097 & 2,326 \\ 1,098 & 3,949 \\ 1,239 & 1,701 \\ 0,975 & 2,874 \\ 1,272 & 3,699 \\ 0,934 & 2,781 \\ 0,671 & 2,807 \\ 1,732 & 1,624 \\ 0,795 & 2,956 \\ 0,776 & 1,743 \\ 0,705 & 2,330 \\ 0,559 & 2,338 \\ 0,518 & 3,527 \\ 0,660 & 2,307 \\ 0,665 & 3,553 \\ 0,526 & 3,147 \\ 0,808 & 1,713 \\ 0,572 & 4,995 \\ 0,662 & 3,203 \\ 0,538 & 2,208 \\ 1,161 & 2,066 \\ & \end{array}$

$\begin{array}{ll}1,081 & 0,890 \\ 1,128 & 0,927 \\ 1,548 & 0,962 \\ 1,729 & 0,886 \\ 2,154 & 0,708 \\ 0,825 & 0,760 \\ 3,061 & 0,892 \\ 1,202 & 0,906 \\ 1,158 & 0,944 \\ 1,315 & 0,939 \\ 1,141 & 0,843 \\ 1,654 & 0,966 \\ 1,344 & 0,944 \\ 1,085 & 0,847 \\ 0,802 & 0,804 \\ 2,077 & 0,830 \\ 0,918 & 0,848 \\ 0,865 & 0,881 \\ 0,830 & 0,823 \\ 0,639 & 0,742 \\ 0,750 & 0,853 \\ 0,740 & 0,876 \\ 0,597 & 0,834 \\ 0,971 & 0,811 \\ 0,633 & 0,874 \\ 0,736 & 0,877 \\ 0,671 & 0,738 \\ 1,289 & 0,895 \\ 2015 & \\ & \end{array}$

$\begin{array}{cc}1181 & 9 \\ 1489 & 8 \\ 1703 & 8 \\ 1259 & 15 \\ 1058 & 30 \\ 1071 & 10 \\ 993 & 29 \\ 1174 & 10 \\ 1605 & 7 \\ 1039 & 9 \\ 1384 & 11 \\ 1551 & 8 \\ 1319 & 8 \\ 1359 & 11 \\ 1024 & 9 \\ 1448 & 22 \\ 1028 & 9 \\ 1211 & 8 \\ 1250 & 9 \\ 1512 & 7 \\ 1172 & 7 \\ 1550 & 6 \\ 1447 & 5 \\ 994 & 11 \\ 1799 & 5 \\ 1420 & 6 \\ 1175 & 8 \\ 1159 & 11 \\ & \\ & \\ 1039 \\ 112\end{array}$

1173
1537
1794
1233
1143
1041
1089
1247
1638
995
1369
1586
1371
1356
960
1363
1023
1227
1209
1549
1239
1531
1442
1022
1835
1484
1188
1127

2015




\begin{tabular}{|c|c|c|c|c|c|c|c|c|c|c|c|c|c|c|}
\hline 0,215 & 0,087 & 0,293 & 0,232 & 0,702 & 2,778 & 0,761 & 0,908 & 1361 & 6 & 1342 & 9 & 1350 & 6 & 98,6 \\
\hline 0,129 & 0,090 & 0,265 & 0,258 & 0,890 & 3,220 & 0,929 & 0,954 & 1434 & 5 & 1481 & 12 & 1462 & 7 & 103,3 \\
\hline 0,030 & 0,070 & 0,251 & 0,168 & 0,739 & 1,627 & 0,780 & 0,938 & 932 & 5 & 1002 & 7 & 981 & 5 & 107,5 \\
\hline 0,069 & 0,077 & 0,705 & 0,207 & 1,637 & 2,196 & 1,782 & 0,916 & 1119 & 14 & 1214 & 18 & 1180 & 12 & 108,5 \\
\hline 0,156 & 0,076 & 0,494 & 0,173 & 1,053 & 1,808 & 1,163 & 0,898 & 1090 & 10 & 1028 & 10 & 1048 & 8 & 94,3 \\
\hline
\end{tabular}

\section{Formação Raizama}

\begin{tabular}{|c|c|c|c|c|c|c|c|c|c|c|c|c|c|c|c|}
\hline \multirow[b]{2}{*}{ Amostra } & \multicolumn{7}{|c|}{ Razões Radiogênicas } & \multirow[b]{2}{*}{ Rho } & \multicolumn{6}{|c|}{ Estimativa de Idade (Ma) } & \multirow[b]{2}{*}{ Conc. } \\
\hline & $\mathrm{Th} / \mathrm{U}$ & $207 \mathrm{~Pb} / 206 \mathrm{~Pb}$ & $\pm 1 \sigma$ & $206 \mathrm{~Pb} / 238 \mathrm{U}$ & $\pm 1 \sigma$ & $207 \mathrm{~Pb} / 235 \mathrm{U}$ & $\pm 1 \sigma$ & & $207 \mathrm{~Pb} / 206 \mathrm{~Pb}$ & $\pm 1 \sigma$ & $206 \mathrm{~Pb} / 238 \mathrm{U}$ & $\pm 1 \sigma$ & $207 \mathrm{~Pb} / 235 \mathrm{U}$ & $\pm 1 \sigma$ & \\
\hline \multirow[t]{18}{*}{ PS 11} & 0,334 & 0,072 & 0,943 & 0,144 & 1,692 & 1,422 & 1,937 & 0,87 & 977 & 19 & 867 & 14 & 898 & 12 & 88,7 \\
\hline & 0,214 & 0,071 & 0,715 & 0,148 & 0,531 & 1,44 & 0,891 & 0,736 & 949 & 15 & 888 & 4 & 906 & 5 & 93,6 \\
\hline & 0,195 & 0,07 & 0,762 & 0,152 & 0,796 & 1,469 & 1,102 & 0,693 & 934 & 16 & 911 & 7 & 918 & 7 & 97,6 \\
\hline & 0,316 & 0,073 & 0,591 & 0,16 & 0,816 & 1,615 & 1,007 & 0,787 & 1018 & 12 & 957 & 7 & 976 & 6 & 94 \\
\hline & 0,328 & 0,073 & 1,123 & 0,161 & 1,256 & 1,627 & 1,685 & 0,735 & 1016 & 23 & 965 & 11 & 981 & 11 & 94,9 \\
\hline & 0,231 & 0,073 & 0,766 & 0,164 & 1,042 & 1,643 & 1,293 & 0,792 & 1004 & 16 & 979 & 9 & 987 & 8 & 97,6 \\
\hline & 0,197 & 0,074 & 1,696 & 0,164 & 0,736 & 1,668 & 1,849 & 0,613 & 1032 & 34 & 980 & 7 & 996 & 12 & 95 \\
\hline & 0,247 & 0,074 & 1,036 & 0,167 & 0,928 & 1,709 & 1,391 & 0,846 & 1046 & 21 & 996 & 9 & 1012 & 9 & 95,2 \\
\hline & 0,235 & 0,073 & 0,581 & 0,169 & 0,988 & 1,699 & 1,146 & 0,85 & 1009 & 12 & 1008 & 9 & 1008 & 7 & 99,9 \\
\hline & 0,558 & 0,08 & 2,157 & 0,17 & 1,025 & 1,86 & 2,39 & 0,665 & 1186 & 42 & 1010 & 10 & 1067 & 16 & 85,2 \\
\hline & 0,314 & 0,073 & 0,818 & 0,17 & 0,655 & 1,718 & 1,049 & 0,797 & 1026 & 17 & 1011 & 6 & 1015 & 7 & 98,5 \\
\hline & 0,108 & 0,074 & 2,316 & 0,173 & 2,405 & 1,758 & 3,338 & 0,717 & 1032 & 47 & 1029 & 23 & 1030 & 22 & 99,7 \\
\hline & 0,301 & 0,074 & 0,502 & 0,173 & 0,798 & 1,776 & 0,943 & 0,826 & 1052 & 10 & 1029 & 8 & 1037 & 6 & 97,9 \\
\hline & 0,266 & 0,078 & 0,587 & 0,175 & 0,858 & 1,884 & 1,04 & 0,806 & 1146 & 12 & 1041 & 8 & 1076 & 7 & 90,9 \\
\hline & 0,342 & 0,094 & 1,7 & 0,19 & 2,058 & 2,478 & 2,69 & 0,767 & 1518 & 32 & 1123 & 21 & 1266 & 19 & 74 \\
\hline & 0,241 & 0,078 & 1,043 & 0,191 & 0,558 & 2,045 & 1,183 & 0,646 & 1136 & 21 & 1128 & 6 & 1131 & 8 & 99,2 \\
\hline & 0,238 & 0,079 & 0,398 & 0,192 & 0,549 & 2,088 & 0,679 & 0,751 & 1169 & 8 & 1132 & 6 & 1145 & 5 & 96,8 \\
\hline & 0,289 & 0,08 & 0,418 & 0,193 & 0,755 & 2,138 & 0,863 & 0,855 & 1205 & 8 & 1137 & 8 & 1161 & 6 & 94,4 \\
\hline
\end{tabular}




\begin{tabular}{|c|c|c|c|c|c|c|c|c|c|c|}
\hline 0,243 & 0,08 & 0,301 & 0,194 & 0,605 & 2,137 & 0,676 & 0,867 & 1199 & 6 & 1141 \\
\hline 0,307 & 0,079 & 0,418 & 0,194 & 0,682 & 2,102 & 0,8 & 0,824 & 1164 & 8 & 1142 \\
\hline 0,301 & 0,078 & 0,747 & 0,194 & 0,954 & 2,088 & 1,212 & 0,77 & 1148 & 15 & 1143 \\
\hline 0,256 & 0,082 & 0,627 & 0,205 & 0,887 & 2,314 & 1,086 & 0,799 & 1246 & 12 & 1200 \\
\hline 0,514 & 0,083 & 1,33 & 0,206 & 0,635 & 2,344 & 1,474 & 0,383 & 1259 & 26 & 1207 \\
\hline 0,458 & 0,082 & 1,156 & 0,209 & 0,684 & 2,369 & 1,343 & 0,465 & 1247 & 23 & 1225 \\
\hline 0,195 & 0,082 & 0,471 & 0,21 & 0,59 & 2,379 & 0,755 & 0,729 & 1249 & 9 & 1229 \\
\hline 0,208 & 0,081 & 0,438 & 0,212 & 0,76 & 2,374 & 0,877 & 0,846 & 1227 & 9 & 1239 \\
\hline 0,361 & 0,08 & 1,435 & 0,215 & 0,945 & 2,373 & 1,718 & 0,528 & 1200 & 28 & 1254 \\
\hline 0,203 & 0,083 & 0,639 & 0,219 & 1,115 & 2,498 & 1,285 & 0,944 & 1262 & 12 & 1277 \\
\hline 0,325 & 0,091 & 0,583 & 0,228 & 0,79 & 2,875 & 0,982 & 0,78 & 1453 & 11 & 1326 \\
\hline 0,337 & 0,089 & 0,297 & 0,229 & 0,483 & 2,826 & 0,567 & 0,779 & 1414 & 6 & 1330 \\
\hline 0,319 & 0,093 & 0,518 & 0,23 & 0,869 & 2,96 & 1,012 & 0,843 & 1491 & 10 & 1336 \\
\hline 0,356 & 0,094 & 0,68 & 0,234 & 2,115 & 3,03 & 2,233 & 0,951 & 1506 & 13 & 1356 \\
\hline 0,438 & 0,089 & 0,386 & 0,234 & 0,741 & 2,871 & 0,836 & 0,928 & 1401 & 7 & 1357 \\
\hline 0,558 & 0,091 & 0,602 & 0,236 & 0,879 & 2,965 & 1,065 & 0,807 & 1447 & 11 & 1367 \\
\hline 0,351 & 0,094 & 0,457 & 0,237 & 0,821 & 3,061 & 0,939 & 0,857 & 1500 & 9 & 1372 \\
\hline 0,483 & 0,093 & 1,086 & 0,24 & 1,034 & 3,07 & 1,5 & 0,865 & 1484 & 21 & 1386 \\
\hline 0,546 & 0,089 & 0,29 & 0,242 & 0,827 & 2,968 & 0,876 & 0,936 & 1405 & 6 & 1396 \\
\hline 0,408 & 0,091 & 0,501 & 0,247 & 0,656 & 3,111 & 0,826 & 0,755 & 1454 & 10 & 1423 \\
\hline 0,326 & 0,095 & 0,423 & 0,256 & 1,043 & 3,367 & 1,125 & 0,921 & 1537 & 8 & 1468 \\
\hline 0,234 & 0,091 & 1,84 & 0,257 & 0,653 & 3,224 & 1,952 & 0,297 & 1447 & 35 & 1474 \\
\hline 0,228 & 0,098 & 0,359 & 0,262 & 0,616 & 3,527 & 0,713 & 0,829 & 1581 & 7 & 1499 \\
\hline 0,348 & 0,091 & 0,583 & 0,262 & 1,351 & 3,29 & 1,472 & 0,915 & 1447 & 11 & 1501 \\
\hline 1,059 & 0,101 & 0,462 & 0,263 & 0,869 & 3,676 & 0,984 & 0,869 & 1647 & 9 & 1507 \\
\hline 0,283 & 0,098 & 0,41 & 0,27 & 0,707 & 3,632 & 0,817 & 0,841 & 1578 & 8 & 1541 \\
\hline 0,875 & 0,106 & 3,153 & 0,288 & 1,023 & 4,209 & 3,317 & 0,295 & 1731 & 57 & 1632 \\
\hline 0,517 & 0,107 & 0,892 & 0,297 & 0,694 & 4,391 & 1,13 & 0,8 & 1753 & 16 & 1676 \\
\hline 0,554 & 0,11 & 0,3 & 0,301 & 0,696 & 4,563 & 0,758 & 0,902 & 1800 & 5 & 1696 \\
\hline
\end{tabular}




\begin{tabular}{|c|c|c|c|c|c|c|c|c|c|c|c|c|c|c|}
\hline 0,723 & 0,109 & 0,499 & 0,306 & 0,751 & 4,607 & 0,902 & 0,808 & 1783 & 9 & 1723 & 11 & 1751 & 8 & $\begin{array}{r}94 \\
96,6\end{array}$ \\
\hline 0,354 & 0,109 & 0,37 & 0,307 & 0,586 & 4,605 & 0,693 & 0,802 & 1780 & 7 & 1725 & 9 & 1750 & 6 & 97 \\
\hline 0,484 & 0,111 & 1,024 & 0,308 & 0,921 & 4,73 & 1,378 & 0,646 & 1824 & 19 & 1729 & 14 & 1772 & 12 & 94,8 \\
\hline 0,638 & 0,108 & 0,437 & 0,31 & 0,651 & 4,639 & 0,784 & 0,795 & 1773 & 8 & 1742 & 10 & 1756 & 7 & 98,2 \\
\hline 0,548 & 0,112 & 1,46 & 0,312 & 0,689 & 4,823 & 1,614 & 0,635 & 1832 & 26 & 1753 & 11 & 1789 & 14 & 95,7 \\
\hline 0,575 & 0,117 & 0,456 & 0,314 & 0,99 & 5,074 & 1,09 & 0,9 & 1915 & 8 & 1759 & 15 & 1832 & 9 & 91,9 \\
\hline 0,591 & 0,113 & 3,221 & 0,314 & 0,571 & 4,891 & 3,271 & 0,146 & 1846 & 58 & 1762 & 9 & 1801 & 28 & 95,5 \\
\hline 1,096 & 0,109 & 0,522 & 0,315 & 0,803 & 4,722 & 0,958 & 0,928 & 1776 & 10 & 1767 & 12 & 1771 & 8 & 99,5 \\
\hline 0,768 & 0,114 & 0,424 & 0,321 & 0,603 & 5,037 & 0,737 & 0,773 & 1864 & 8 & 1792 & 9 & 1826 & 6 & 96,2 \\
\hline 0,413 & 0,108 & 0,777 & 0,325 & 0,754 & 4,862 & 1,083 & 0,856 & 1773 & 14 & 1815 & 12 & 1796 & 9 & 102,4 \\
\hline
\end{tabular}

Razões Radiogênicas

Estimativa de Idade (Ma)

\begin{tabular}{|c|c|c|c|c|c|c|c|c|c|c|c|c|c|c|c|}
\hline \multirow{2}{*}{ Amostra } & \multirow[b]{2}{*}{$\mathrm{Th} / \mathrm{U}$} & & \multirow[b]{2}{*}{ Rho } & & \multirow[b]{2}{*}{ Conc. } \\
\hline & & $207 \mathrm{~Pb} / 206 \mathrm{~Pb}$ & $\pm 1 \sigma$ & $206 \mathrm{~Pb} / 238 \mathrm{U}$ & $\pm 1 \sigma$ & $207 \mathrm{~Pb} / 235 \mathrm{U}$ & $\pm 1 \sigma$ & & $207 \mathrm{~Pb} / 206 \mathrm{~Pb}$ & $\pm 1 \sigma$ & $206 \mathrm{~Pb} / 238 \mathrm{U}$ & $\pm 1 \sigma$ & $207 \mathrm{~Pb} / 235 \mathrm{U}$ & $\pm 1 \sigma$ & \\
\hline PS 30 & 0,383 & 0,072 & 1,365 & 0,162 & 0,81 & 1,609 & 1,589 & 0,48 & 988 & 28 & 967 & 7 & 974 & 10 & 98 \\
\hline & 0,254 & 0,071 & 2,988 & 0,162 & 1,912 & 1,596 & 3,574 & 0,534 & 965 & 60 & 970 & 18 & 969 & 22 & 101 \\
\hline & 0,131 & 0,074 & 0,287 & 0,168 & 0,574 & 1,704 & 0,642 & 0,861 & 1034 & 6 & 999 & 5 & 1010 & 4 & 97 \\
\hline & 0,25 & 0,078 & 0,437 & 0,184 & 0,762 & 1,971 & 0,878 & 0,848 & 1136 & 9 & 1090 & 8 & 1106 & 6 & 96 \\
\hline & 0,105 & 0,08 & 1,649 & 0,188 & 0,625 & 2,069 & 1,763 & 0,543 & 1193 & 33 & 1111 & 6 & 1139 & 12 & 93 \\
\hline & 0,399 & 0,081 & 0,872 & 0,191 & 1,062 & 2,143 & 1,374 & 0,759 & 1233 & 17 & 1125 & 11 & 1163 & 10 & 91 \\
\hline & 0,19 & 0,079 & 0,366 & 0,192 & 0,665 & 2,092 & 0,759 & 0,85 & 1175 & 7 & 1131 & 7 & 1146 & 5 & 96 \\
\hline & 0,254 & 0,081 & 0,844 & 0,195 & 0,841 & 2,19 & 1,192 & 0,679 & 1227 & 17 & 1151 & 9 & 1178 & 8 & 94 \\
\hline & 0,271 & 0,081 & 0,397 & 0,196 & 0,996 & 2,197 & 1,073 & 0,923 & 1231 & 8 & 1153 & 11 & 1180 & 7 & 94 \\
\hline & 0,326 & 0,083 & 1,458 & 0,197 & 0,9 & 2,253 & 1,714 & 0,501 & 1267 & 28 & 1159 & 10 & 1198 & 12 & 91 \\
\hline & 0,263 & 0,081 & 0,592 & 0,198 & 0,897 & 2,217 & 1,075 & 0,818 & 1224 & 12 & 1166 & 10 & 1186 & 8 & 95 \\
\hline & 0,38 & 0,083 & 0,557 & 0,204 & 0,595 & 2,328 & 0,815 & 0,855 & 1267 & 11 & 1195 & 6 & 1221 & 6 & 94 \\
\hline & 0,194 & 0,084 & 0,337 & 0,205 & 0,555 & 2,362 & 0,65 & 0,807 & 1286 & 7 & 1200 & 6 & 1231 & 5 & 93 \\
\hline & 0,146 & 0,082 & 0,55 & 0,205 & 0,701 & 2,318 & 0,891 & 0,752 & 1241 & 11 & 1205 & 8 & 1218 & 6 & 97 \\
\hline & 0,255 & 0,112 & 1,474 & 0,219 & 2,313 & 3,376 & 2,77 & 0,841 & 1830 & 26 & 1276 & 27 & 1499 & 21 & 70 \\
\hline & 0,157 & 0,087 & 0,413 & 0,22 & 0,686 & 2,642 & 0,801 & 0,829 & 1363 & 8 & 1282 & 8 & 1312 & 6 & 94 \\
\hline
\end{tabular}




\begin{tabular}{|c|c|c|c|c|c|c|c|c|c|c|c|c|c|c|}
\hline 0,266 & 0,085 & 0,349 & 0,22 & 0,542 & 2,574 & 0,645 & 0,787 & 1309 & 7 & 1284 & 6 & 1293 & 5 & $\begin{array}{c}95 \\
98\end{array}$ \\
\hline 0,445 & 0,091 & 0,772 & 0,234 & 0,975 & 2,922 & 1,243 & 0,768 & 1441 & 15 & 1353 & 12 & 1388 & 9 & 94 \\
\hline 0,431 & 0,092 & 0,703 & 0,235 & 0,952 & 2,997 & 1,183 & 0,788 & 1474 & 13 & 1363 & 12 & 1407 & 9 & 92 \\
\hline 0,184 & 0,091 & 0,31 & 0,236 & 0,603 & 2,965 & 0,678 & 0,858 & 1450 & 6 & 1365 & 7 & 1399 & 5 & 94 \\
\hline 0,201 & 0,093 & 0,816 & 0,238 & 0,628 & 3,057 & 1,029 & 0,78 & 1493 & 15 & 1375 & 8 & 1422 & 8 & 92 \\
\hline 0,303 & 0,091 & 0,323 & 0,238 & 0,542 & 2,998 & 0,631 & 0,809 & 1455 & 6 & 1376 & 7 & 1407 & 5 & 95 \\
\hline 0,295 & 0,087 & 0,694 & 0,238 & 0,947 & 2,858 & 1,174 & 0,79 & 1359 & 13 & 1378 & 12 & 1371 & 9 & 101 \\
\hline 0,244 & 0,094 & 0,544 & 0,241 & 0,702 & 3,111 & 0,888 & 0,903 & 1502 & 10 & 1391 & 9 & 1435 & 7 & 93 \\
\hline 0,437 & 0,085 & 1,243 & 0,242 & 1,398 & 2,829 & 1,87 & 0,739 & 1311 & 24 & 1397 & 18 & 1363 & 14 & 107 \\
\hline 0,344 & 0,094 & 0,749 & 0,245 & 0,743 & 3,177 & 1,055 & 0,861 & 1508 & 14 & 1413 & 9 & 1452 & 8 & 94 \\
\hline 0,202 & 0,094 & 0,543 & 0,247 & 0,803 & 3,191 & 0,97 & 0,807 & 1504 & 10 & 1421 & 10 & 1455 & 7 & 94 \\
\hline 0,133 & 0,095 & 0,639 & 0,249 & 0,793 & 3,251 & 1,018 & 0,752 & 1522 & 12 & 1433 & 10 & 1469 & 8 & 94 \\
\hline 0,246 & 0,095 & 0,512 & 0,251 & 0,717 & 3,305 & 0,881 & 0,906 & 1538 & 10 & 1444 & 9 & 1482 & 7 & 94 \\
\hline 0,287 & 0,095 & 0,346 & 0,252 & 0,578 & 3,296 & 0,673 & 0,816 & 1528 & 7 & 1447 & 7 & 1480 & 5 & 95 \\
\hline 0,5 & 0,096 & 0,271 & 0,252 & 0,549 & 3,346 & 0,612 & 0,86 & 1552 & 5 & 1450 & 7 & 1492 & 5 & 93 \\
\hline 0,235 & 0,091 & 0,787 & 0,254 & 0,749 & 3,18 & 1,087 & 0,654 & 1443 & 15 & 1459 & 10 & 1452 & 8 & 101 \\
\hline 0,213 & 0,096 & 0,25 & 0,255 & 0,592 & 3,381 & 0,643 & 0,897 & 1553 & 5 & 1463 & 8 & 1500 & 5 & 94 \\
\hline 0,33 & 0,096 & 0,382 & 0,256 & 0,526 & 3,379 & 0,651 & 0,743 & 1543 & 7 & 1469 & 7 & 1499 & 5 & 95 \\
\hline 0,494 & 0,095 & 0,337 & 0,258 & 0,565 & 3,37 & 0,658 & 0,814 & 1523 & 6 & 1479 & 7 & 1497 & 5 & 97 \\
\hline 0,315 & 0,097 & 0,981 & 0,261 & 0,592 & 3,48 & 1,146 & 0,706 & 1561 & 18 & 1495 & 8 & 1523 & 9 & 96 \\
\hline 0,384 & 0,096 & 0,293 & 0,262 & 0,584 & 3,469 & 0,654 & 0,862 & 1547 & 5 & 1501 & 8 & 1520 & 5 & 97 \\
\hline 0,237 & 0,096 & 0,432 & 0,262 & 0,66 & 3,481 & 0,789 & 0,804 & 1552 & 8 & 1502 & 9 & 1523 & 6 & 97 \\
\hline 0,637 & 0,098 & 1,433 & 0,263 & 1,395 & 3,536 & 2 & 0,688 & 1580 & 27 & 1503 & 19 & 1535 & 16 & 95 \\
\hline 0,254 & 0,103 & 5,539 & 0,265 & 1,361 & 3,771 & 5,706 & 0,431 & 1681 & 99 & 1517 & 19 & 1587 & 45 & 90 \\
\hline 0,161 & 0,097 & 0,406 & 0,265 & 0,787 & 3,542 & 0,885 & 0,872 & 1564 & 8 & 1517 & 11 & 1537 & 7 & 97 \\
\hline 0,449 & 0,095 & 0,815 & 0,27 & 1,096 & 3,537 & 1,366 & 0,791 & 1530 & 15 & 1539 & 15 & 1535 & 11 & 101 \\
\hline 0,318 & 0,097 & 0,374 & 0,275 & 0,648 & 3,701 & 0,748 & 0,836 & 1576 & 7 & 1568 & 9 & 1572 & 6 & 100 \\
\hline 0,302 & 0,108 & 1,141 & 0,293 & 0,753 & 4,355 & 1,368 & 0,755 & 1760 & 21 & 1658 & 11 & 1704 & 11 & 94 \\
\hline 0,499 & 0,114 & 0,974 & 0,299 & 0,839 & 4,688 & 1,285 & 0,625 & 1860 & 18 & 1686 & 12 & 1765 & 11 & 91 \\
\hline
\end{tabular}




\begin{tabular}{|c|c|c|c|c|c|c|c|c|c|c|c|c|c|c|}
\hline 0,7 & 0,11 & 0,216 & 0,299 & 0,614 & 4,558 & 0,651 & 0,928 & 1808 & 4 & 1687 & 9 & 1742 & 5 & $\begin{array}{c}96 \\
93\end{array}$ \\
\hline 0,38 & 0,108 & 0,448 & 0,301 & 0,697 & 4,504 & 0,828 & 0,813 & 1772 & 8 & 1698 & 10 & 1732 & 7 & 96 \\
\hline 0,57 & 0,111 & 0,432 & 0,304 & 0,661 & 4,669 & 0,789 & 0,804 & 1822 & 8 & 1711 & 10 & 1762 & 7 & 94 \\
\hline 0,376 & 0,105 & 0,648 & 0,307 & 0,867 & 4,436 & 1,082 & 0,917 & 1712 & 12 & 1725 & 13 & 1719 & 9 & 101 \\
\hline 0,565 & 0,111 & 1,706 & 0,31 & 1,005 & 4,741 & 1,98 & 0,741 & 1816 & 31 & 1740 & 15 & 1774 & 17 & 96 \\
\hline 0,546 & 0,11 & 1,468 & 0,312 & 1,384 & 4,73 & 2,017 & 0,677 & 1800 & 27 & 1750 & 21 & 1773 & 17 & 97 \\
\hline 0,489 & 0,11 & 0,329 & 0,313 & 0,931 & 4,759 & 0,987 & 0,937 & 1803 & 6 & 1756 & 14 & 1778 & 8 & 97 \\
\hline 0,342 & 0,115 & 0,302 & 0,313 & 0,543 & 4,956 & 0,621 & 0,829 & 1874 & 5 & 1758 & 8 & 1812 & 5 & 94 \\
\hline 0,736 & 0,12 & 0,969 & 0,322 & 0,798 & 5,347 & 1,255 & 0,824 & 1960 & 17 & 1802 & 13 & 1876 & 11 & 92 \\
\hline 0,335 & 0,115 & 1,426 & 0,323 & 0,935 & 5,105 & 1,707 & 0,526 & 1875 & 25 & 1804 & 15 & 1837 & 14 & 96 \\
\hline 0,628 & 0,121 & 0,382 & 0,328 & 0,686 & 5,491 & 0,785 & 0,849 & 1976 & 7 & 1830 & 11 & 1899 & 7 & 93 \\
\hline 0,526 & 0,117 & 0,516 & 0,329 & 0,903 & 5,324 & 1,04 & 0,854 & 1917 & 9 & 1833 & 14 & 1873 & 9 & 96 \\
\hline 0,722 & 0,125 & 5,546 & 0,34 & 2,101 & 5,872 & 5,931 & 0,599 & 2034 & 98 & 1885 & 34 & 1957 & 51 & 93 \\
\hline 0,129 & 0,118 & 0,503 & 0,343 & 0,925 & 5,592 & 1,053 & 0,867 & 1930 & 9 & 1900 & 15 & 1915 & 9 & 98 \\
\hline
\end{tabular}

\section{Formação Diamantino}

\begin{tabular}{|c|c|c|c|c|c|c|c|c|c|c|c|c|c|c|c|}
\hline \multirow[b]{2}{*}{ Amostra } & \multirow[b]{2}{*}{$\mathrm{Th} / \mathrm{U}$} & \multicolumn{5}{|c|}{ Razões Radiogênicas } & \multirow[b]{2}{*}{ $\pm 1 \sigma$} & \multirow[b]{2}{*}{ Rho } & \multicolumn{6}{|c|}{ Estimativa de Idade (Ma) } & \multirow[b]{2}{*}{ Conc. } \\
\hline & & $207 \mathrm{~Pb} / 206 \mathrm{~Pb}$ & $\pm 1 \sigma$ & $206 \mathrm{~Pb} / 238 \mathrm{U}$ & $\pm 1 \sigma$ & $207 \mathrm{~Pb} / 235 \mathrm{U}$ & & & $207 \mathrm{~Pb} / 206 \mathrm{~Pb}$ & $\pm 1 \sigma$ & $206 \mathrm{~Pb} / 238 \mathrm{U}$ & $\pm 1 \sigma$ & $207 \mathrm{~Pb} / 235 \mathrm{U}$ & $\pm 1 \sigma$ & \\
\hline \multirow[t]{10}{*}{ PS 10} & 0,264 & 0,059 & 0,77 & 0,092 & 0,744 & 0,745 & 1,076 & 0,659 & 558 & 17 & 567 & 4 & 566 & 5 & 101,8 \\
\hline & 0,381 & 0,061 & 1,537 & 0,094 & 1,659 & 0,792 & 2,262 & 0,727 & 655 & 33 & 576 & 9 & 593 & 10 & 87,9 \\
\hline & 0,974 & 0,064 & 0,741 & 0,095 & 0,798 & 0,845 & 1,089 & 0,704 & 755 & 16 & 586 & 4 & 622 & 5 & 77,7 \\
\hline & 0,192 & 0,064 & 0,741 & 0,106 & 1,135 & 0,94 & 1,356 & 0,827 & 744 & 16 & 652 & 7 & 673 & 7 & 87,6 \\
\hline & 0,587 & 0,064 & 0,641 & 0,107 & 0,636 & 0,951 & 0,903 & 0,654 & 754 & 14 & 656 & 4 & 678 & 4 & 86,9 \\
\hline & 0,25 & 0,075 & 2,565 & 0,108 & 1,628 & 1,122 & 3,038 & 0,529 & 1080 & 51 & 660 & 10 & 764 & 16 & 61,1 \\
\hline & 0,605 & 0,065 & 2,167 & 0,109 & 0,533 & 0,976 & 2,231 & 0,367 & 775 & 46 & 666 & 3 & 691 & 11 & 85,9 \\
\hline & 0,83 & 0,062 & 6,617 & 0,109 & 1,611 & 0,926 & 6,815 & 0,431 & 658 & 136 & 668 & 10 & 666 & 33 & 101,5 \\
\hline & 0,626 & 0,064 & 1,775 & 0,11 & 0,705 & 0,971 & 1,91 & 0,573 & 747 & 38 & 671 & 4 & 689 & 10 & 89,9 \\
\hline & 0,041 & 0,063 & 0,362 & 0,114 & 0,675 & 0,984 & 0,766 & 0,857 & 702 & 8 & 694 & 4 & 696 & 4 & 98,9 \\
\hline
\end{tabular}




\begin{tabular}{|c|c|c|c|c|c|c|c|c|c|c|}
\hline 0,213 & 0,074 & 1,122 & 0,143 & 1,183 & 1,448 & 1,63 & 0,713 & 1029 & 23 & 861 \\
\hline 0,268 & 0,07 & 0,712 & 0,149 & 0,862 & 1,447 & 1,118 & 0,749 & 940 & 15 & 896 \\
\hline 0,297 & 0,073 & 1,278 & 0,154 & 0,805 & 1,549 & 1,51 & 0,75 & 1012 & 26 & 923 \\
\hline 0,205 & 0,071 & 0,436 & 0,154 & 0,564 & 1,515 & 0,713 & 0,734 & 963 & 9 & 926 \\
\hline 0,563 & 0,072 & 0,62 & 0,157 & 0,877 & 1,564 & 1,074 & 0,798 & 994 & 13 & 940 \\
\hline 0,773 & 0,073 & 0,627 & 0,159 & 0,676 & 1,603 & 0,922 & 0,691 & 1021 & 13 & 950 \\
\hline 0,491 & 0,073 & 2,279 & 0,159 & 1,303 & 1,601 & 2,625 & 0,74 & 1011 & 46 & 953 \\
\hline 0,23 & 0,074 & 3,121 & 0,161 & 0,792 & 1,65 & 3,222 & 0,421 & 1055 & 62 & 960 \\
\hline 0,4 & 0,075 & 2,426 & 0,161 & 2,084 & 1,662 & 3,203 & 0,647 & 1069 & 48 & 961 \\
\hline 0,26 & 0,076 & 1,461 & 0,161 & 0,552 & 1,677 & 1,562 & 0,296 & 1084 & 29 & 962 \\
\hline 0,074 & 0,074 & 0,855 & 0,162 & 0,651 & 1,642 & 1,075 & 0,555 & 1032 & 17 & 966 \\
\hline 0,486 & 0,075 & 2,129 & 0,162 & 2,251 & 1,673 & 3,099 & 0,723 & 1061 & 43 & 970 \\
\hline 0,404 & 0,074 & 0,457 & 0,167 & 0,662 & 1,713 & 0,804 & 0,788 & 1049 & 9 & 997 \\
\hline 0,111 & 0,075 & 0,943 & 0,169 & 0,859 & 1,754 & 1,276 & 0,852 & 1072 & 19 & 1008 \\
\hline 0,054 & 0,079 & 1,867 & 0,172 & 0,919 & 1,871 & 2,081 & 0,676 & 1174 & 37 & 1021 \\
\hline 0,398 & 0,075 & 0,558 & 0,174 & 0,735 & 1,793 & 0,922 & 0,767 & 1059 & 11 & 1035 \\
\hline 0,464 & 0,074 & 4,255 & 0,175 & 2,161 & 1,789 & 4,772 & 0,708 & 1042 & 86 & 1041 \\
\hline 0,337 & 0,078 & 0,49 & 0,176 & 0,523 & 1,892 & 0,717 & 0,65 & 1142 & 10 & 1047 \\
\hline 0,179 & 0,084 & 2,278 & 0,179 & 2,071 & 2,082 & 3,079 & 0,872 & 1296 & 44 & 1064 \\
\hline 0,42 & 0,076 & 0,534 & 0,18 & 0,762 & 1,885 & 0,93 & 0,793 & 1094 & 11 & 1066 \\
\hline 0,384 & 0,079 & 1,257 & 0,182 & 0,901 & 1,967 & 1,546 & 0,558 & 1161 & 25 & 1075 \\
\hline 0,64 & 0,079 & 1,192 & 0,191 & 1,623 & 2,092 & 2,021 & 0,801 & 1185 & 23 & 1126 \\
\hline 0,149 & 0,081 & 6,651 & 0,195 & 1,008 & 2,19 & 6,727 & 0,276 & 1232 & 131 & 1149 \\
\hline 0,249 & 0,083 & 0,885 & 0,198 & 0,9 & 2,274 & 1,262 & 0,69 & 1280 & 17 & 1163 \\
\hline 0,198 & 0,096 & 0,672 & 0,232 & 1,717 & 3,08 & 1,844 & 0,929 & 1553 & 13 & 1345 \\
\hline 0,243 & 0,095 & 0,787 & 0,239 & 2,18 & 3,121 & 2,318 & 0,94 & 1520 & 15 & 1383 \\
\hline 0,419 & 0,098 & 0,963 & 0,258 & 0,616 & 3,492 & 1,143 & 0,726 & 1591 & 18 & 1479 \\
\hline 0,453 & 0,103 & 3,674 & 0,272 & 1,271 & 3,854 & 3,887 & 0,555 & 1673 & 68 & 1552 \\
\hline 0,936 & 0,109 & 0,351 & 0,273 & 0,571 & 4,104 & 0,67 & 0,807 & 1783 & 6 & 1556 \\
\hline
\end{tabular}




\begin{tabular}{|c|c|c|c|c|c|c|c|c|c|c|c|c|c|c|}
\hline 0,228 & 0,103 & 1,657 & 0,281 & 0,661 & 3,996 & 1,784 & 0,569 & 1681 & 31 & 1597 & 9 & 1633 & 14 & $\begin{array}{c}98 \\
95\end{array}$ \\
\hline 0,546 & 0,11 & 1,204 & 0,299 & 0,846 & 4,529 & 1,471 & 0,546 & 1797 & 22 & 1686 & 13 & 1736 & 12 & 93,8 \\
\hline 0,821 & 0,114 & 0,529 & 0,305 & 2,063 & 4,798 & 2,13 & 0,968 & 1864 & 10 & 1717 & 31 & 1785 & 18 & 92,1 \\
\hline 0,381 & 0,118 & 1,588 & 0,319 & 0,509 & 5,18 & 1,667 & 0,244 & 1925 & 28 & 1783 & 8 & 1849 & 14 & 92,6 \\
\hline 0,381 & 0,115 & 0,511 & 0,32 & 0,84 & 5,083 & 0,983 & 0,837 & 1886 & 9 & 1788 & 13 & 1833 & 8 & 94,8 \\
\hline 0,835 & 0,115 & 0,241 & 0,32 & 0,522 & 5,063 & 0,575 & 0,869 & 1874 & 4 & 1791 & 8 & 1830 & 5 & 95,6 \\
\hline 0,73 & 0,115 & 1,304 & 0,328 & 0,762 & 5,184 & 1,51 & 0,72 & 1876 & 24 & 1827 & 12 & 1850 & 13 & 97,4 \\
\hline 0,723 & 0,116 & 1,461 & 0,33 & 1,082 & 5,289 & 1,818 & 0,578 & 1900 & 26 & 1837 & 17 & 1867 & 16 & 96,7 \\
\hline 0,702 & 0,124 & 0,23 & 0,33 & 0,461 & 5,655 & 0,515 & 0,83 & 2016 & 4 & 1840 & 7 & 1924 & 4 & 91,3 \\
\hline 0,318 & 0,159 & 0,465 & 0,339 & 0,558 & 7,435 & 0,727 & 0,706 & 2447 & 8 & 1881 & 9 & 2165 & 7 & 76,9 \\
\hline 0,245 & 0,123 & 0,246 & 0,341 & 0,475 & 5,787 & 0,535 & 0,826 & 2002 & 4 & 1891 & 8 & 1944 & 5 & 94,5 \\
\hline 0,605 & 0,125 & 2,397 & 0,346 & 2,038 & 5,97 & 3,146 & 0,857 & 2032 & 42 & 1914 & 34 & 1971 & 27 & 94,2 \\
\hline 0,289 & 0,128 & 0,276 & 0,36 & 0,465 & 6,342 & 0,54 & 0,782 & 2070 & 5 & 1980 & 8 & 2024 & 5 & 95,7 \\
\hline 0,199 & 0,127 & 0,319 & 0,365 & 0,917 & 6,404 & 0,971 & 0,939 & 2061 & 6 & 2005 & 16 & 2033 & 9 & 97,3 \\
\hline 0,308 & 0,166 & 1,033 & 0,448 & 1,648 & 10,23 & 1,945 & 0,843 & 2515 & 17 & 2385 & 33 & 2456 & 18 & 94,9 \\
\hline 0,153 & 0,174 & 0,42 & 0,473 & 1,004 & 11,369 & 1,092 & 0,916 & 2599 & 7 & 2498 & 21 & 2554 & 10 & 96,1 \\
\hline 0,326 & 0,2 & 0,367 & 0,5 & 0,818 & 13,784 & 0,896 & 0,901 & 2826 & 6 & 2613 & 18 & 2735 & 8 & 92,5 \\
\hline 0,475 & 0,202 & 0,483 & 0,565 & 0,771 & 15,755 & 0,91 & 0,825 & 2843 & 8 & 2889 & 18 & 2862 & 9 & 101,6 \\
\hline
\end{tabular}

